NBSIR 74-361

\title{
ELECTROMAGNETIC INTERFERENCE MEASUREMENTS AT ASA, FORT HUACHUCA, ARIZONA
}

H. E. Taggart

J. W. Adams

- Electromagnetic Division Institute for Basic Standards National Bureau of Standards Boulder, Colorado 80302

December 1973

Prepared for:

U. S. Army Security Agency Test and Evaluation Center Fort Huachuca, Arizona 



\section{ELECTROMAGNETIC INTERFERENCE MEASUREMENTS AT ASA, FORT HUACHUCA, ARIZONA}

H. E. Taggart

J. W. Adams

Electromagnetics Division Institute for Basic Standards

National Bureau of Standards

Boulder, Colorado 80302

December 1973

Prepared for:

U. S. Army Security Agency

Test and Evaluation Center

Fort Huachuca, Arizona

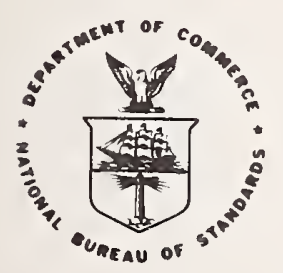

U.S. DEPARTMENT OF COMMERCE, Frederick B. Dent, Secretary NATIONAL BUREAU OF STANDARDS. Richard W Roberts. Director 

1.0 INTRODUCTION ...................................... $\frac{\text { Page }}{1}$

1.1 Types of Noise $\ldots \ldots \ldots 2$

1.2 Measurement Sites and Types of Measurements-.- 4

1.3 Shielded Enclosure Measurements........... 6

2.0 EMI MEASUREMENT TECHNIQUES -.................. 6

2.1 Radiated Measurements .................. 6

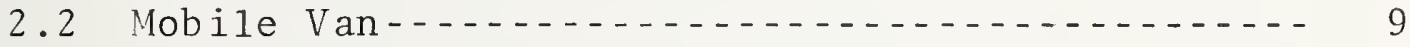

2.3 Measurement Equipment in the Mobile Van-..... 11

2.4 Conducted Measurements ....................... 11

2.5 APD Measurements $\ldots \ldots \ldots 12$

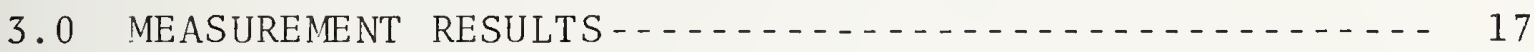

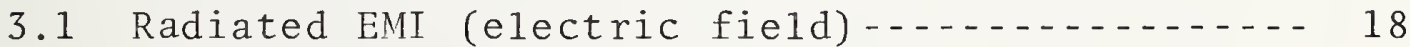

3.2 Radiated EMI (magnetic field) -.......... 42

3.3 Selected Frequency Radiated EMI (electric

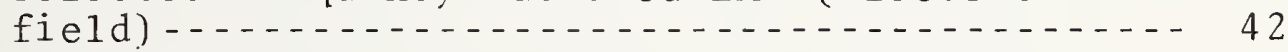

3.4 Conducted EMI $\ldots \ldots \ldots$

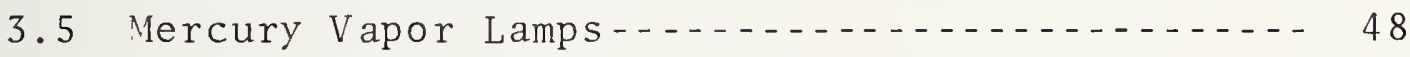

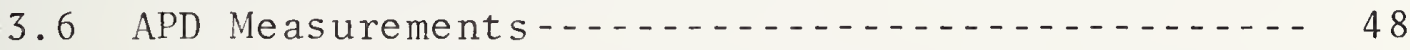

3.7 Evaluation of the Shielded Room-......... 51

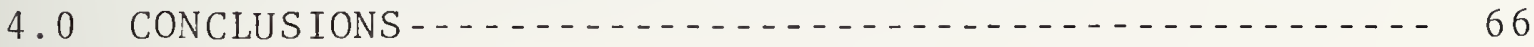

5.0 RECOMMENDAT IONS - _... $\ldots \ldots$

ACKNOWLEDGMENTS - - - - - - - - - -

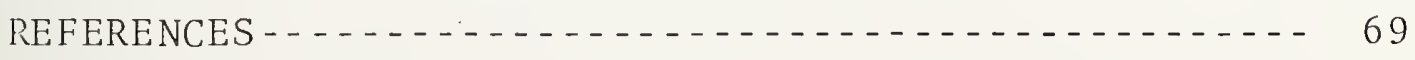




\title{
ELECTROMAGNETIC INTERFERENCE MEASUREMENTS
}

\author{
AT ASA, FORT HUACHUCA, ARIZONA
}

H.E. Taggart and J.W. Adams

This report describes the work performed for the U.S. Army Security Agency Test and Evaluation Center (USASATEC), Fort Huachuca, Arizona, during the period from April 1973 to November 1973. The purpose of the project was to measure, analyze, and evaluate the electromagnetic environment at selected sites and to recommend methods of reducing the present levels of electromagnetic interference (EMI). Chief sources of EMI were the power lines in the area and sferics from thunderstorms. Both broadband EMI measurements and amplitude probability distribution measurements were made. Both electric and magnetic fields were measured. The frequency range covered was $15 \mathrm{kHz}$ to $10 \mathrm{GHz}$. Measurements were made at three locations: 1) at Fort Huachuca USASATEC; 2) Willcox Dry Lake; and 3) Boulder, Colorado. The report contains a description of the test procedures, test results, conclusions, and recommendations.

Key words: APD measurements; broadband EMI; electromagnetic interference; power 1 ine EMI.

\subsection{INTRODUCTION}

This report describes the work performed for the U.S. Army Security Agency Test and Evaluation Center (USASATEC), Fort Huachuca, Arizona, during the period from April 1973 to November 1973.

The purpose of the project was to measure, analyze, and evaluate the electromagnetic environment at selected sites and to recommend methods of reducing the present levels of electromagnetic interference (EMI). 


\subsection{Types of Noise}

There are three basic types of interference or "noise" discussed in this report:

1. Man-made noise: This includes any noise generated by machines, computers, transmitters, high-voltage lines, or any other electrical noise caused by human activities.

2. Natural noise: This includes noise that is generated as a result of natural phenomena such as galactic noise, solar noise, general atmospheric noise, and local thunderstorms.

3. Receiver noise: This is the white noise associated with receiver input circuits and is always present. If a noise source has a lower level than the receiver noise, the source cannot be measured using the techniques and instruments described here. Thus, on data plots where "receiver noise" is indicated, only noise levels above this "receiver noise" can be measured.

In this measurement program, man-made noise was of primary interest and in most cases was the dominating source of interference. However, during certain parts of the day, atmospheric noise due to large thunderstorms was dominant. In most cases, it is possible to distinguish man-made noise from atmospheric noise. Figure 1 illustrates typical values of electromagnetic interference (EMI) from various sources.

In the broad sense, sources of man-made noise can be divided into four categories:

1. CW signals: Including the various types of communication signals, FM, AM, television, etc. (relatively narrowband signals).

2. Impulsive interference: Caused by electrical motors, arc welders, ignition noise from gasoline engines, corona discharge, and computers (broadband noise sources).

3. Power line hum: The result of the $60 \mathrm{~Hz}$ line current and its related harmonics.

4. Rectangular wave signals: Produced by digital transmission systems including computers, data transmission lines, etc. 


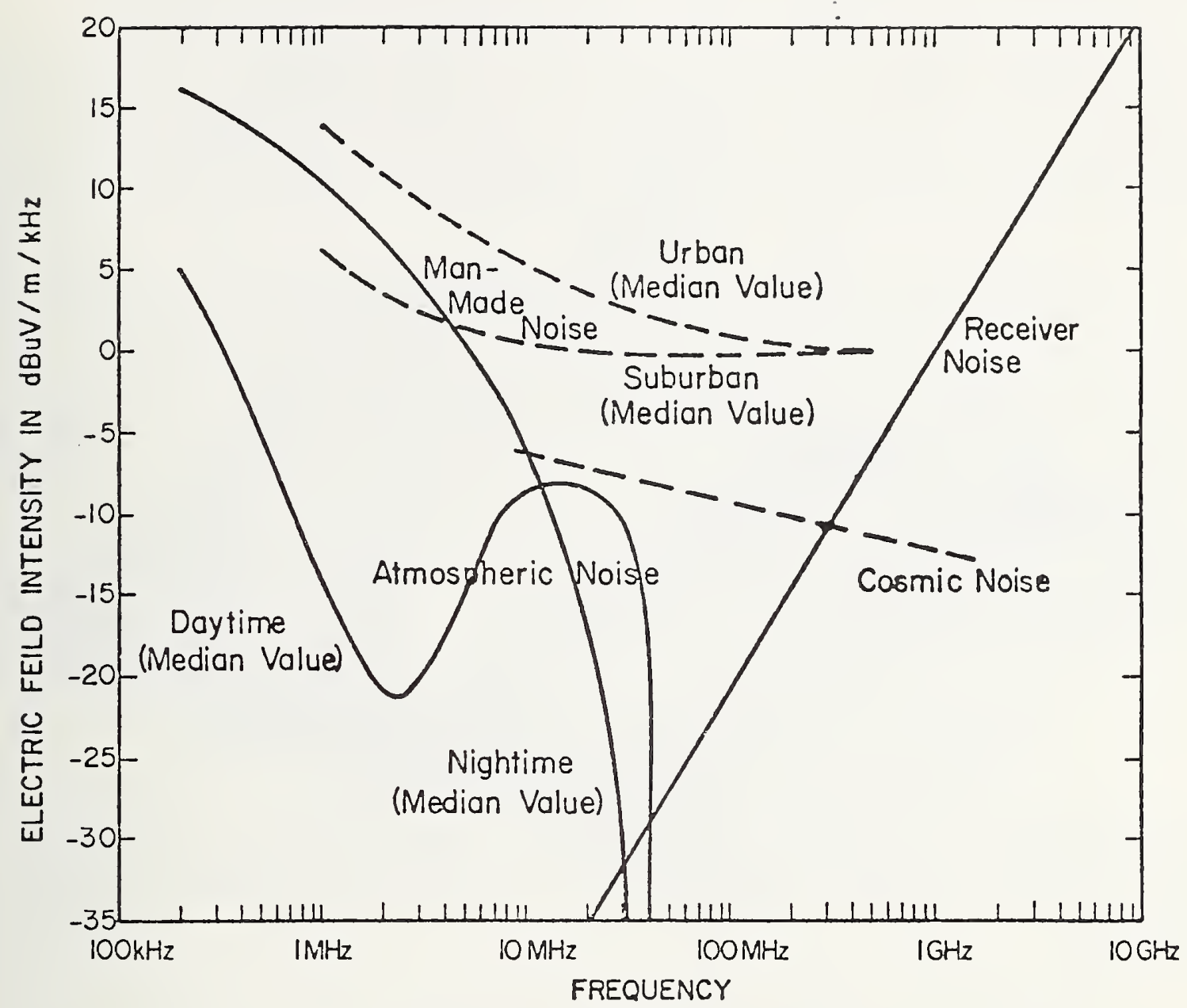

Figure I Typical values of EMI from various sources. 
All of the above signals contribute to the EMI environment. Since the primary objective of the project was to determine the amount of EMI, and since the recorded data contained both broadband EMI and narrowband CW signals, narrowband signals were deleted from some results. This allows much easier interpretation of the broadband EMI characteristics. Both the narrowband and broadband signals are shown in some results. The number and the magnitude of the narrowband signals vary widely depending on time of day, polarization, frequency, and location.

An important characteristic of electromagnetic noise is its variation with time. This is illustrated in figure 2, which shows typical noise caused by impulsive (1ightning) sources. In digital communication systems, where codes do not have the redundancy of human voice, these time variations become increasingly important. Therefore, a basic statistical form will be used in presenting the measured noise data. This is the amplitude probability distribution (APD) [1]. This topic will be explained in the section on Measurement Techniques. One horizontal component of the magnetic field strength was measured for APD analysis.

\subsection{Measurement Sites and Types of Measurements}

Selected sites for the measurements were the USASATEC facility and compound (Hayes Hall) at Fort Huachuca, Arizona; the USASATEC antenna site located at Willcox Dry Lake, near Willcox, Arizona; and, for comparison, two sites at Boulder, Colorado.

Measurements were made at frequencies from $14 \mathrm{kHz}$ to $10 \mathrm{GHz}$. Radiated and conducted measurements, including both the electric (E) and magnetic (H) components of the radiated field, were measured at Hayes Hall. Only radiated E and $H$ measurements were made at Willcox Dry Lake.

At Hayes Hall, radiated measurements were made at a number of locations inside and outside the compound. The location of the $15-\mathrm{kV}$ power lines, test facilities, and buildings, as well as the positions where the measurements were made, are shown in section 3.0 of this report.

Measurements at Willcox Dry Lake were made at ASA benchmark 102 , a location several miles from the nearest power line. This location was the "best" or quietest of the sites selected. 


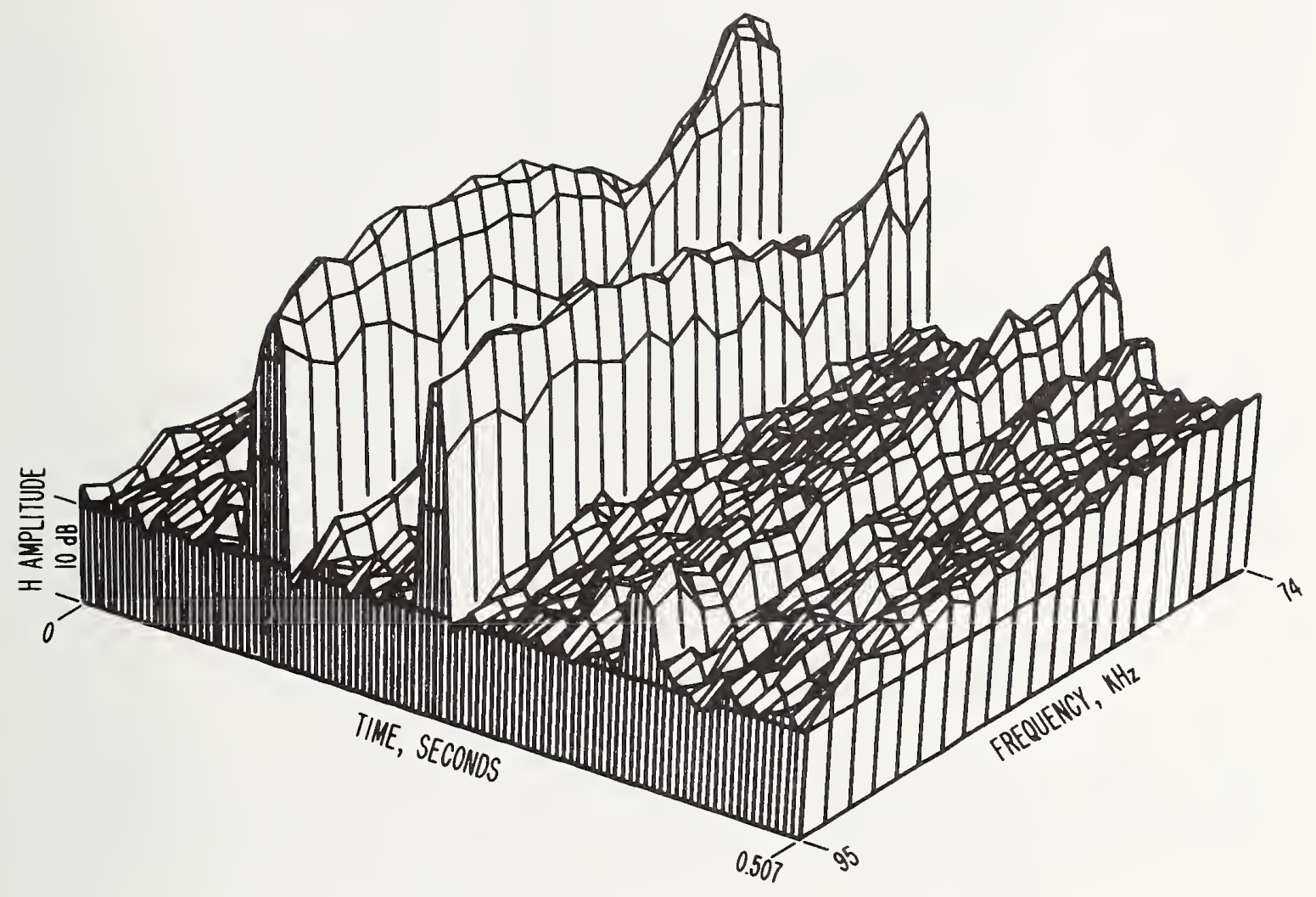

Figure 2 Three-dimensional illustration of the effects of impulsive noise. 
Noise energy normally varies with time and can vary as much as $100 \mathrm{~dB}$ over a diurnal cycle. Typical variations in noise caused by impulsive (1ightning) sources are shown dramatically in figure 3 . The upper curve of figure 3 shows EMI recorded during heavy thunderstorm activity, and the lower curve shows EMI recorded at the same location on a clear day. Therefore, continuous measurements of EMI at selected frequencies ( 25 and $250 \mathrm{kHz}$ and $1,3,10$, and $30 \mathrm{MHz}$ ) were made for a 24-hour period so that diurnal variations, as well as other variations of the EMI, could be presented on a statistical basis. Data are presented in amplitude probability distributions.

\subsection{Shielded Enclosure Measurements}

In addition to the EMI measurements discussed above, plane-wave shielding effectiveness of the shielded enclosure located in the Hayes Hall Electronics Maintenance Branch was measured. This test was conducted at two frequencies, 420 and $1000 \mathrm{MHz}$.

\subsection{EMI MEASUREMENT TECHNIQUES}

This section discusses the techniques used for measuring conducted EMI, radiated EMI, and APD's. The types of equipment used for the measurements are also discussed. Calibrations were done in accordance with NBS calibration techniques [2].

\section{$2.1 \quad$ Radiated Measurements}

A swept-frequency technique was used to evaluate the characteristics of the radiated energy. This technique provides a measurement of either the electric or magnetic field strength. Electric field strength is measured as a function of receiver bandwidth in decibels above one microvolt per meter per megahertz, $\mathrm{dB}(\mu \mathrm{V} / \mathrm{m}) / \mathrm{MHz}$. In the case of magnetic field strength measurements, the units are decibels above one microampere per meter per megahertz, dB $\left(\mu_{\mathrm{A}} / \mathrm{m}\right) / \mathrm{MHz}$.

Me asurements of radiated interference were made at various locations during normal working hours (0730 to 1630). Electric field strength was measured at frequencies from $14 \mathrm{kHz}$ to $10 \mathrm{GHz}$, and magnetic field strength was measured at frequencies from $14 \mathrm{kHz}$ to $30 \mathrm{MHz}$. 

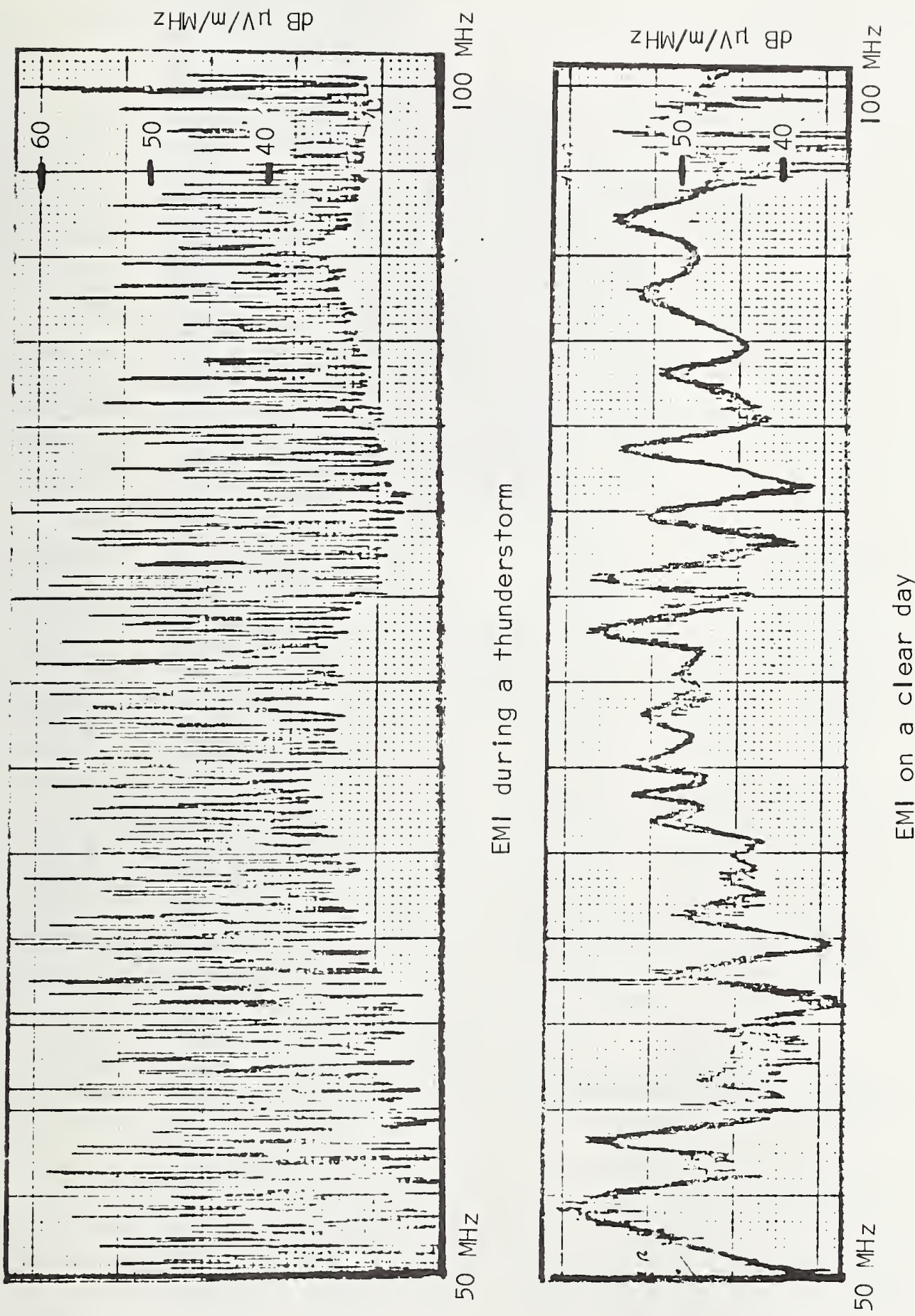

\begin{tabular}{l}
0 \\
$U$ \\
0 \\
0 \\
0 \\
0 \\
$\frac{1}{1}$ \\
0 \\
+ \\
+ \\
\hline
\end{tabular}

$\because$

(1)

ธำ

त 0

है 1

$+0$

U

(1)

त

ए

믕 둥

- 4

U

는

บ

(1) $\frac{1}{0}$

+ 득

ᄃ $\frac{5}{+}$

$\begin{array}{ll}c & + \\ 0 & 0\end{array}$

- 10

เ

ㄷ. 드

हิํํำ

m

¿

ำ

ㄴ 


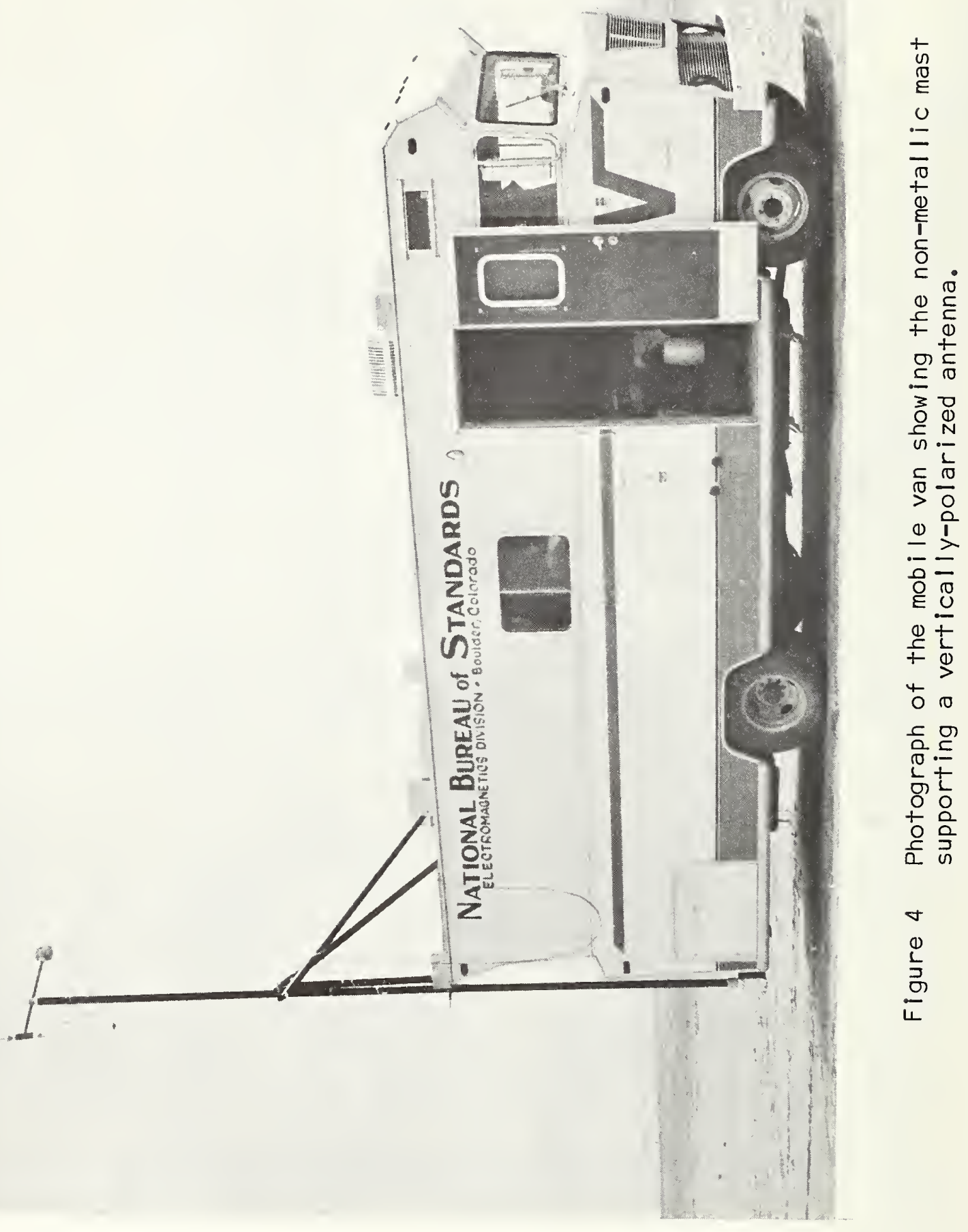


Electric field strength (E) is calculable from the magnetic field strength $(H)$ by the simple free-space plane wave condition; $E=\eta_{0} H$, where $\eta_{0}$ is 377 ohms, the intrinsic impedance of free space. For approximate comparisons, the magnetic field strength in $\mathrm{dB} \mu \mathrm{A} / \mathrm{m}$ can be converted to the electric field strength in $\mathrm{dB} \mu \mathrm{V} / \mathrm{m}$ by adding $51 \mathrm{~dB}$ to the magnetic field strength. Where free-space conditions prevail, use of this $51 \mathrm{~dB}$ will allow conversion from either $\mathrm{E}$ or $\mathrm{H}$ to the other. Since most of the field strength measurements at Ft. Huachuca were made near a ground plane, free-space conditions did not prevail, and exact comparisons cannot be expected.

Both magnetic and electric fields were recorded. Electrostatically shielded loop antennas were used to detect the magnetic EMI. Various types of antennas, including monopole, biconical, log-spiral, and dipole, were used to detect the electric field EMI. The choice depended upon the desired frequency.

Antennas used from $14 \mathrm{kHz}$ to $200 \mathrm{MHz}$ were positioned for vertical polarization during the measurements. Above $200 \mathrm{MHz}$, circularly polarized antennas were used. Although EMI varies somewhat as a function of the polarization of the antenna, measurements indicated that the overall results were not significantly changed by using just one antenna polarization. If directional antennas were used, the antennas were oriented for maximum gain in the direction of the nearest power line.

Radiated EllI was continuously recorded on an $x-y$ recorder using a swept-frequency receiver. Frequency bands of the receivers were usually about one octave wide. The bandwidth and frequency range for each band are shown in Table 1. The receiver was calibrated in terms of an impulse generator in $\mathrm{dB} \mu \mathrm{V} / \mathrm{MHz}$. Receiver bandwidth varies as a function of frequency, but all results are normalized to a one megahertz bandwidth.

\subsection{Mobile Van}

The EMI receivers and all ancillary equipment were housed in a mobile van with the antennas mounted 20 feet above the ground on a non-metallic mast. A photograph of the mobile van with the mast in position is shown in figure 4. All equipment was operated from batteries so that no EMI was generated from the vehicle engine or from the gasoline-driven motor-generator unit in the mobile van. 
Table 1. Receiver Bandwidths

(Manufacturer's Specifications)

\section{Receiver A}

\begin{tabular}{|c|c|c|c|}
\hline Band & Frequenc & cy Range & Bandwidth \\
\hline 1 & $14.0 \mathrm{kHz}-$ & $-30.0 \mathrm{kHz}$ & $4 \mathrm{kHz}$ \\
\hline 2 & $30.0 \mathrm{kHz}-$ & $-60.0 \mathrm{kHz}$ & $4 \mathrm{kHz}$ \\
\hline 3 & $60.0 \mathrm{kHz}-$ & - $\quad 120 \mathrm{kHz}$ & $4 \mathrm{kHz}$ \\
\hline 4 & $120 \mathrm{kHz}-$ & $240 \mathrm{kHz}$ & $4 \mathrm{kHz}$ \\
\hline 5 & $240 \mathrm{kHz}-$ & $500 \mathrm{kHz}$ & $4 \mathrm{kHz}$ \\
\hline 6 & $0.5 \mathrm{MHz}-$ & $-1.1 \mathrm{MHz}$ & $5 \mathrm{kHz}$ \\
\hline 7 & $1.1 \mathrm{MHz}-$ & $-2.30 \mathrm{MHz}$ & $5 \mathrm{kHz}$ \\
\hline 8 & $2.30 \mathrm{MHz}-$ & $-5.00 \mathrm{MHz}$ & $50 \mathrm{kHz}$ \\
\hline 9 & $5.00 \mathrm{MHz}-$ & $-11.0 \mathrm{MHz}$ & $50 \mathrm{kHz}$ \\
\hline 10 & $11.0 \mathrm{MHz}-$ & $-25.0 \mathrm{MHz}$ & $50 \mathrm{kHz}$ \\
\hline 11 & $25.0 \mathrm{MHz}-$ & $-50.0 \mathrm{MHz}$ & $500 \mathrm{kHz}$ \\
\hline 12 & $50.0 \mathrm{MHz}-$ & - $\quad 100 \mathrm{MHz}$ & $500 \mathrm{kHz}$ \\
\hline 13 & $100 \mathrm{MHz}$ & - $\quad 200 \mathrm{MHz}$ & $500 \mathrm{kHz}$ \\
\hline 14 & $200 \mathrm{MHz}$ - & $-\quad 500 \mathrm{MHz}$ & $500 \mathrm{kHz}$ \\
\hline 15 & $500 \mathrm{MHz}$ - & $-1000 \mathrm{MHz}$ & $500 \mathrm{kHz}$ \\
\hline
\end{tabular}

\section{$\underline{\text { Receiver } B}$}

$1-2 \mathrm{GHz}$

$5 \mathrm{MHz}$

2

$2-4.4 \mathrm{GHz}$

$5 \mathrm{MHz}$

3

$4.4-10 \mathrm{GHz}$

$5 \mathrm{MHz}$ 


\subsection{Measurement Equipment in the Mobile Van}

The equipment used included the following:

a. EMI Analyzer (Receiver A), frequency range: $14 \mathrm{kHz}$ to $1 \mathrm{GHz}$, see table 1 .

b. EMI Analyzer (Receiver B),

frequency range: 1 to $10 \mathrm{GHz}$, see table 1 .

c. $x-y$ Recorde $r$

d. Active, Broadband, Monopole Antenna, frequency range: $10 \mathrm{kHz}$ to $40 \mathrm{MHz}$.

e. Biconical Antenna,

frequency range: 20 to $200 \mathrm{MHz}$.

f. Conical, Log-Spiral Antenna,

frequency range: 200 to $1000 \mathrm{MHz}$.

g. Conica1, Log-Spira1 Antenna, frequency range: 1 to $10 \mathrm{GHz}$.

h. Co11apsible Loop Antenna, frequency range: 10 to $250 \mathrm{kHz}$.

i. Loop Antenna,

frequency range: $150 \mathrm{kHz}$ to $30 \mathrm{MHz}$.

j. Current Probe, frequency range: $20 \mathrm{~Hz}$ to $10 \mathrm{kHz}$.

k. Current Probe,

frequency range: 1 to $1000 \mathrm{MHz}$.

When possible, equipment was calibrated in terms of NBS standards .

\subsection{Conducted Measurements}

The conducted EMI on the power lines was measured at two locations within Hayes Hall at frequencies from $14 \mathrm{kHz}$ to 1 $\mathrm{GHz}$. Conducted EMI was recorded in terms of voltage in decibels above one microvolt per megahertz of receiver bandwidth $(\mathrm{dB} \mu \mathrm{V} / \mathrm{MHz})$. 
The conducted EMI measurements were performed by coupling into the $60 \mathrm{~Hz}$ power line by means of a capacitive network. Swept frequency techniques were used similar to the radiated measurement techniques.

An attempt to use the current probes listed in this section proved unsuccessful because of insufficient current probe sensitivity. By direct capacitive coupling the sensitivity of the system was improved by approximately 35 decibe $1 \mathrm{~s}$. Good sensitivity was essential, because some measurements were performed within a shielded enclosure that used power-line filters.

\subsection{APD Measurements}

This section of the report describes the system used to measure amplitude probability distribution statistics of electromagnetic noise. The system is an extension of one designed by Matheson [3]. The systems used for recording and data processing are shown in figures 5 and 6 . Measurements were made at the following frequencies: 25 and $250 \mathrm{kHz}$ and $1,3,10$, and $30 \mathrm{MHz}$.

In order to characterize time variations of the EMI, APD's are produced which require special techniques and equipment. The final outputs are APD figures. These are plots of the amplitude of time-varying parameter versus the percent of time a given level is exceeded. By plotting the cumulative APD on Rayleigh graph paper, one can clearly show the fraction of time the parameter exceeds various levels. See figure 7 . The measured parameter is one horizontal component of magnetic field strength.

The APD's are integrated to give rms and average values of the field strength, according to the equations

$$
H_{\text {avg }}=-\int_{0}^{\infty} H \operatorname{dp}(H)
$$

and

$$
H_{r m s}=\left(-\int_{0}^{\infty} H^{2} \mathrm{dp}(H)\right\}^{\frac{1}{2}} \text {, }
$$




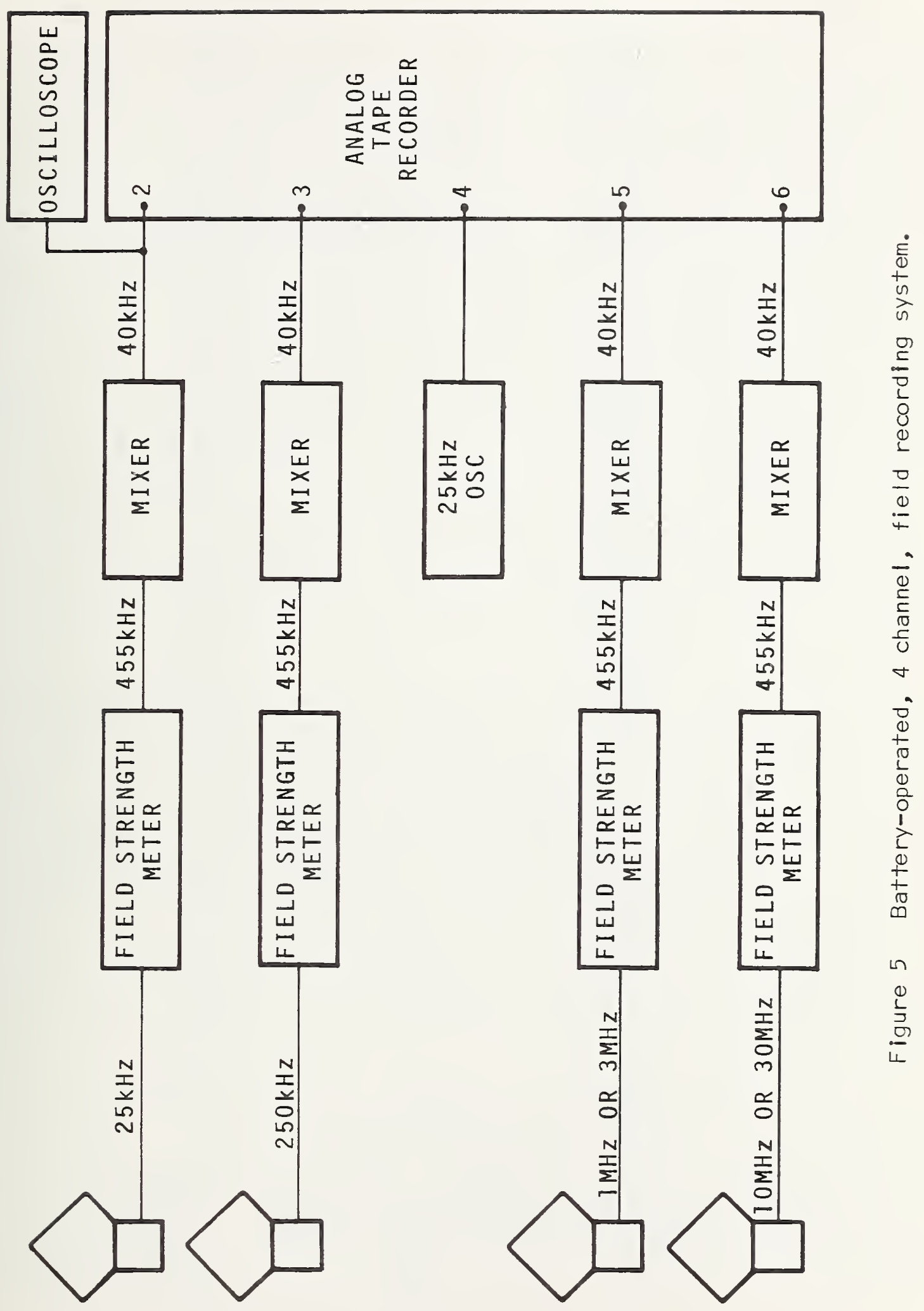




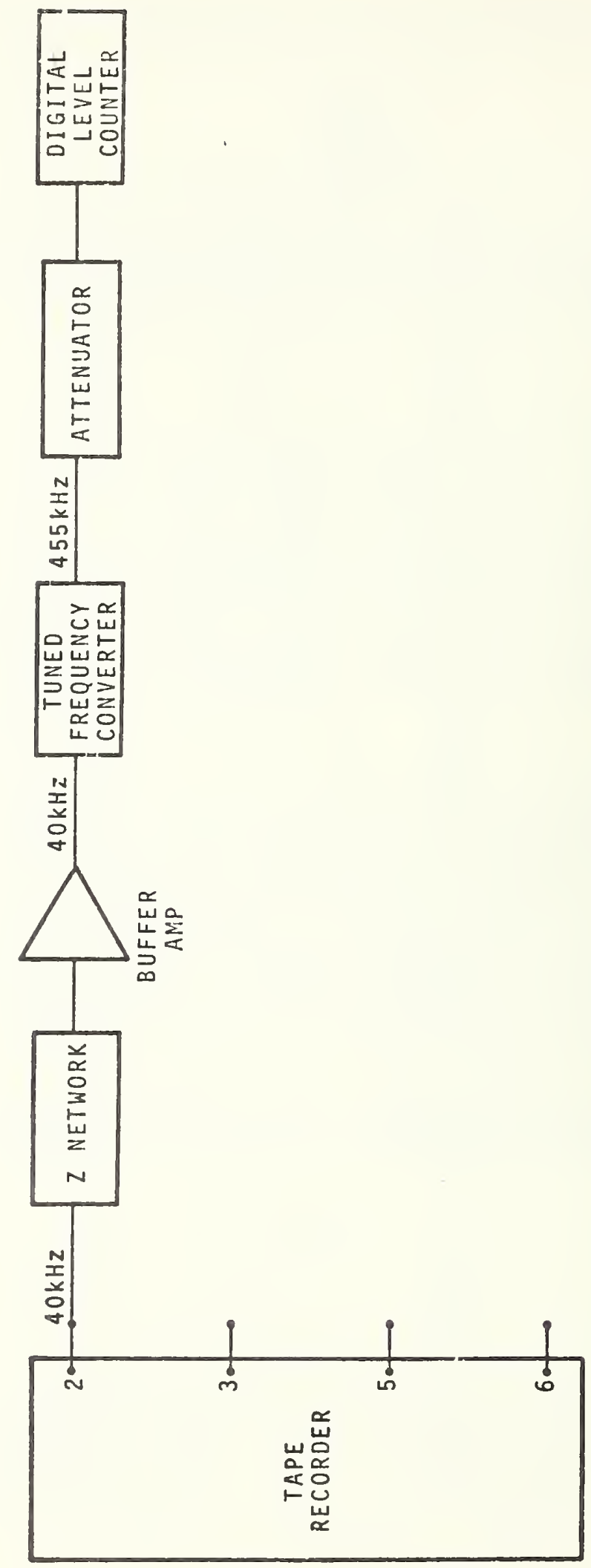

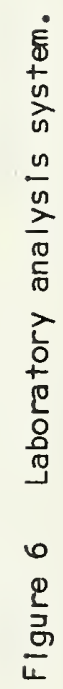




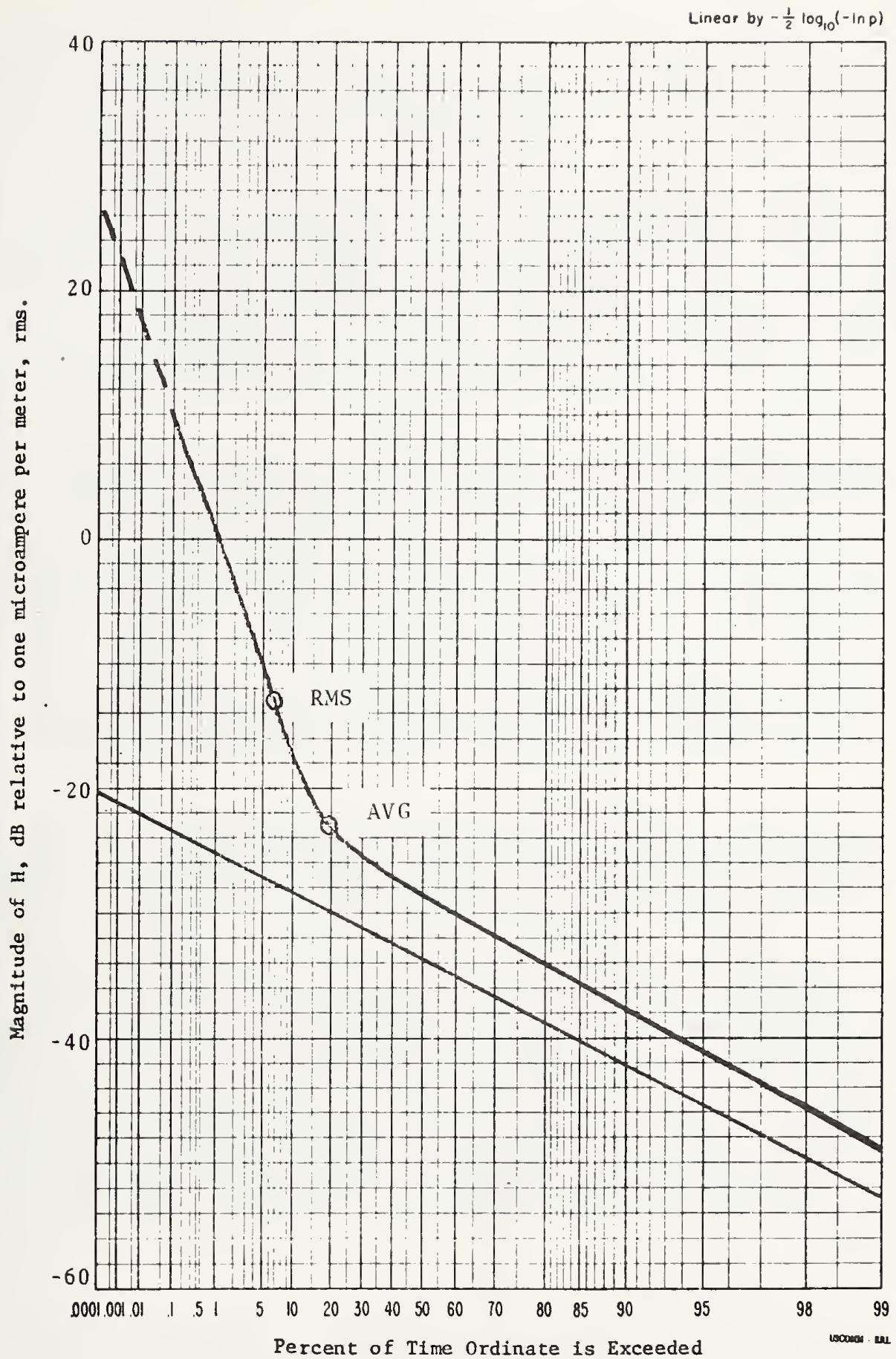

Figure 7 APD, $1 \mathrm{MHz}$, Horizontal E-W Component of Magnetic Field, $1 \mathrm{kHz}$ Predetection Bandwidth, Hayes Hall, position 1, 6:00 p.m., July 2, 1973 . 
where $H$ represents the magnetic field strength of the noise, and $\mathrm{p}$ is the probability that measured field strength exceeds the value $H$. The rms and average values are identified on each graph and are time averages (30 minutes) of these timedependent parameters. These quantities are also dependent upon bandwidth of the system, length of the data run, and possibly other parameters. Finite series are actually used for the numerical integration. If the tapes are played into ordinary rms reading meters, the meter readings will vary 10 to $20 \mathrm{~dB}$ over fractions of a second. The rms value is directly relatable to noise power. With these wide variations of field strength with time, the most suitable presentations are statistical ones.

The measurement technique is to record on magnetic tape a time-varying, analog signal that is proportional to the magnetic field strength as seen through a specific receiver bandwidth. This analog signal must be converted down to be within the passband of the tape recorder. Four signals whose amplitudes are proportional to EMI at four frequencies are tape recorded simultaneously on four channels for about 30 minutes. $1 \mathrm{MHz}$ and $3 \mathrm{MHz}$ recordings were alternated with $10 \mathrm{MHz}$ and $30 \mathrm{MHz}$ recordings to give better spectral coverage, while $25 \mathrm{kHz}$ and $250 \mathrm{kHz}$ recordings were made during every run.

The data-processing system consists principal1y of the analog magnetic tape recorder as a playback unit, an amplifier, a tuned frequency converter, and a digital leve 1 counter. A stable $25-\mathrm{kHz}$ signal recorded on channe1 4 at the time of recording is used during playback to control a servo system to remove flutter and wow. The amplifier is used primarily for impedance conversion between the output impedance of the tape recorder and the input impedance of a tuned fre quency converter. The $40-\mathrm{kHz}$ output of the tape recorder is converted up to $455 \mathrm{kHz}$ by the tuned frequency converter in order to match the response band of the digital level counter. The digital level counter provides a direct digital display of the percentage of the time each of 15 leve1s, 6-dB apart, is exceeded.

The 3-dB bandwidth of the whole system, including recording, transcribing, and data-processing systems, is primarily determined by the data-processing system. It was found to be about $1 \mathrm{kHz}$ for the $25 \mathrm{kHz}$ and $250 \mathrm{kHz}$ data and $1.2 \mathrm{kHz}$ for other frequencies. For approximate comparison with other data in the report given in $\mathrm{dB}(\mu \mathrm{A} / \mathrm{m}) / \mathrm{MHz}$, add $60 \mathrm{~dB}$ to the $\mathrm{APD}$ measurement data which is given in $\mathrm{dB}(\mu \mathrm{A} / \mathrm{m}) / \mathrm{kHz}$. 
The dynamic range of the whole system is about $60 \mathrm{~dB}$. A portable oscilloscope was used to monitor signal levels to be recorded in order to use the 60 dB dynamic range to obtain the most useful part of the noise data.

The calibration of the entire measurement system, including loop antennas, field strength meters, mixers, magnetic tape recorders, impedance transforming amplifiers, and the digital level counter, was performed by immersing the receiving loop antennas in a known field, generated at the NBS field strength calibration site [2]. Thus all levels of field strength are given in absolute units.

Estimated limits of error for the APD noise measurements are $\pm 3 \mathrm{~dB}$. Several sources of error that are critical to the overall accuracy of the measurements are listed below:

1. Calibration of the discrete digital level counter by means of a $1 \mathrm{~dB}$ step attenuator contributes $\pm 1-\mathrm{dB}$ quantization error limit.

2. The calibration of the field recording system, i.e., recording, and data processing, has an uncertainty of $\pm 0.5 \mathrm{~dB}[4]$.

3. The estimated uncertainty involved in using the tape recorder for record and playback is $\pm 0.5 \mathrm{~dB}$ due to harmonic distortion, flutter, dropout, cross-talk, gain instability, etc.

4. Gain instability during measurements, gain changes between measurements and calibration, and the nonlinearity of field strength meters and mixers, all combined, contribute $\pm 0.5 \mathrm{~dB}$ uncertainty.

5. Gain instability and nonlinearity of the digital level counter, the tuned frequency converter, the amplifier, and attenuators, all combined, contribute $\pm 0.5 \mathrm{~dB}$ uncertainty.

\subsection{MEASUREMENT RESULTS}

This section contains the following measurement results:

1. Radiated EMI (electric field) at three locations, Hayes Hall, Willcox Dry Lake, and Boulder, Colorado. 
2. Radiated EMI (magnetic field) at two locations, Hayes Hall and Willcox Dry Lake.

3. Selected frequency radiated EMI (electric field) at Hayes Hall.

4. Conducted EMI at Hayes Hall.

5. Evaluation of the mercury vapor lamps at Hayes Hall as EMI source.

6. APD measurements at Hayes Hall and Willcox Dry Lake.

7. Evaluation of the shielded room in Hayes Hall.

Exact location of the measurement points in the Hayes Ha11 Area is shown in figure 8. Numbers listed in this figure will be referred to by position number throughout this report.

Measurements at Willcox Dry Lake were made at ASA benchmark number 102, approximately one mile south of the ASA test site buildings.

Measurements were made at two locations in Boulder, Colorado: 1) near a $15 \mathrm{kV}$ power line that feeds the Radio Building at NBS, and 2) at a nearby antenna site where the nearest power line is approximately 100 meters distant.

\subsection{Radiated EMI (electric field)}

Measurement results of the radiated EMI (electric field) at the various locations are shown in graphic form. Each plot of the spectrum is from $14 \mathrm{kHz}$ to $1 \mathrm{GHz}$, showing the magnitude of the EMI in $\mathrm{dB}(\mu \mathrm{V} / \mathrm{m}) / \mathrm{MHz}$, the frequency, the date of the measurement, and the approximate time of the measurement. Each scan of the spectrum requires more than one page to provide adequate resolution of the EMI. The measurement data shown in figures 9 through 13 are only plotted up to $1 \mathrm{GHz}$. Measurements were made from 1 to $10 \mathrm{GHz}$; however, no EMI was detected above $1 \mathrm{GHz}$ that exceeded receiver noise. Measurements were made at the following locations: 


\section{IRWIN STREET}

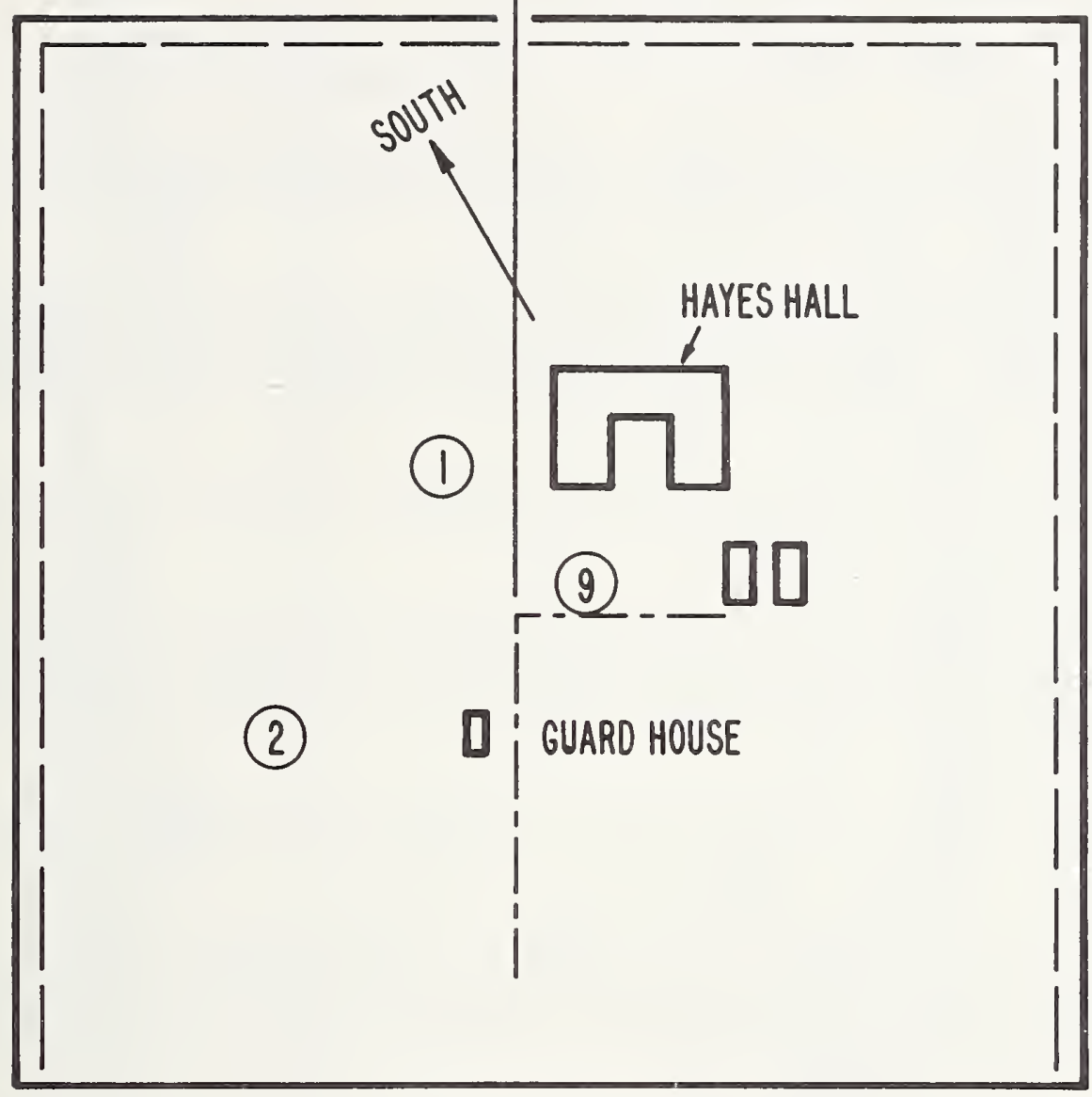

Figure 8 Measurement locations at Hayes Hall. 
position 2. Hayes Hall area (110 volt line);

position 5. Hayes Hall area (outside ASA compound);

position 9. Hayes Ha11 area (15 KV 1ine);

position 35. Willcox Dry Lake;

position B1. Boulder, Colø. (15 KV line); and

position B2. Boulder, Colo. (antenna site).

Figures 9(a), 9(b), 9(c) compare the EMI at position 9 (generally the highest level of EMI) with position 35 (generally the lowest level of EMI).

Figures $10(\mathrm{a}), 10(\mathrm{~b}), 10(\mathrm{c})$ compare the EMI at position 2 (generally the lowest level of EMI within the ASA compound) with position 5 (generally the lowest level of EMI outside the ASA compound).

Figures $11(\mathrm{a}), 11(\mathrm{~b}), 11(\mathrm{c})$ compare the EMI at position 9 with that at position 5 .

Figures 12(a), 12(b), $12(\mathrm{c})$ compare EMI at position 9 (generally the highest level within the ASA compound) with that at position 2 (generally the lowest level of EMI within the ASA compound).

Figures 13(a), 13(b), 13(c) compare the EMI at the two locations in Boulder, Colorado, B1 and B2.

The data in figures 9 through 13 show on $1 y$ the broadband EMI. The carriers from the numerous transmitters were deleted in order that the broadband data could be more easily studied and understood.

Figures $14(\mathrm{a}), 14(\mathrm{~b}), 14(\mathrm{c})$ and $15(\mathrm{a}), 15(\mathrm{~b}), 15(\mathrm{c})$ show only the average $C W$ signals (narrowband) at positions 2 and 35 respectively. The units of measure are decibels above one microvolt per meter. It should be pointed out that the meas ured values of all the carriers may not be accurate because some antennas used to measure the EMI were directional and may not have been directed toward the carrier sources. Also, the linearly polarized antennas were always positioned for vertical polarization. The carrier signals can usually be identified in the background EMI by their narrowband character. However, they are not readily discernible in all cases. No attempt was made to identify the source of each carrier signal in figures 14 and 15 . 
$\mathrm{dB}(\mu \mathrm{V} / \mathrm{m}) / \mathrm{MHz}$
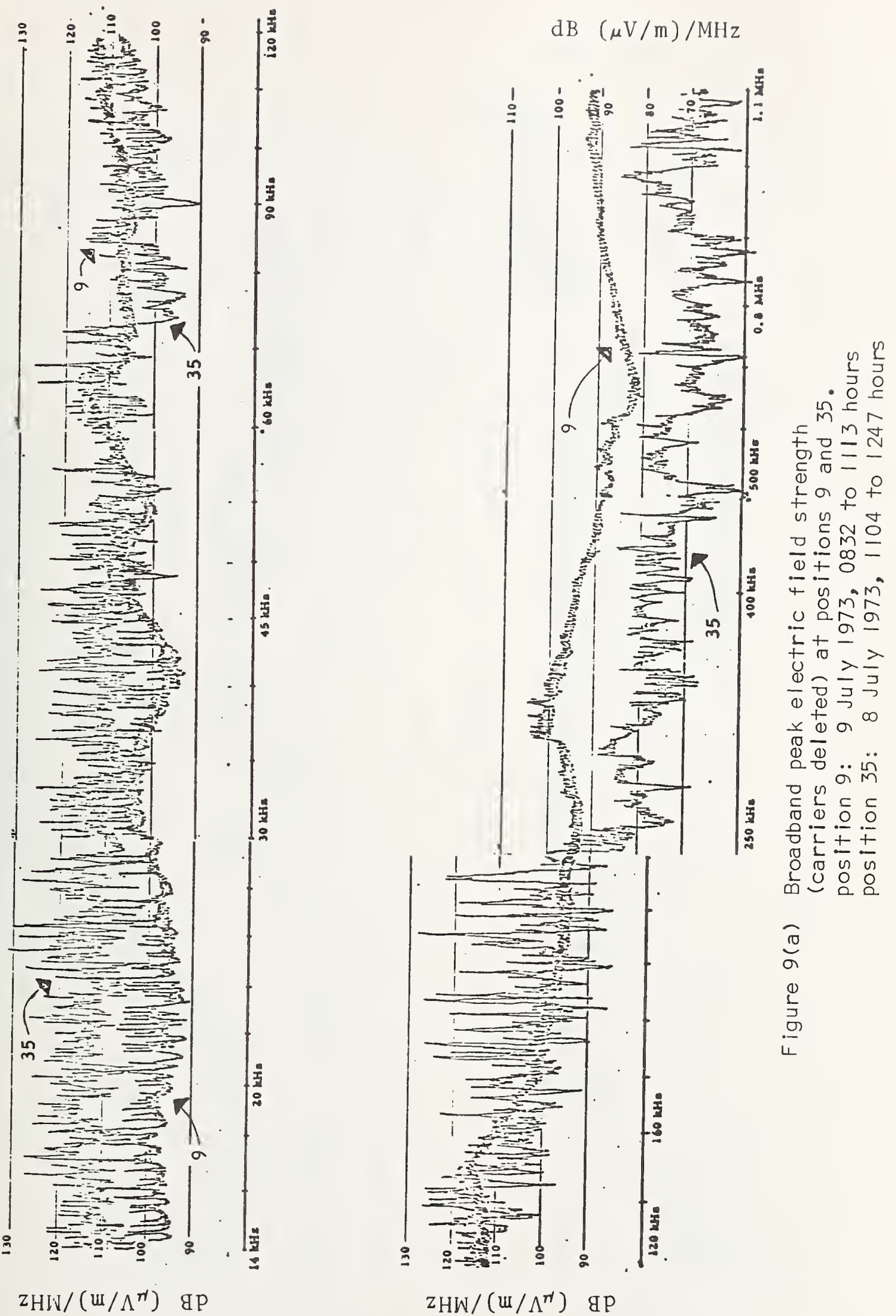


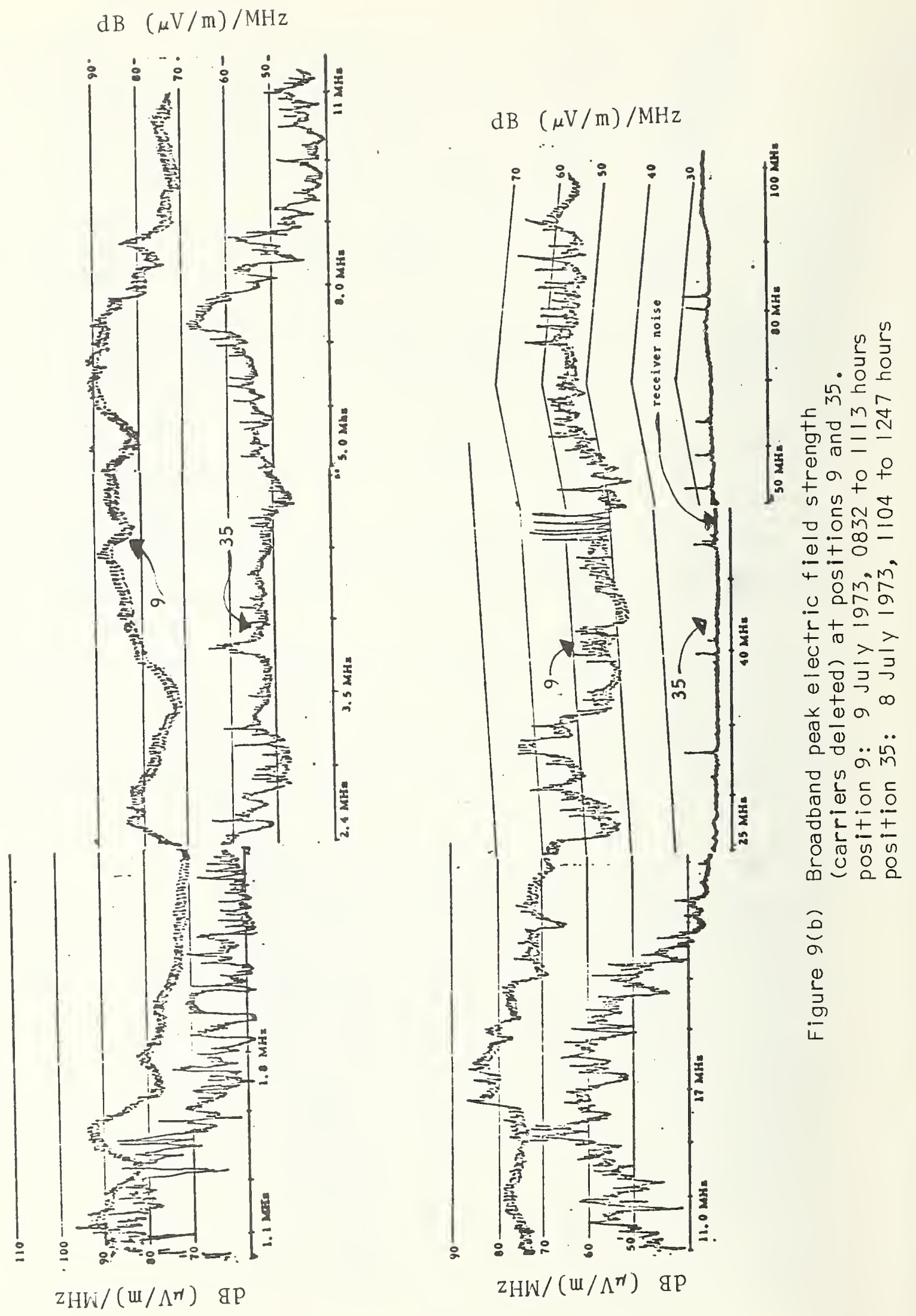




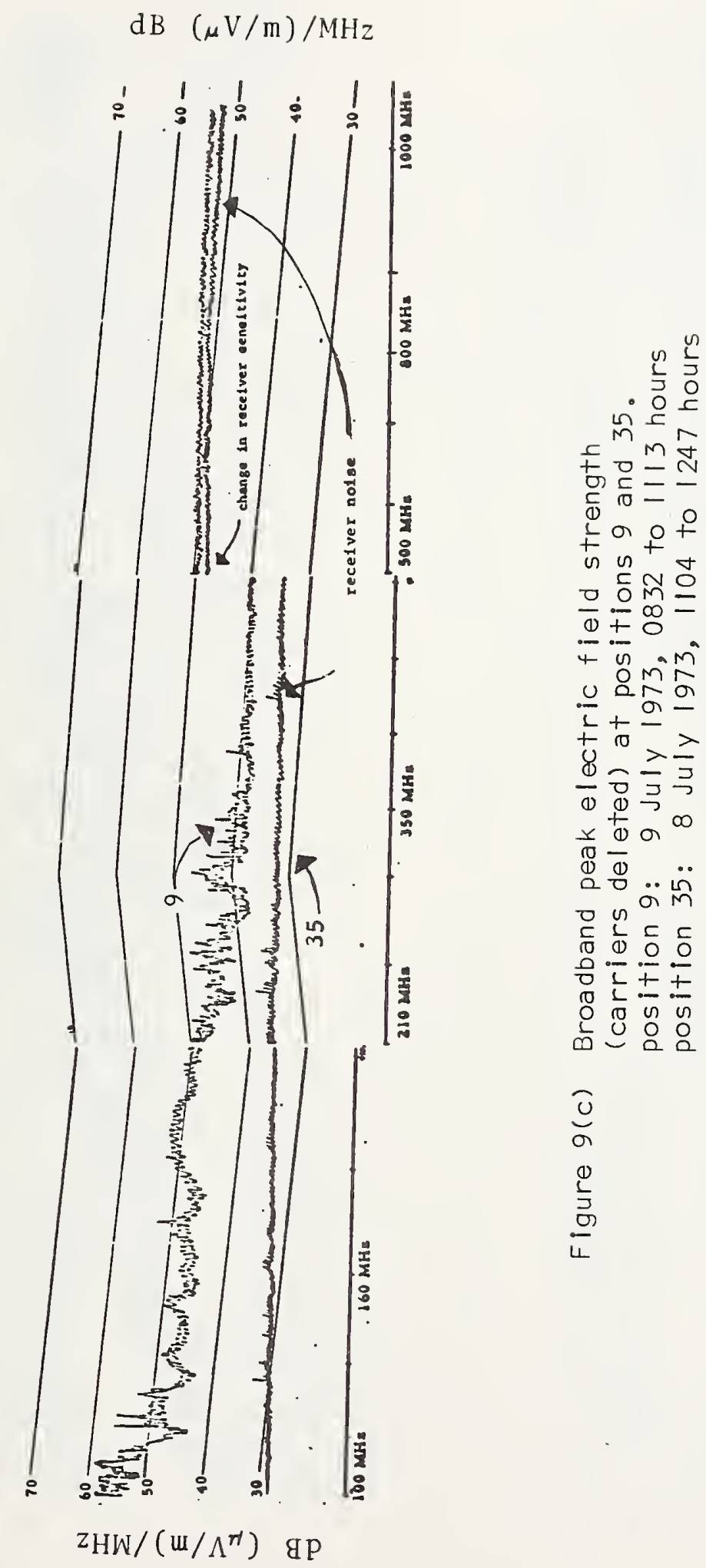



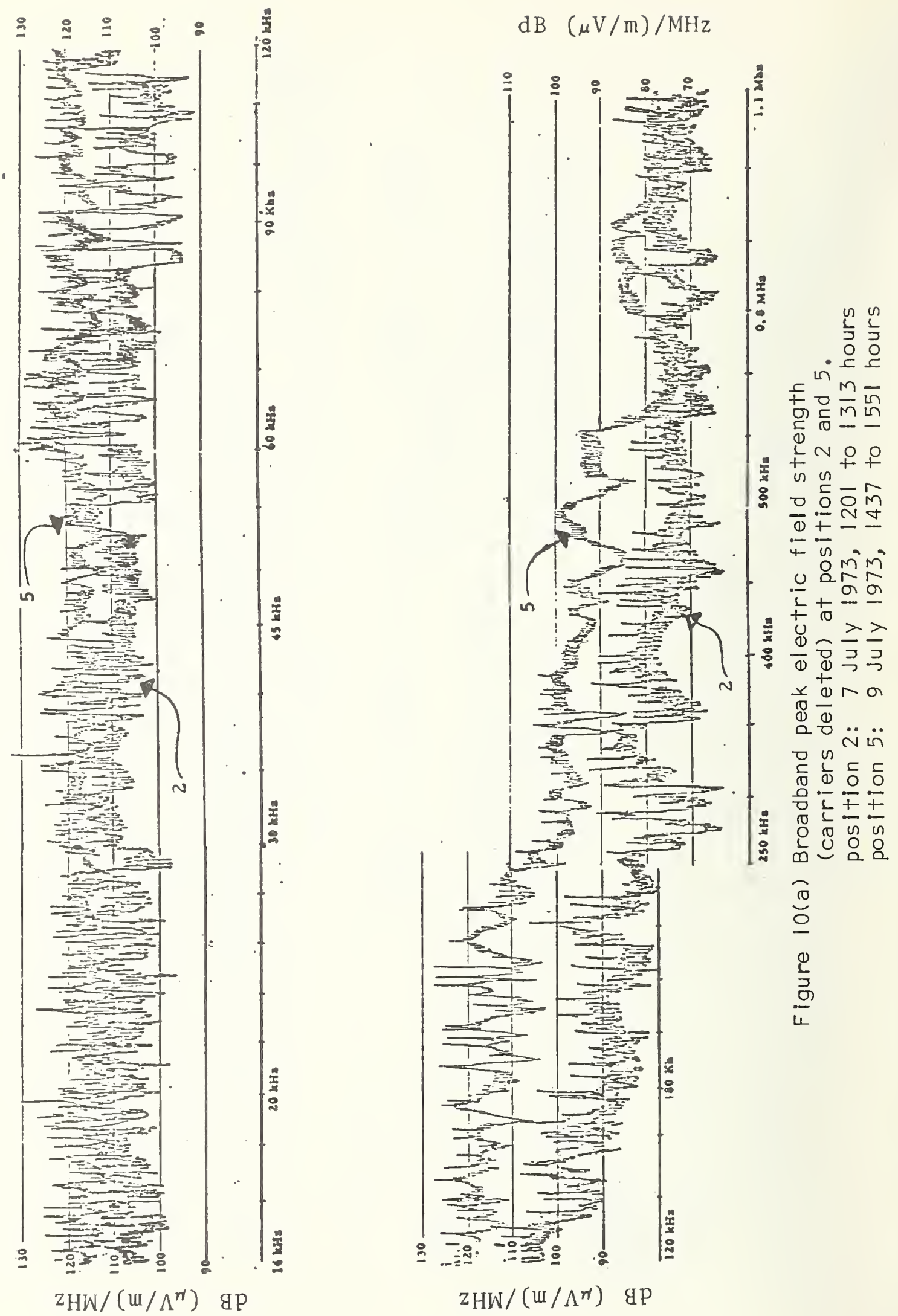
$\mathrm{dB}\left({ }_{\mu} \mathrm{V} / \mathrm{m}\right) / \mathrm{MHz}$

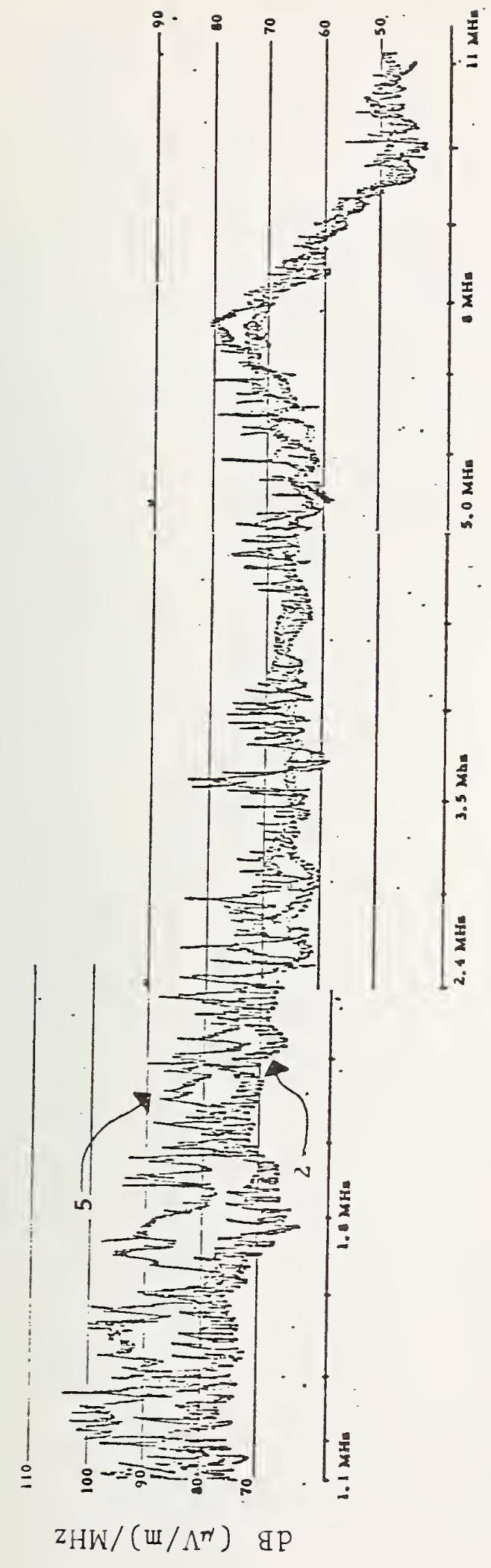

$\mathrm{dB}(\mu \mathrm{V} / \mathrm{m}) / \mathrm{MHz}$

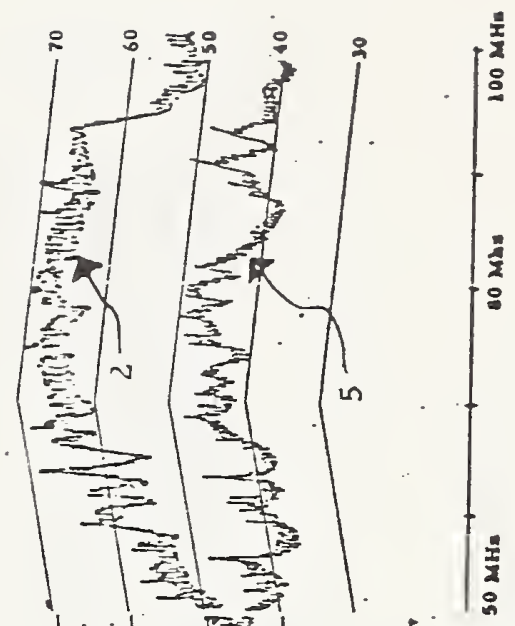

$\begin{array}{ll}n & 01 \\ \frac{1}{3} & \frac{1}{3} \\ 0 & 0\end{array}$

$e^{n-1}$

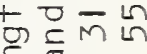
inO u u 믕요 믄

+ 므므 $++\frac{-}{0}$ 엉 드ㄹㅡㅗ +人 त ¿ N in ए

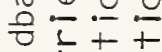
舟市的

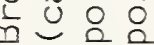

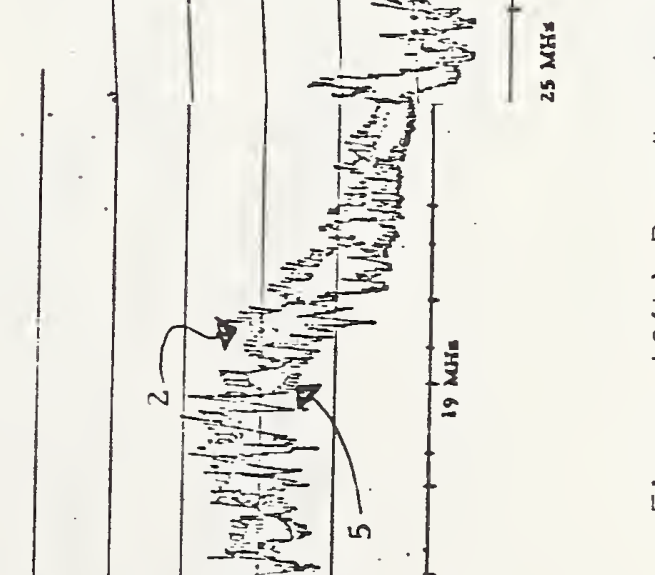
웅
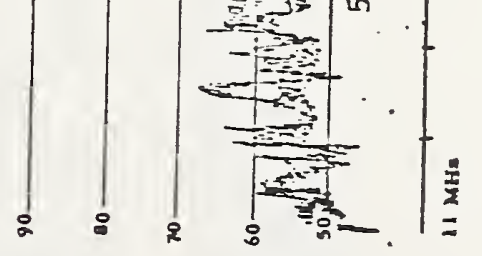

$z_{H W} /\left(\omega / \Lambda^{\mu}\right)$ gp 


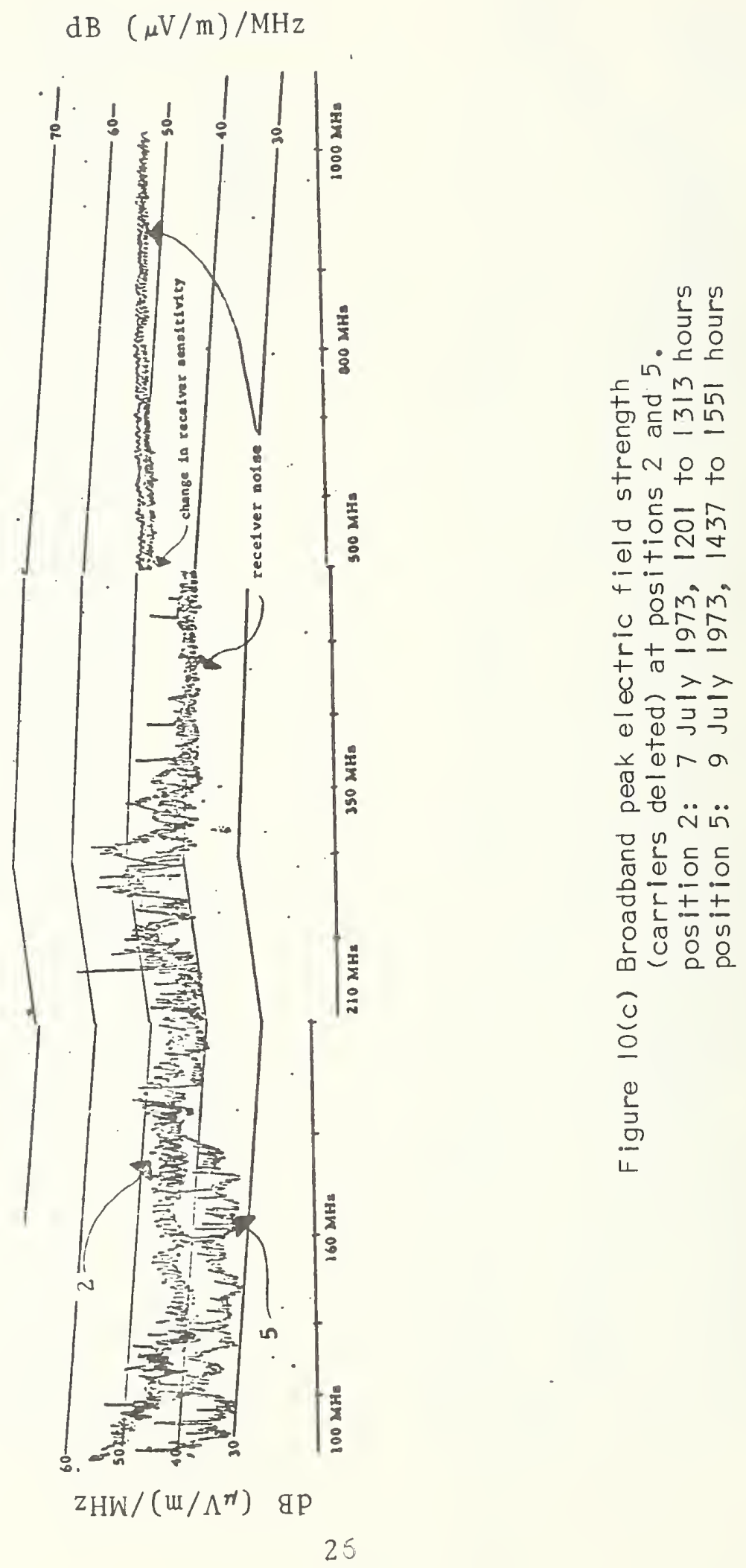




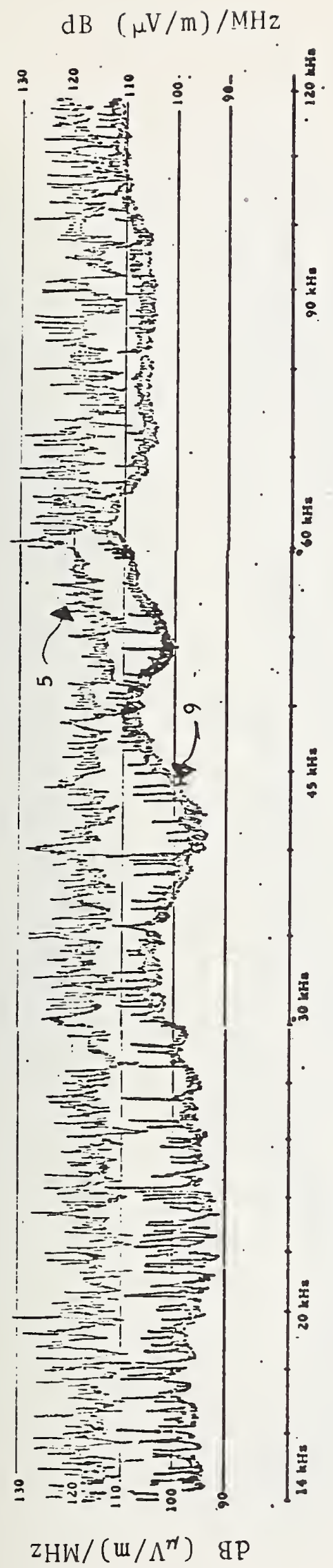

$\mathrm{dB}(\mu \mathrm{V} / \mathrm{m}) / \mathrm{MHz}$

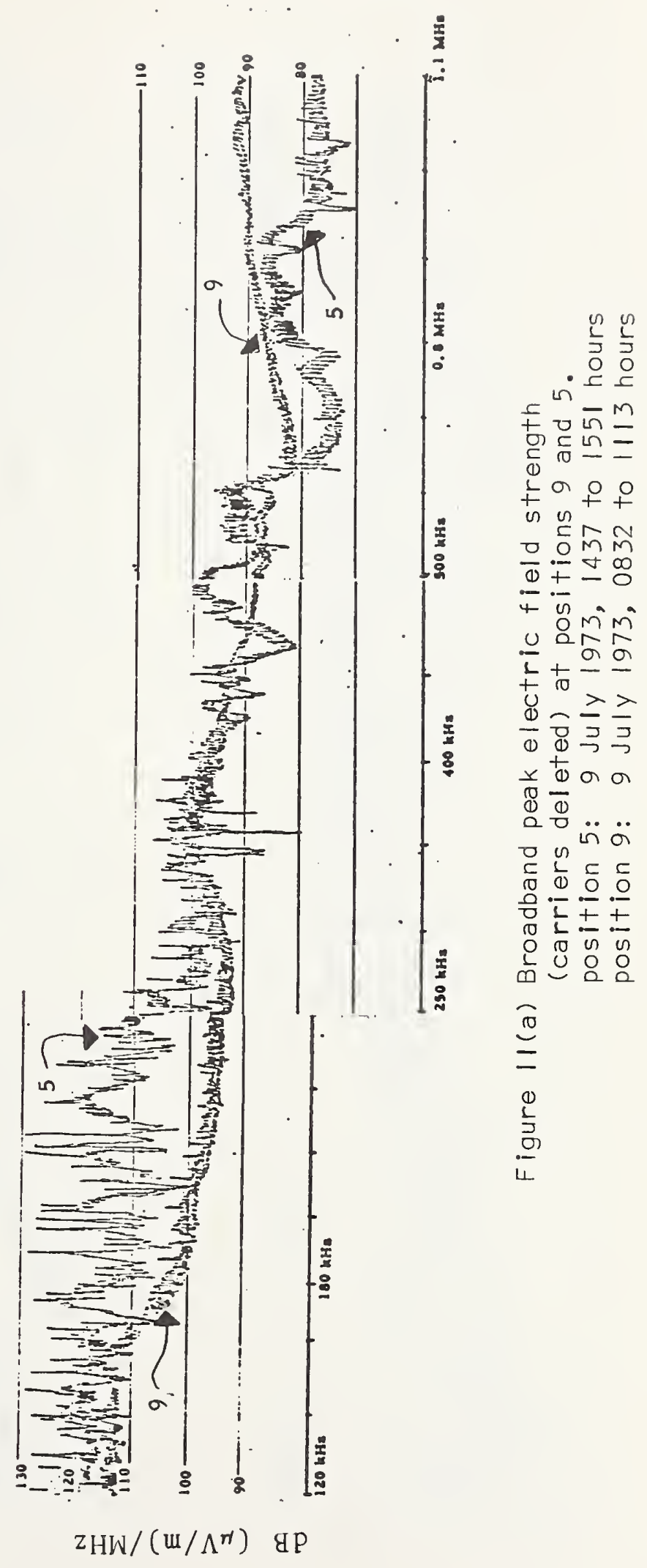



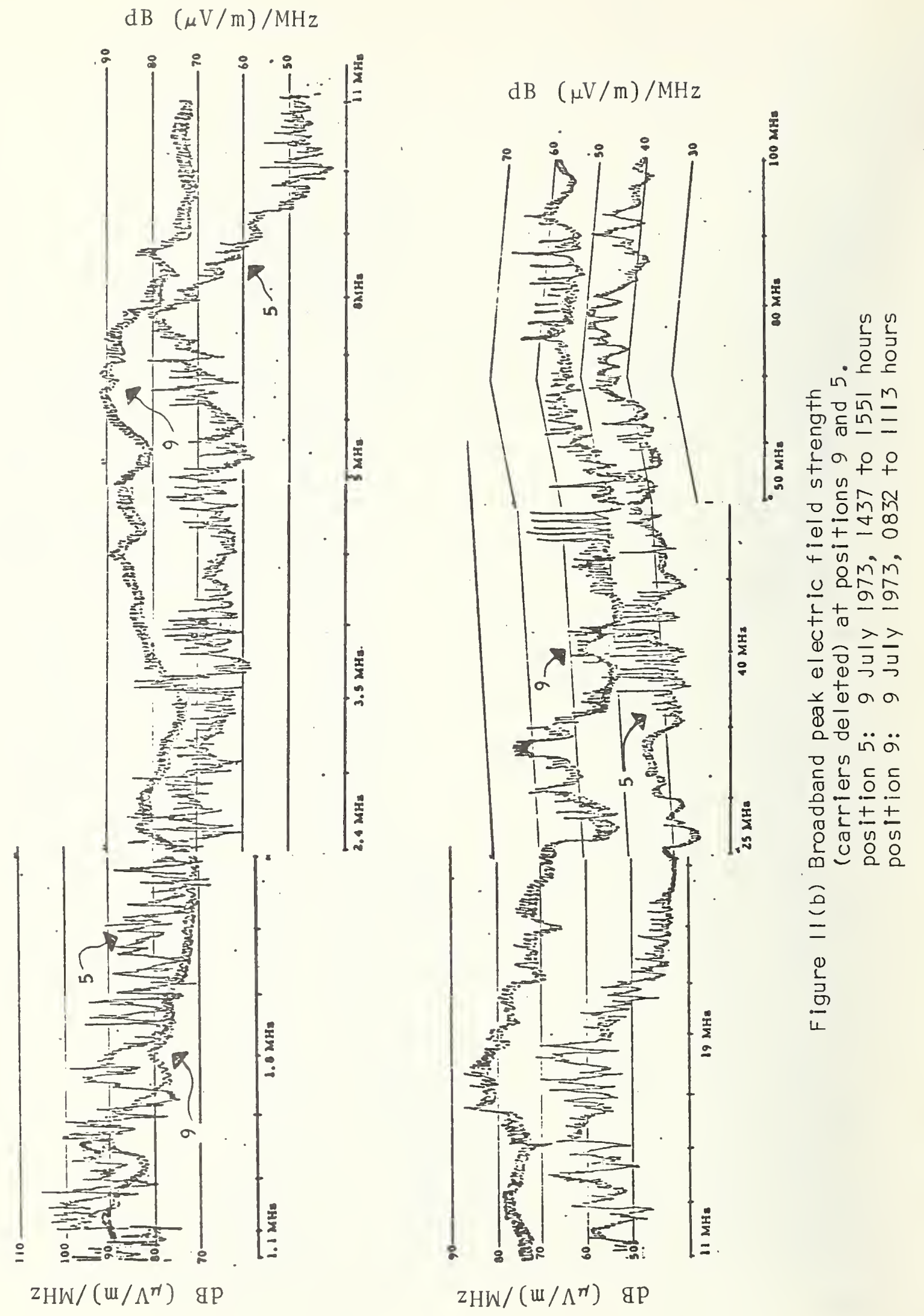
$\mathrm{dB}(\mu \mathrm{V} / \mathrm{m}) / \mathrm{MHz}$

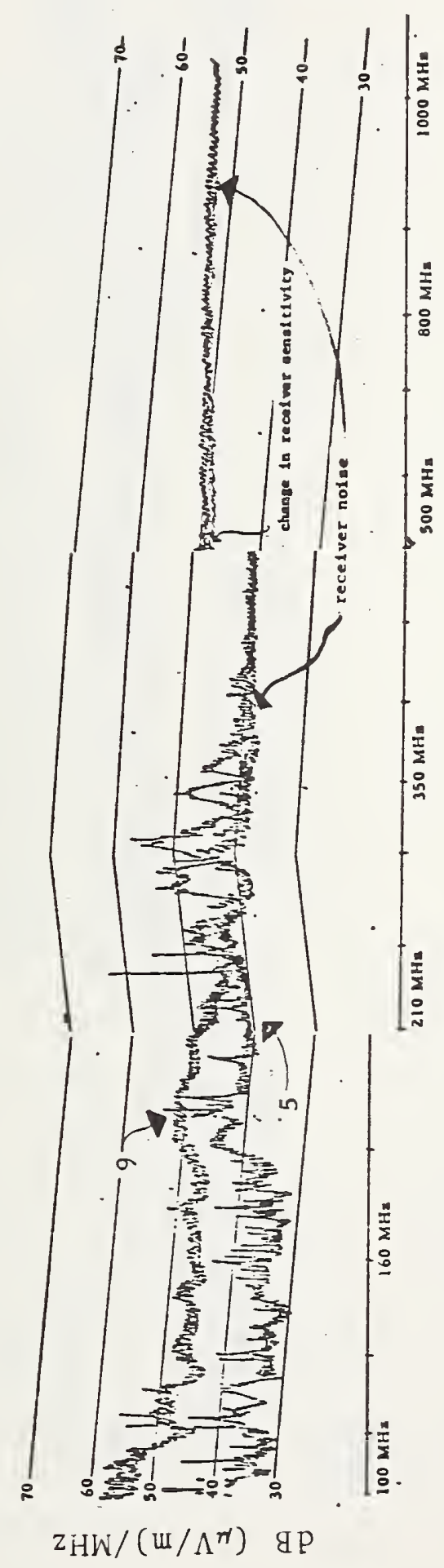

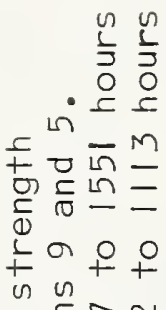

प

$\overline{1}+ \pm 0$

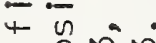

U 口î́

$\frac{a}{2}+2$

$\frac{1}{0}>x$

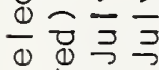

뭉

¿

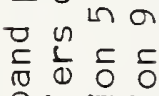

음푸

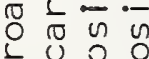

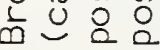

0
$=$
$=$
$\frac{1}{5}$
$\frac{0}{4}$ 
$\mathrm{dB}(\mu \mathrm{V} / \mathrm{m}) / \mathrm{MHz}$
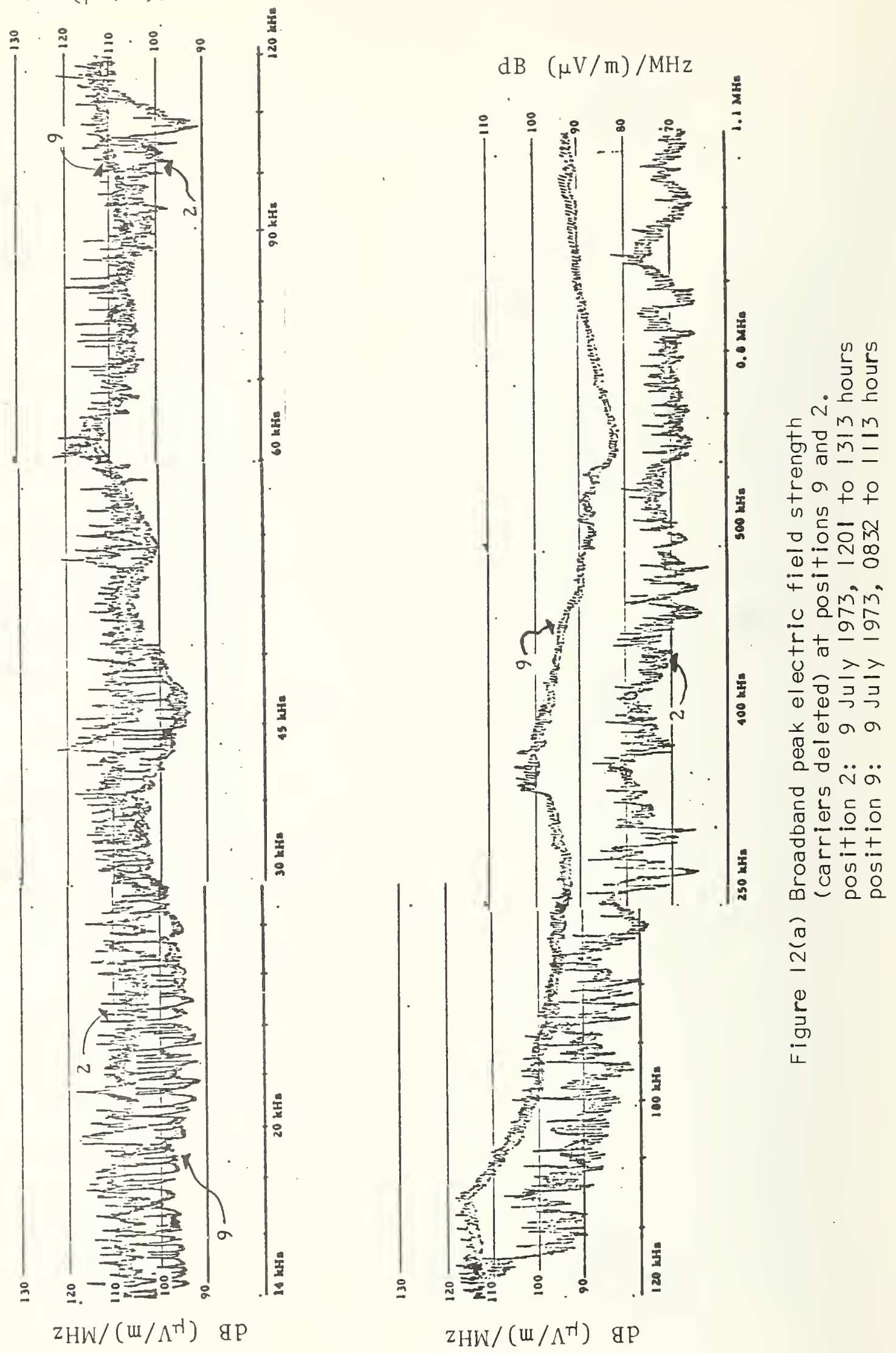

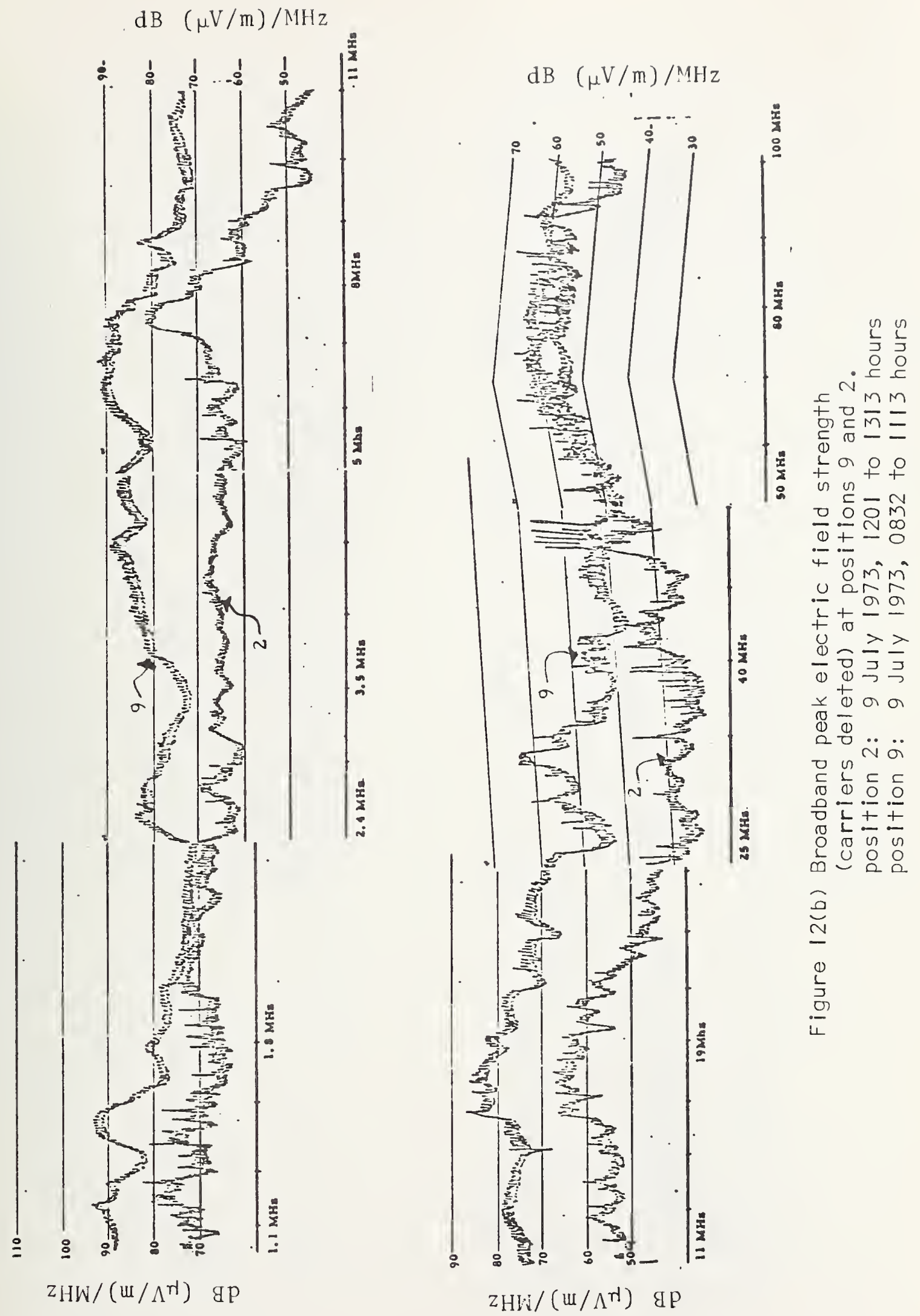


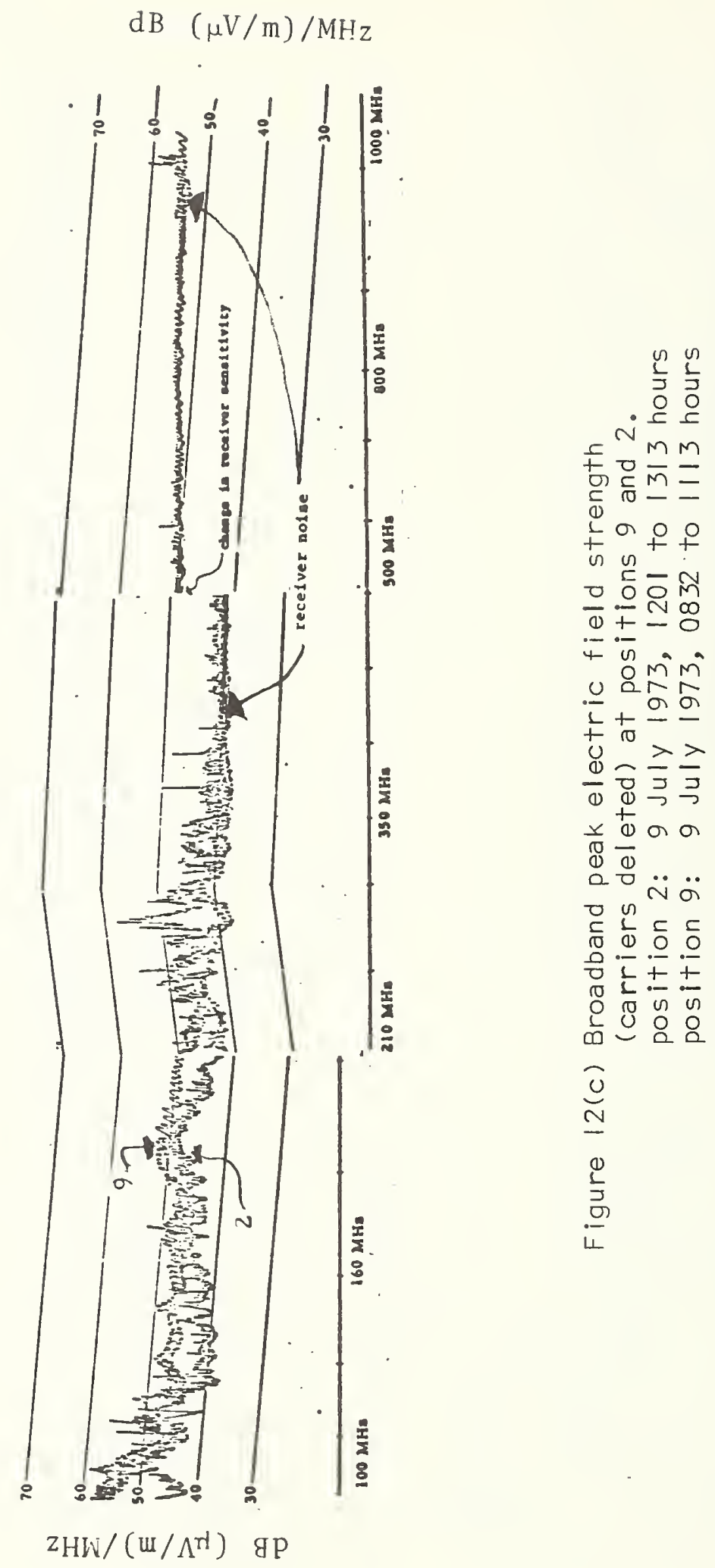




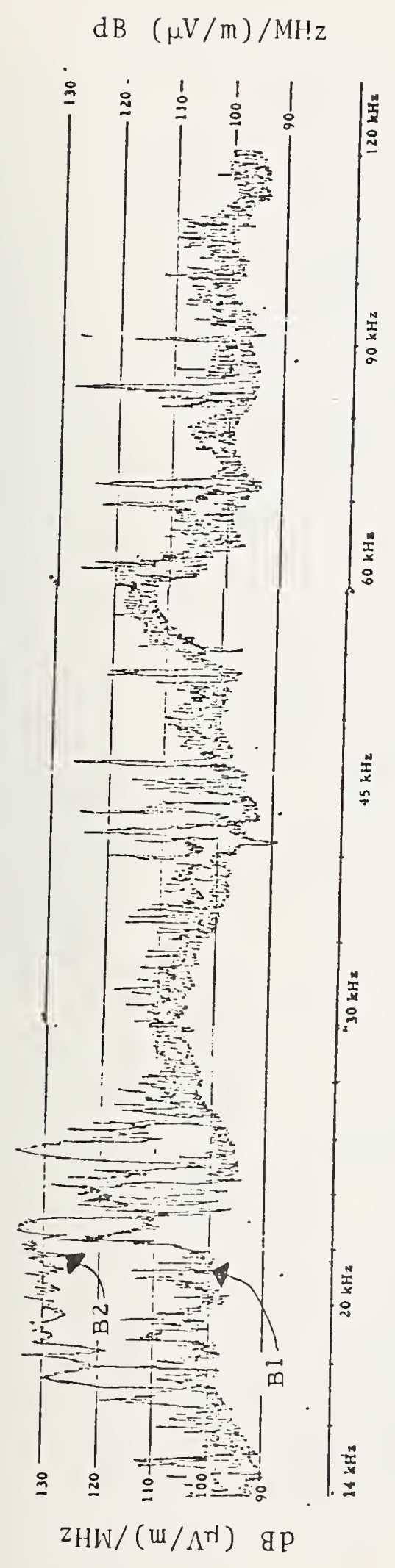

$\mathrm{dB}(\mu \mathrm{V} / \mathrm{m}) / \mathrm{MHz}$

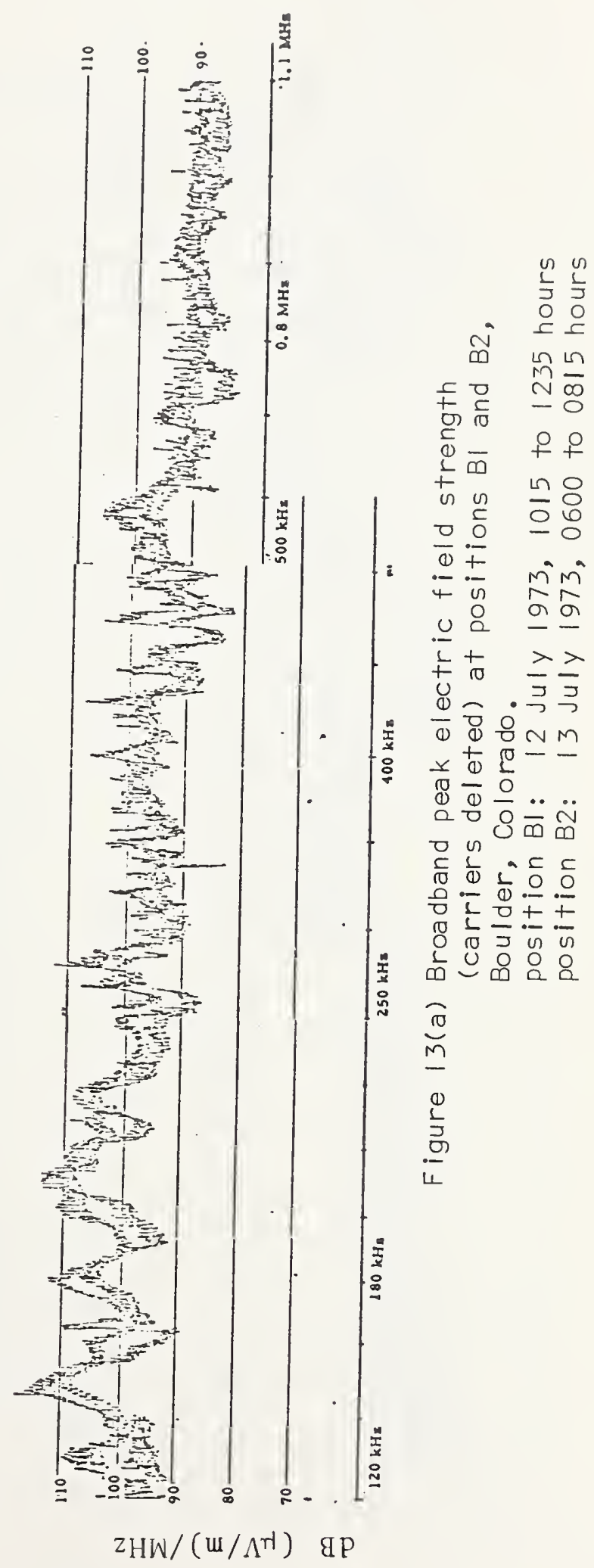



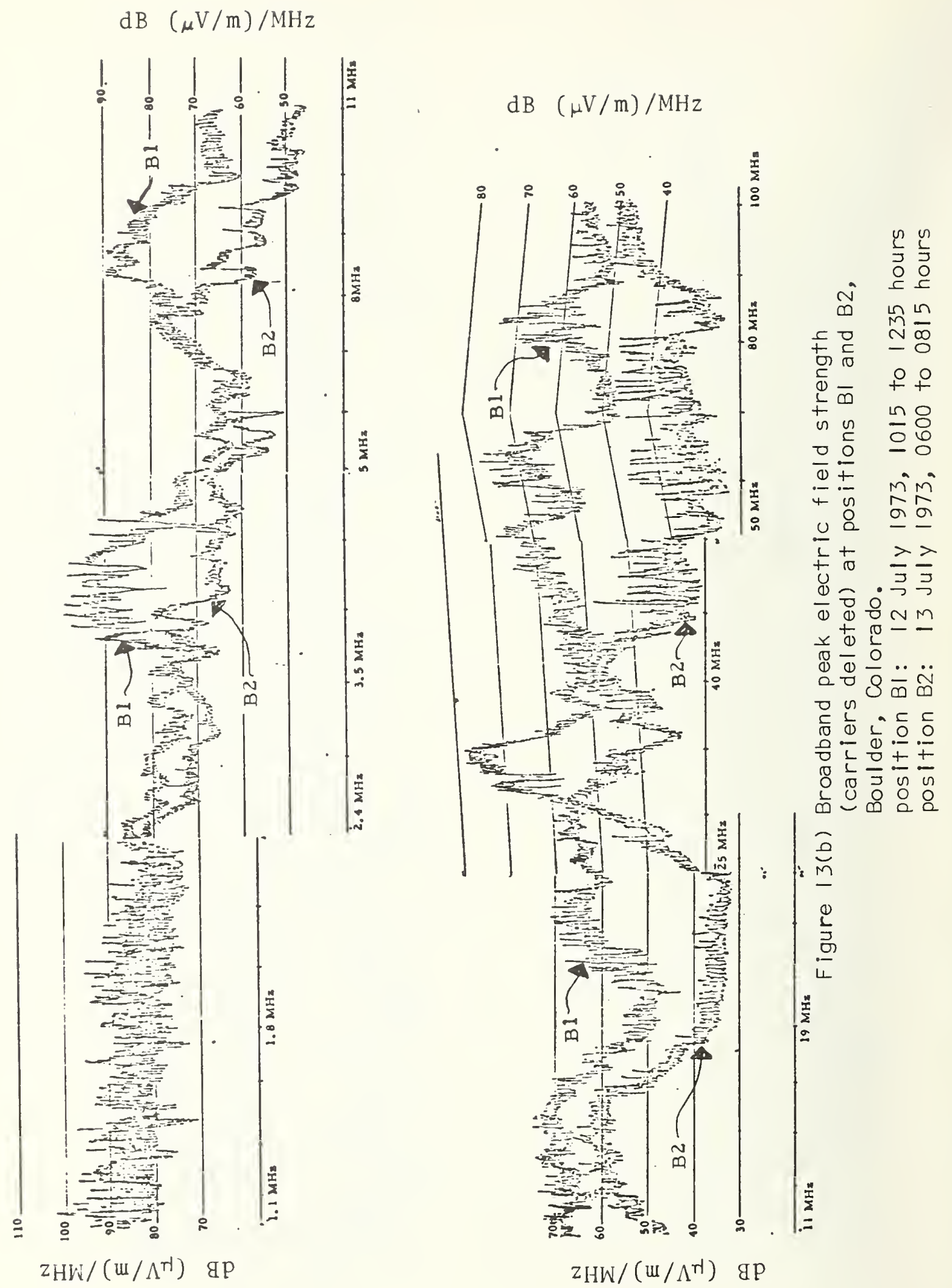
dB $(\mu \mathrm{V} / \mathrm{m}) / \mathrm{MHz}$

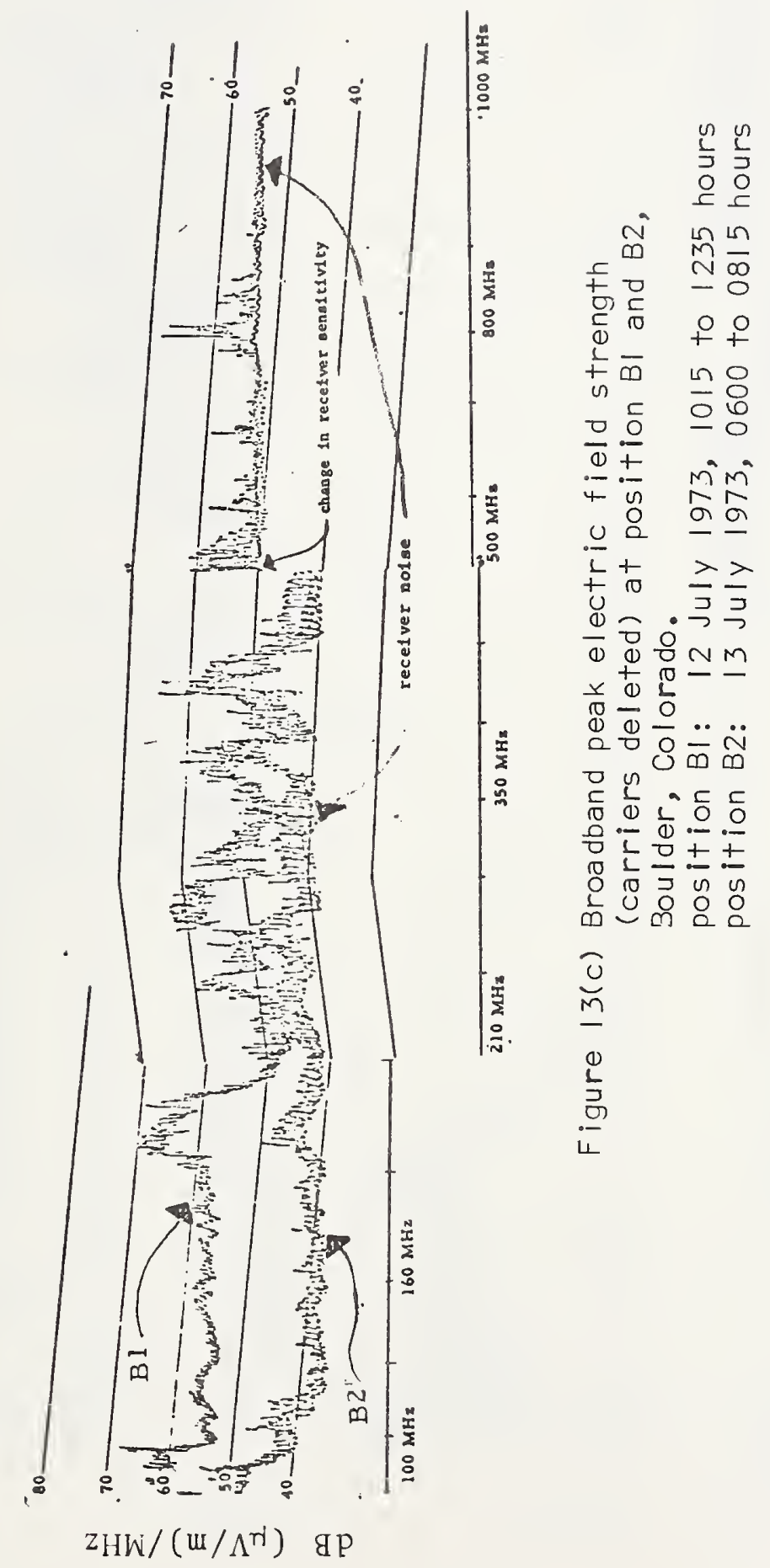




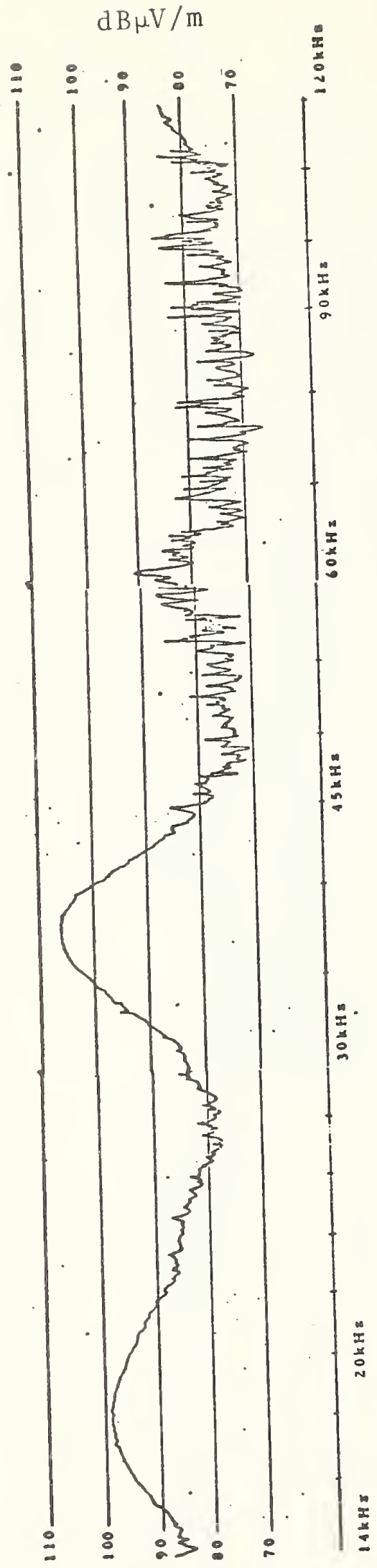

$u / \Lambda^{\text {rdgp }}$

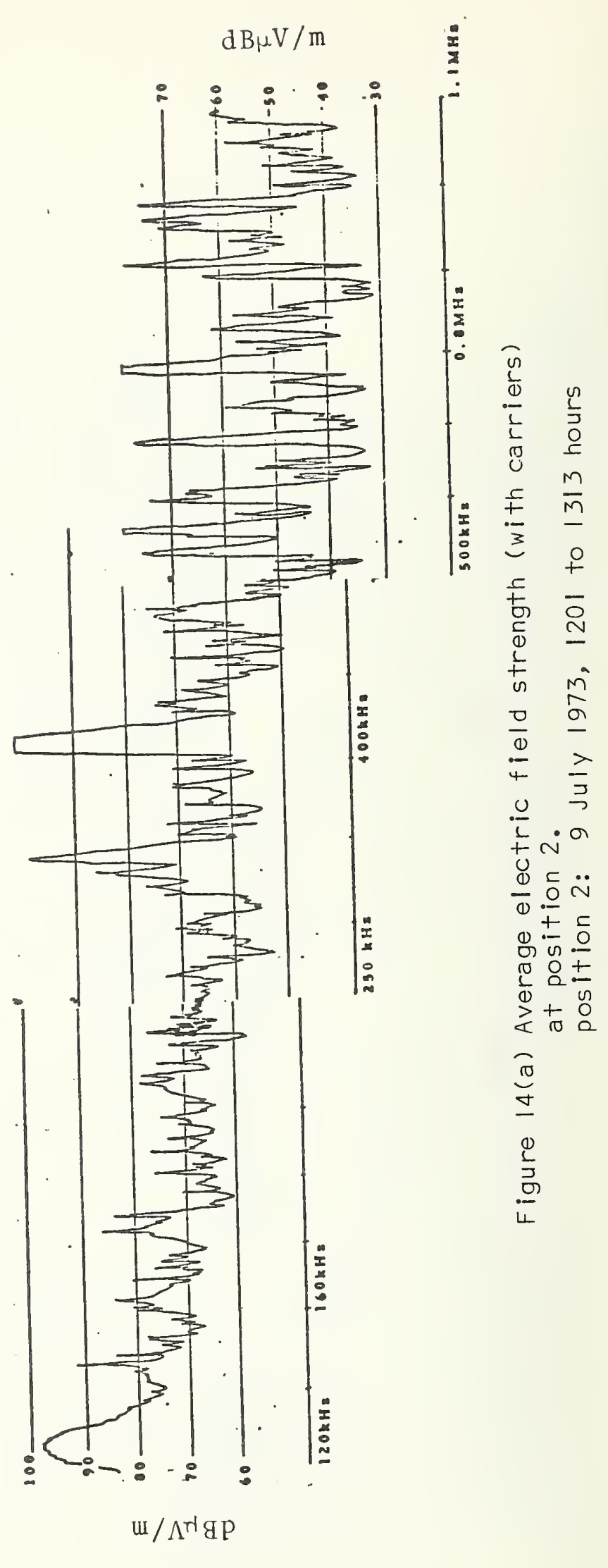




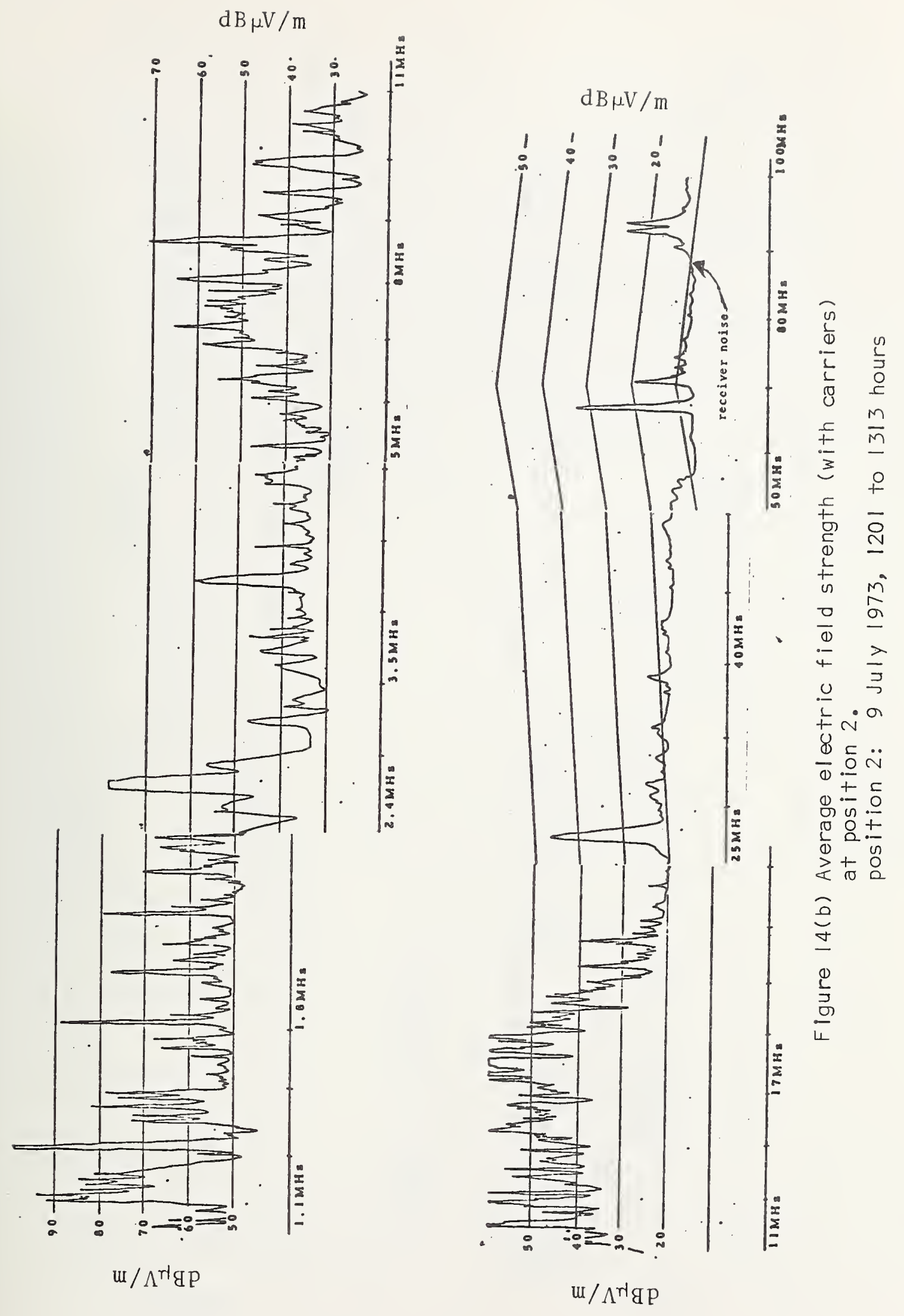




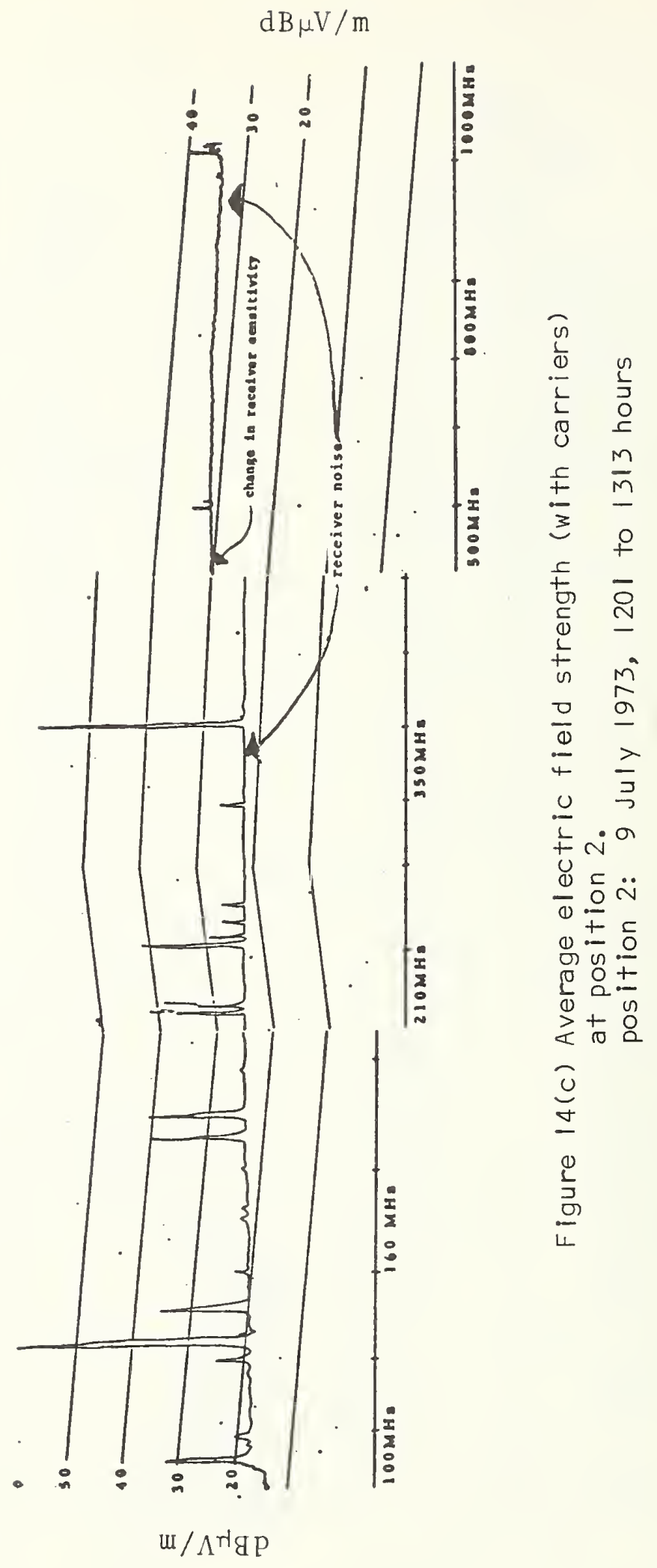




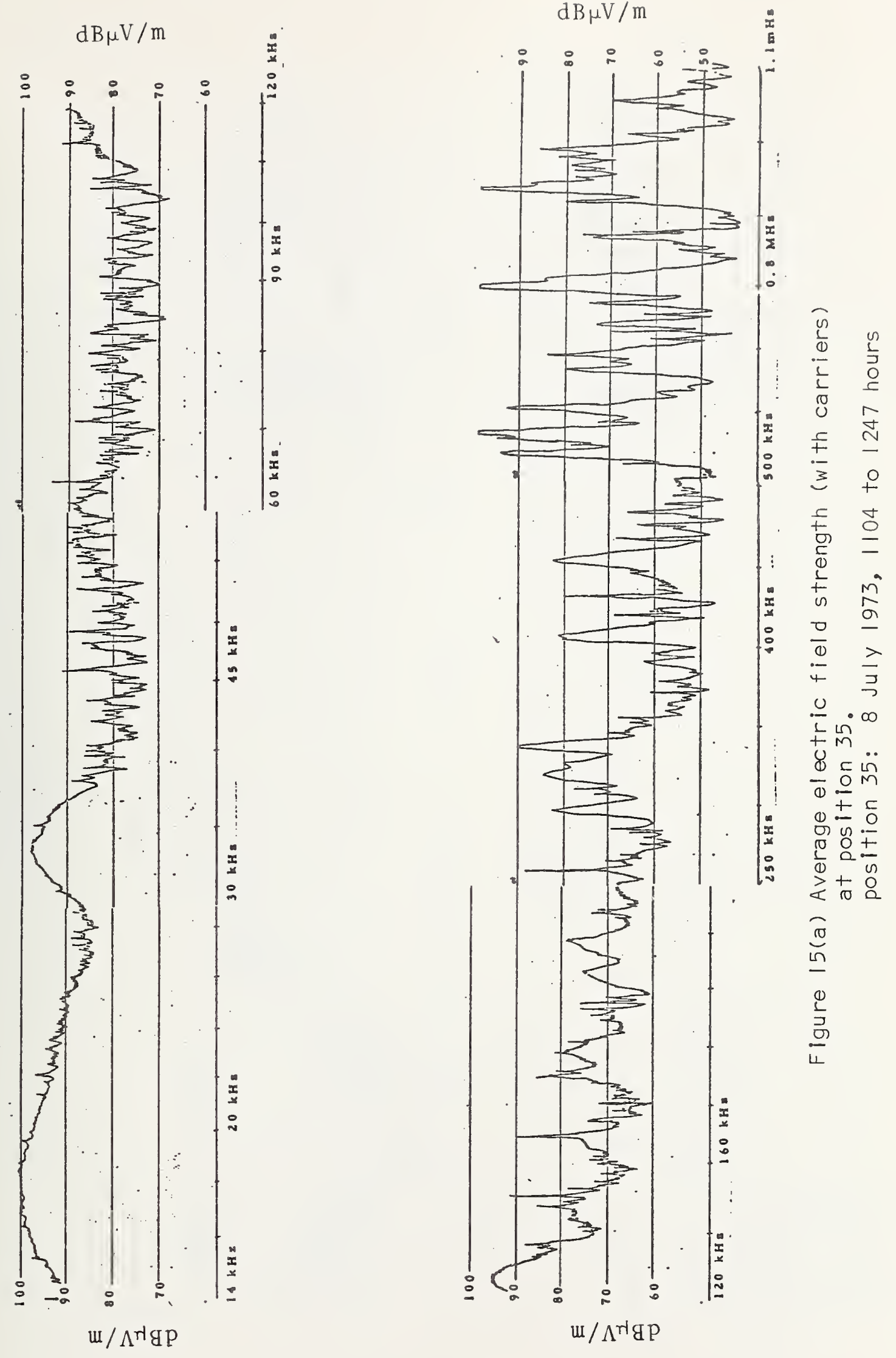




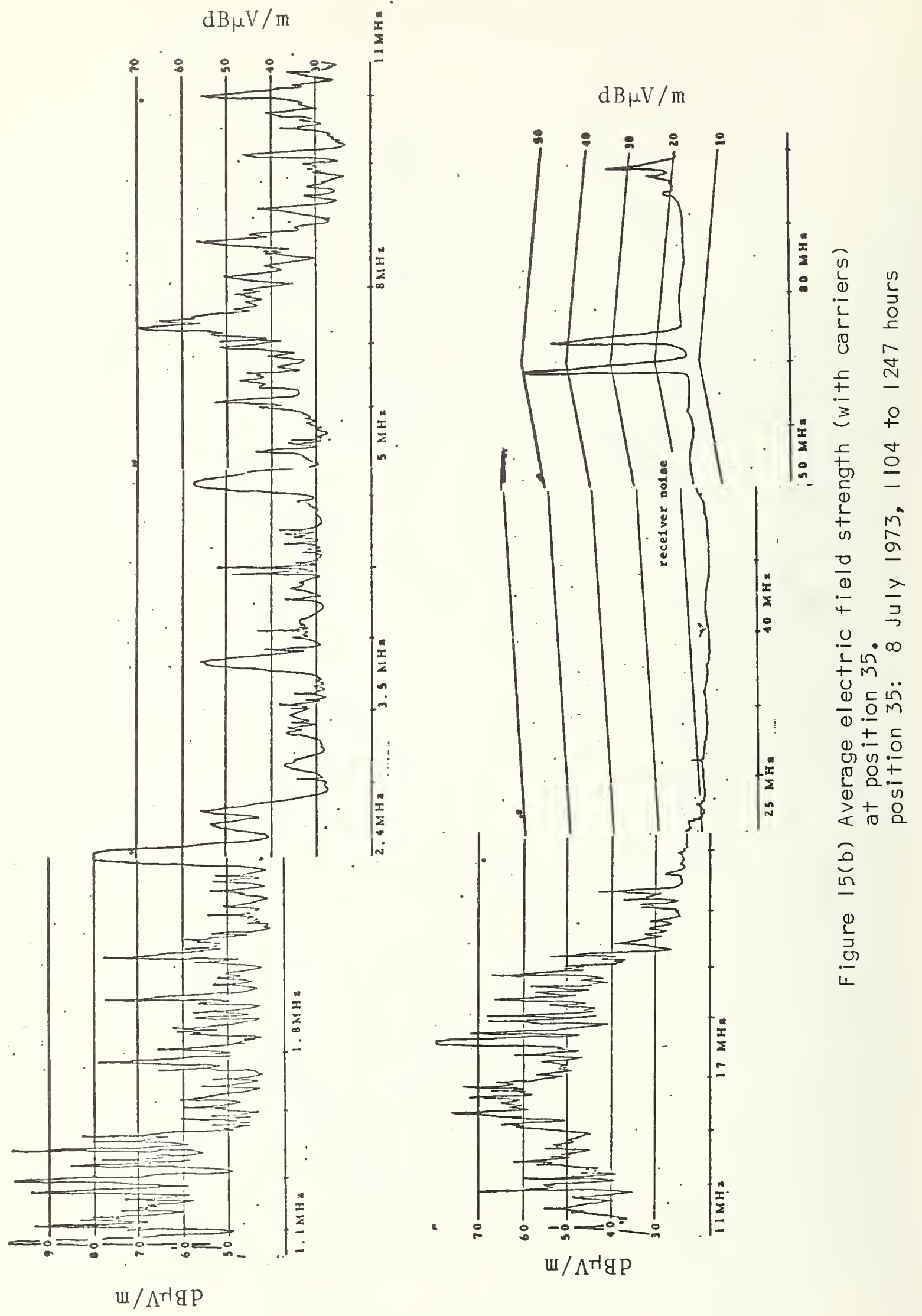




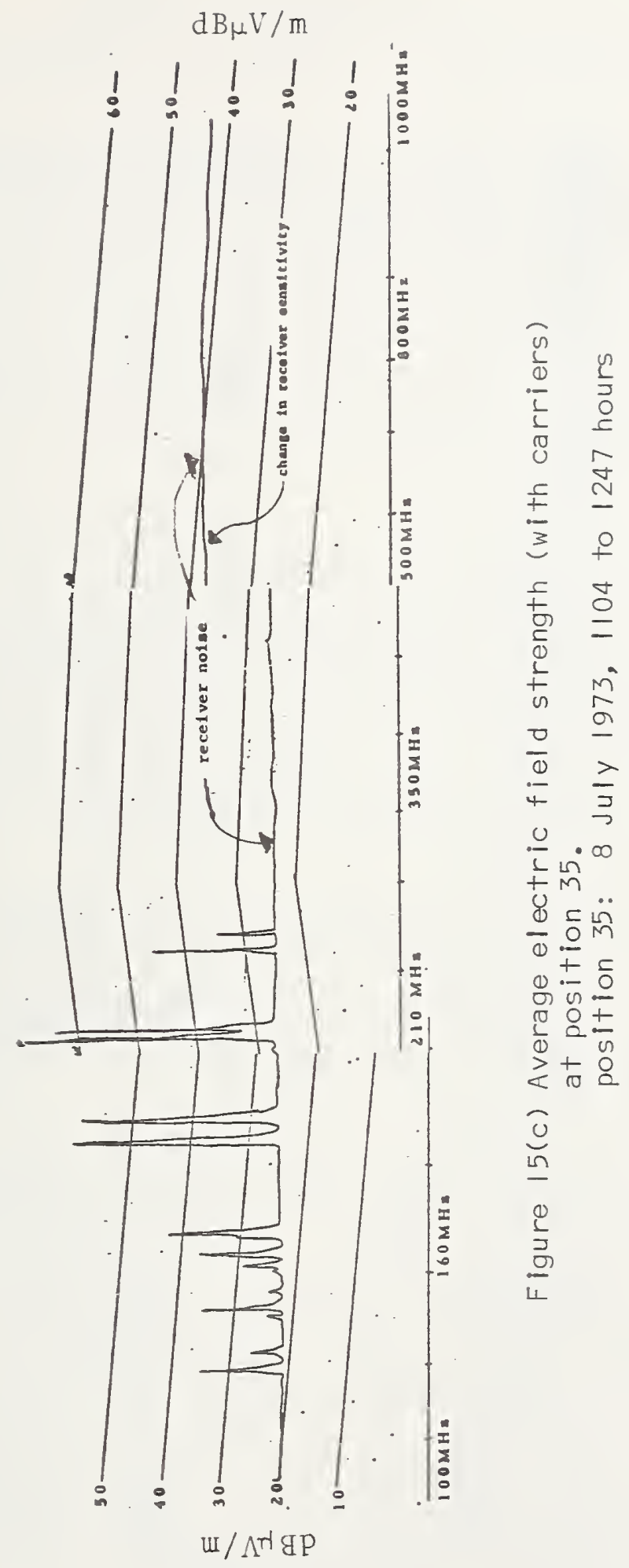




\subsection{Radiated EMI (magnetic field)}

The magnetic field EMI was measured at the following positions:

position 5. Hayes Ha11 Area (outside ASA compound); position 9. Hayes Ha11 Area (15 KV 1ine); and position 35. Willcox Dry Lake.

Figures $16(\mathrm{a})$ and 16 (b) compare the magnetic EMI at position 9 and 5 .

Figures $17(\mathrm{a})$ and $17(\mathrm{~b})$ compare the magnetic EMI at positions 9 and 35 .

\subsection{Selected-Frequency Radiated EMI (electric field)}

In addition to making the swept frequency measurements just described, radiated electric field measurements were also made at a number of sites in and about the ASA Compound at three selected frequencies. The selected frequencies were 40,54 , and $200 \mathrm{MHz}$. As a result of these measurements, an EMI map of the area was drawn, showing the variations in field strength. This map is shown in figure 18 .

The numbers on the map represent the measured EMI in decibels at that particular location at the respective frequencies of 40,54 , and $200 \mathrm{MHz}$. The top number is the $40 \mathrm{MHz}$ measurement followed by the 54 and $200 \mathrm{MHz}$ measurements. These measurements were made relative to each other; therefore, they can be compared with each other but cannot be compared with other data in this report.

In genera1, the EMI levels near Irwin Street (front of the compound) were higher. This was expected, since the power lines paralle1 Irwin Street. As the distance from Irwin Street (and the power 1ines) was increased, the overa11 EMI within the compound decreased. The levels at the extreme rear of the compound were 10 to 30 decibels lower than at the front of the compound. Measurements at $40 \mathrm{MHz}$ were made at two locations approximately 300 feet and 500 feet north of the compound. EMI at these two locations outside the compound were about the same level as that at the quietest location inside the compound. These two locations were farthest from the power lines, and here the measured EMI was the lowest (approximately 30 decibels lower than the EMI measured at the front of the compound). 

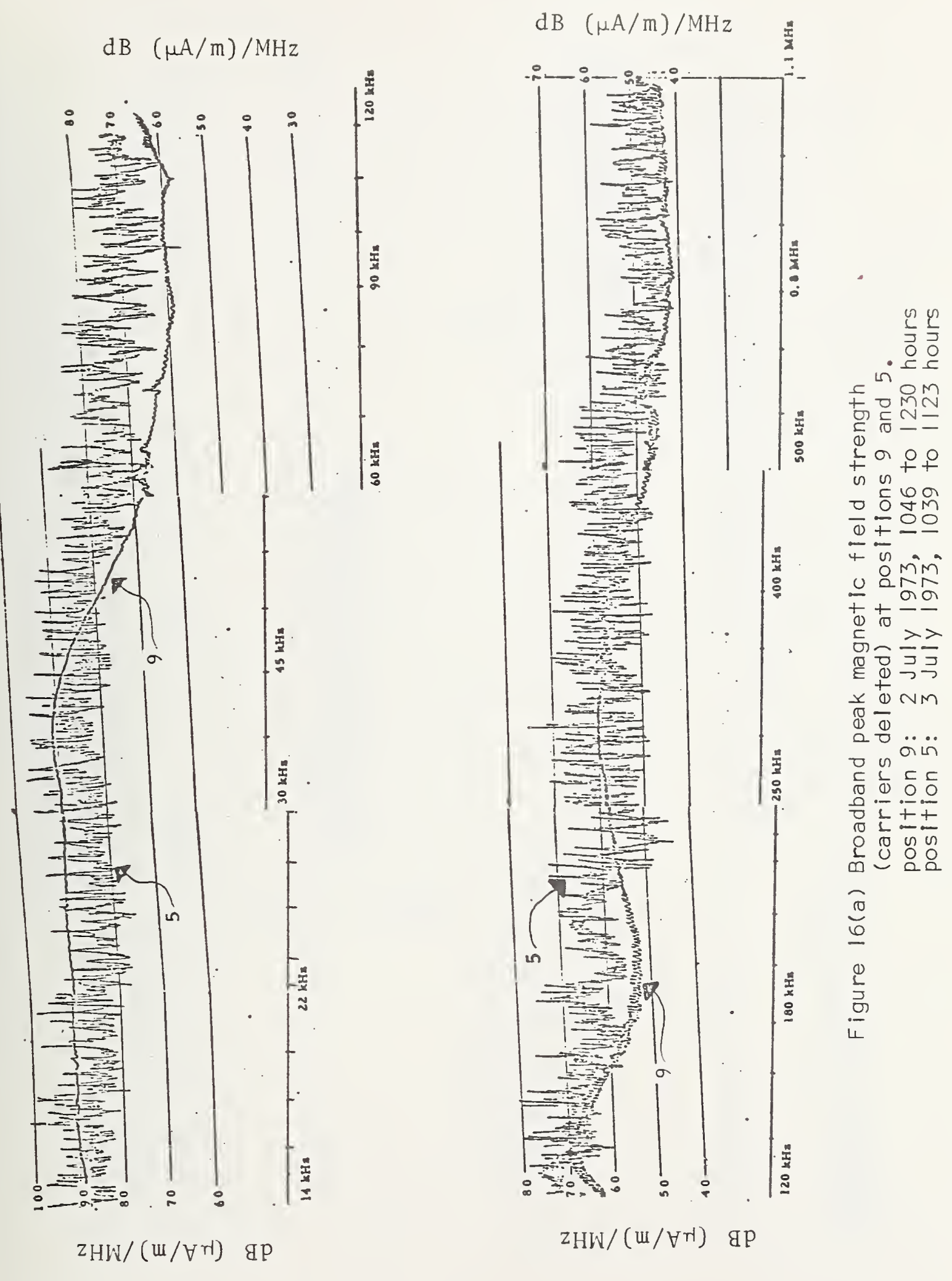

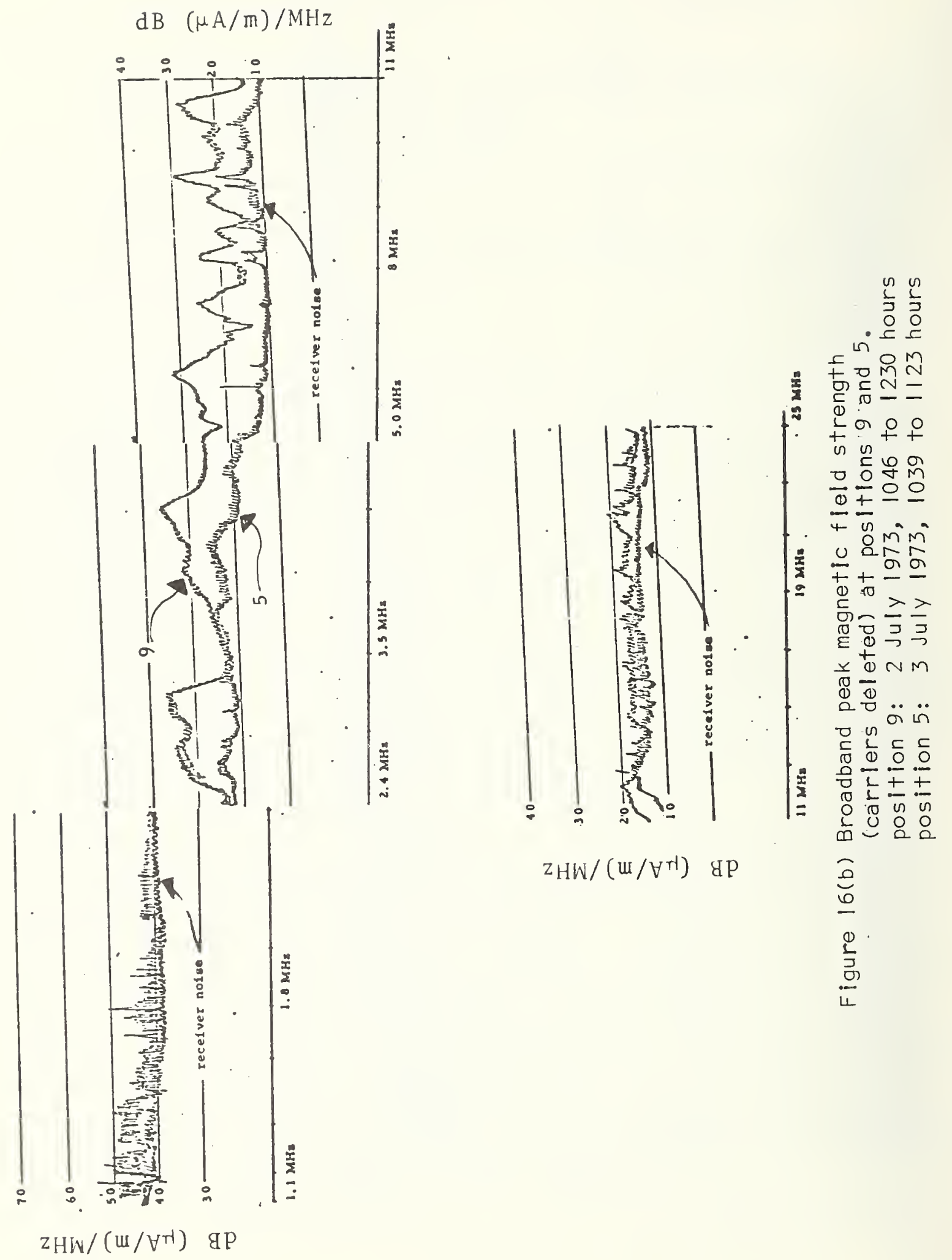
$\mathrm{dB}(\mu \mathrm{A} / \mathrm{m}) / \mathrm{MHz}$

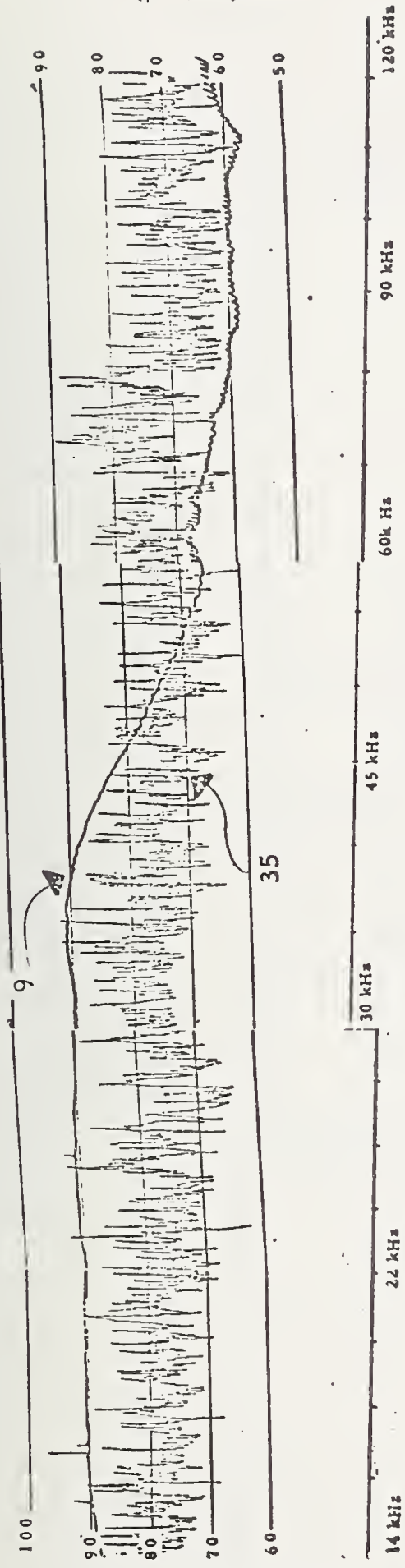

$z_{H W} /\left(w / \forall^{H}\right)$ gp

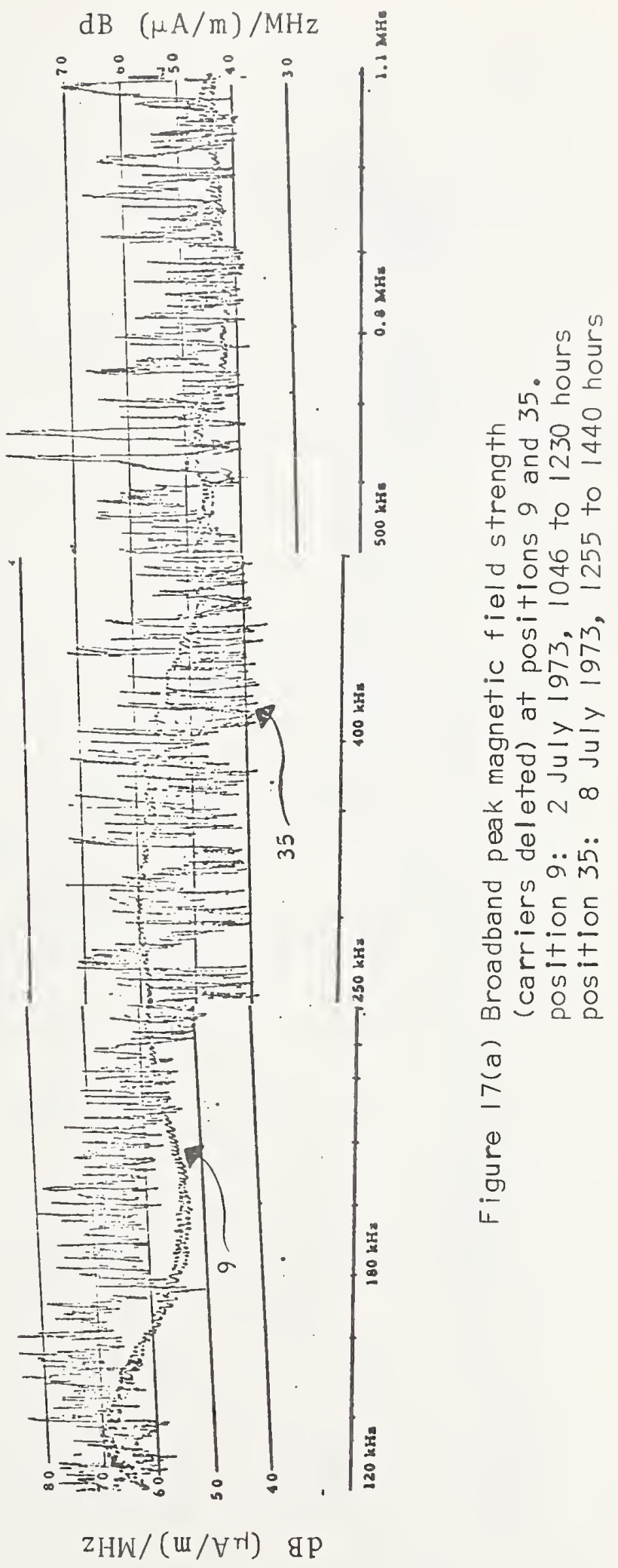




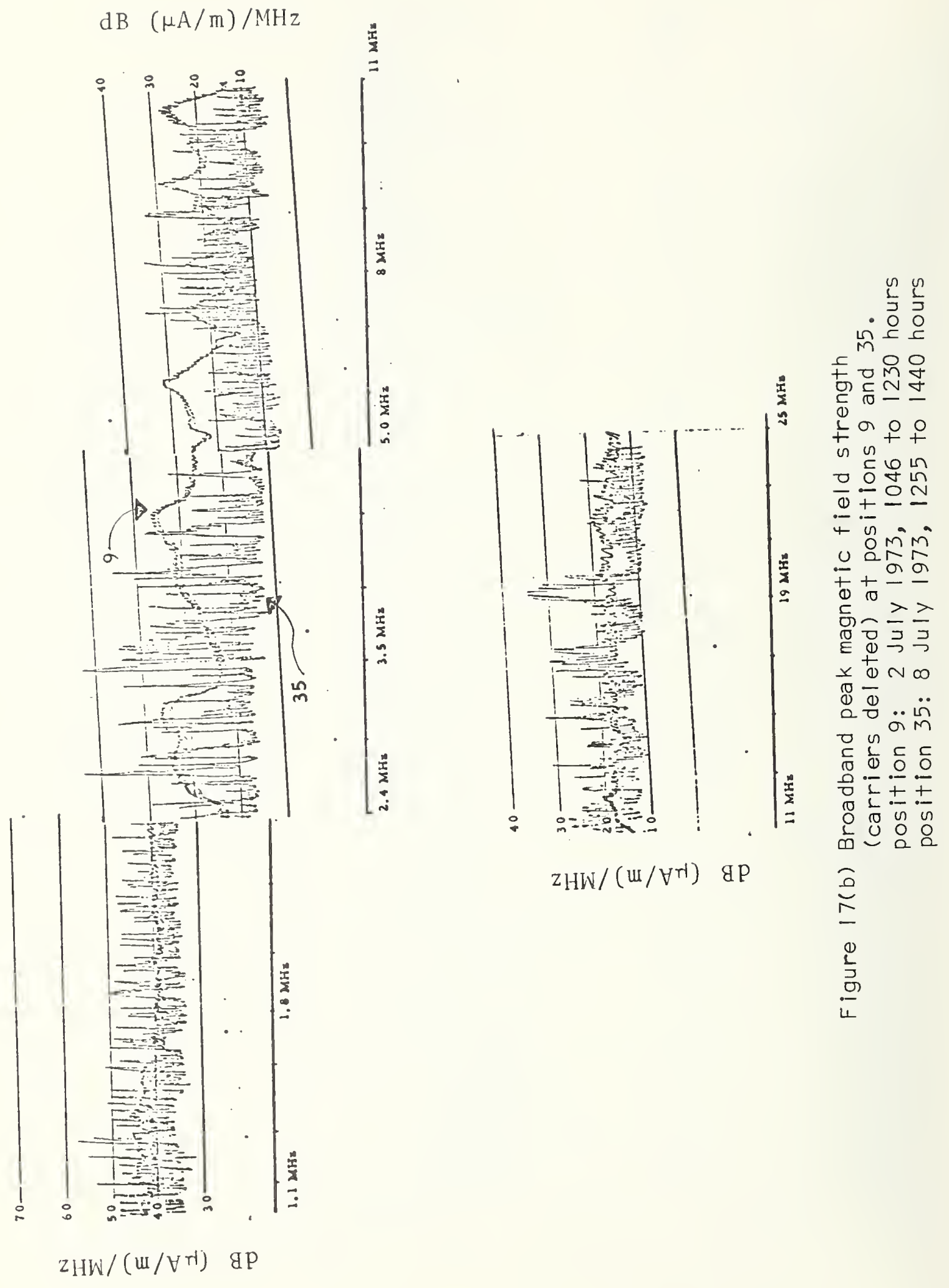




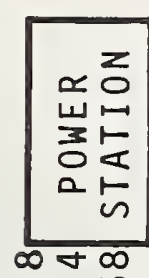

$\sim \Omega$

ARI ZONA

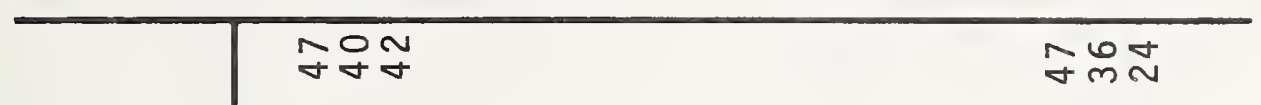

(1)

(1)

气

C i 1

(1) $\frac{10}{0}$

只

倞

- 8

o 0

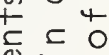

宓

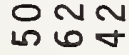

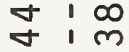

$\underset{\forall}{\sim} \mathrm{O}$

().

$\infty \infty$

Nmm

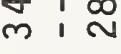

$\bar{E}+$

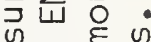

(1)

(8) $\stackrel{0}{>} \frac{5}{2}$

$\varepsilon \div \stackrel{0}{\mp} \div$ 入再两 U⿺辶寸

o $1+$ 궁

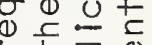
$4+. \frac{1}{0}$ $+\cdots$

(1) वे $\backsim 4$

+ N土

U 0

(1) 立视

+ow $\quad \hat{m} m$

ब)

$\infty 0 \underset{m}{m}$

m엄

$\infty$

$\infty: m$

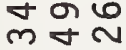

ㄴํㄴ

tor

N N 
Additional measurements were also made at the main power station west of Greeley Hall and at two locations just west of the ASA compound. These measurements were near power lines, and, as expected, the EMI levels were comparable to those measured near the front of the compound. The highest EMI levels were measured at the power station where there are higher power line voltages.

\subsection{Conducted EMI}

Figures 19 (a) and 19 (b) compare the conducted EMI in the 110 volt AC line located in the Systems-Evaluation Laboratory (at a workbench) with the conducted EMI within the ElectronicsMaintenance Branch shielded room. The difference between the curves illustrates the effectiveness of the line filters in reducing conducted EMI. The bottom curve is the conducted EMI within the shielded room.

\subsection{Mercury Vapor Lamps}

Mercury vapor lamps are positioned at selected points on the periphery of the ASA compound and are used as security lights during darkness. The contribution of the mercury vapor lamps to the tota1 EM environment was not certain. Therefore, measurements were made in the immediate vicinity of several of the lamps to determine if they contributed significantly to the overall EMI environment.

Selection of test locations was based on location of lamps relative to power 1ines. In areas where EMI levels were lowest, such as near the rear of the compound, EMI generated by the lamps was insignificant compared to EMI emanating from the power line. The general conclusion is that mercury vapor lamps at the ASA compound do not contribute significantly to the EMI environment.

\subsection{APD Measurements}

Measured data were processed and presented as about 150 APD's. These 150 APD's are not included in the body of this report. These large amounts of data are more easily comprehended in summary forms. Diurnal variation for each frequency 
$\mathrm{dB} \mu \mathrm{V}$

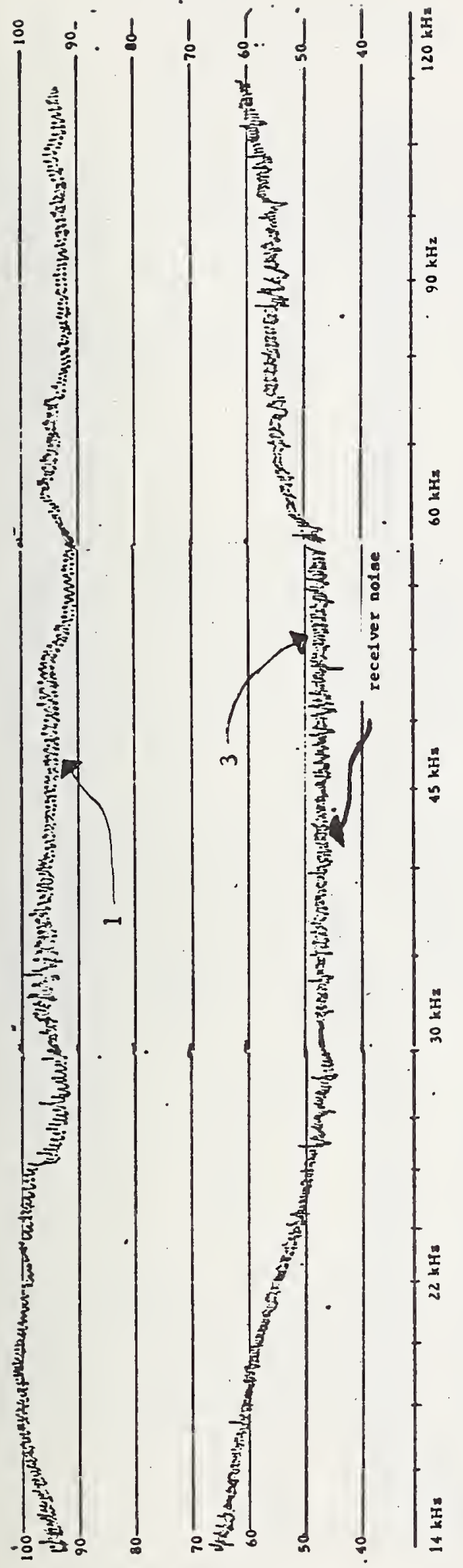

$\Lambda^{\text {rg p }}$ $\mathrm{d} B \mu \mathrm{V}$

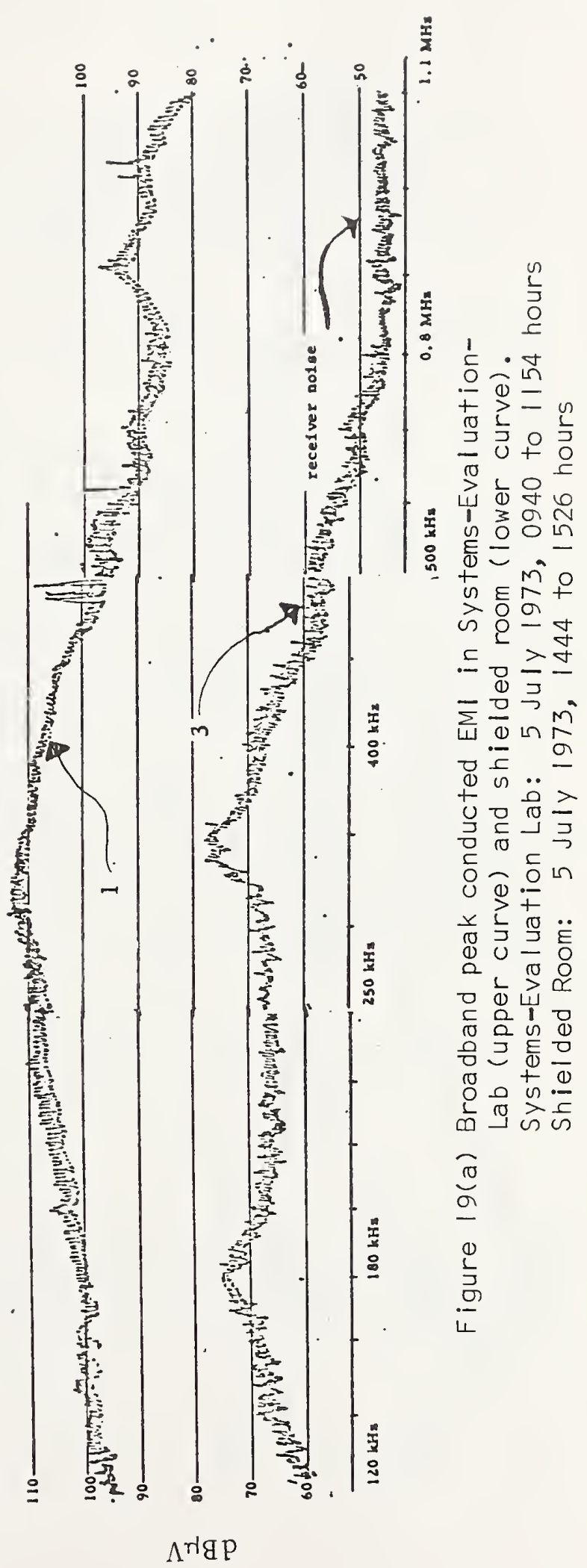



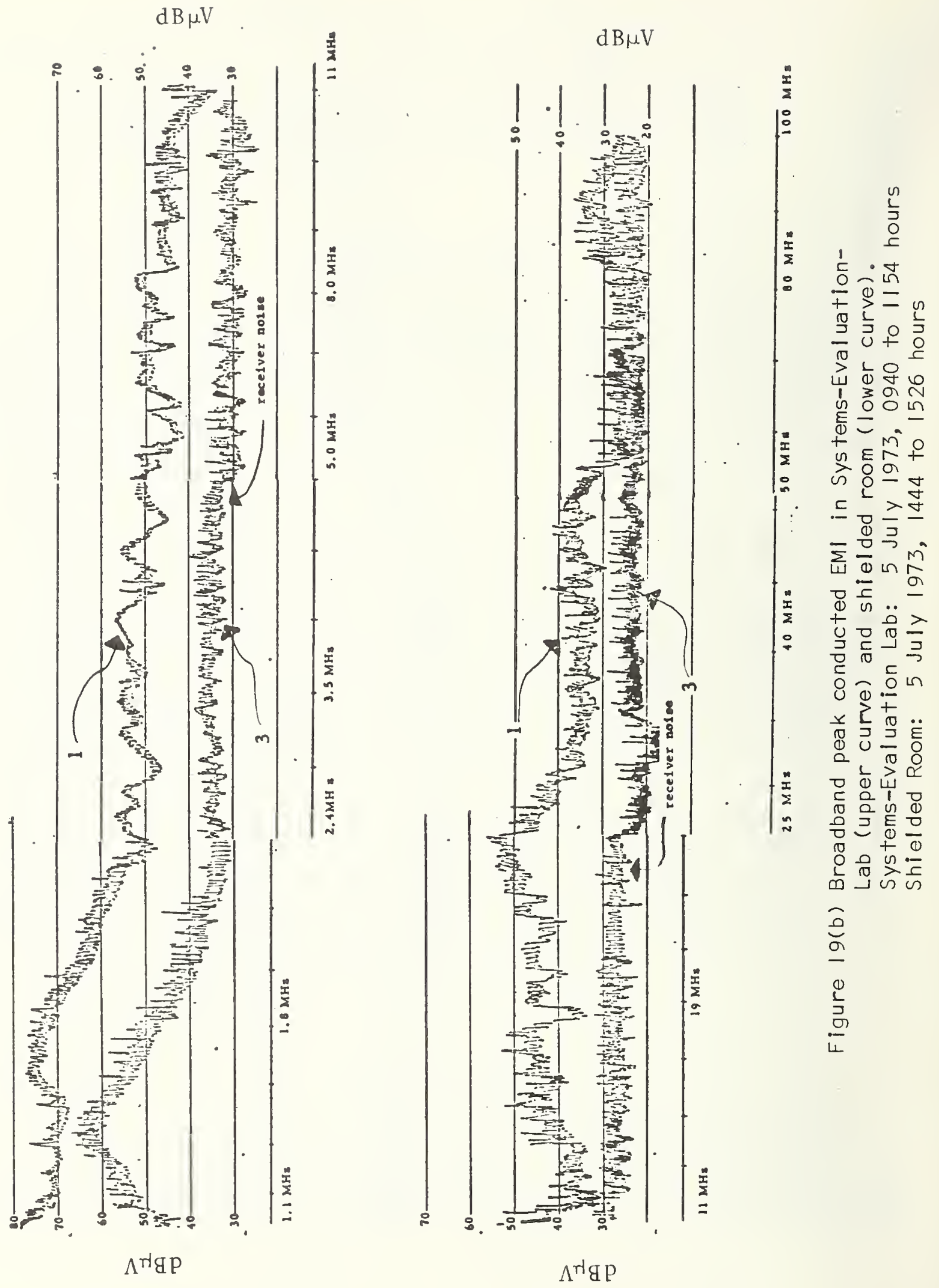
at locations 1 and 35 is compiled from the APD's. The 0.001 percent value, the time-averaged rms value, and the 99 percent value are given for a 24 -hour period. These are shown in figures 20 to 31 .

Also, since time variations versus frequency may be of interest, these are summarized for locations 1 and 35. The maximum (.001 percent) value during the 24 -hour period, the linearly averaged rms value, and the minimum (99 percent) value are plotted in figures 32 and 33.

The detailed information in the APD's may be obtained from the authors.

\subsection{Evaluation of the Shielded Room}

In response to a request to measure shielding effectiveness of the shielded room in the Electronics Maintenance Branch, limited measurements were performed. Since the original measurements plan did not include evaluation of the shielded room, NBS personnel did not bring all of the required equipment necessary for complete evaluation. Therefore, measurements were made using what equipment was available.

Shielding effectiveness was measured at $420 \mathrm{MHz}$ and $1000 \mathrm{MHz}$ frequencies. Measurements were performed by 1 aunching a planewave field from a transmitter approximately 12 meters from the shielded room. Shielding effectiveness was determined by the difference between measured magnitudes in $\mathrm{dB} \mu \mathrm{V} / \mathrm{m}$ of the launched field outside and inside the shielded room. Results are listed below:

\begin{tabular}{ccc}
$\begin{array}{c}\text { frequency } \\
\text { MHz }\end{array}$ & $\begin{array}{c}\text { type of } \\
\text { field }\end{array}$ & $\begin{array}{c}\text { shielding effectiveness } \\
\text { decibels }\end{array}$ \\
\cline { 1 - 1 } 420 & $\begin{array}{c}\text { planewave } \\
\text { planewave }\end{array}$ & $>70$ \\
1000 & & 51
\end{tabular}

The measurement system dynamic range at $420 \mathrm{MHz}$ was only 70 decibels, and shielding effectiveness of the room exceeded that value. Primary sources of $\mathrm{rf}$ leakage at $1000 \mathrm{MHz}$ were in the vicinities of the door and the line filters, with the door leaking the most. 


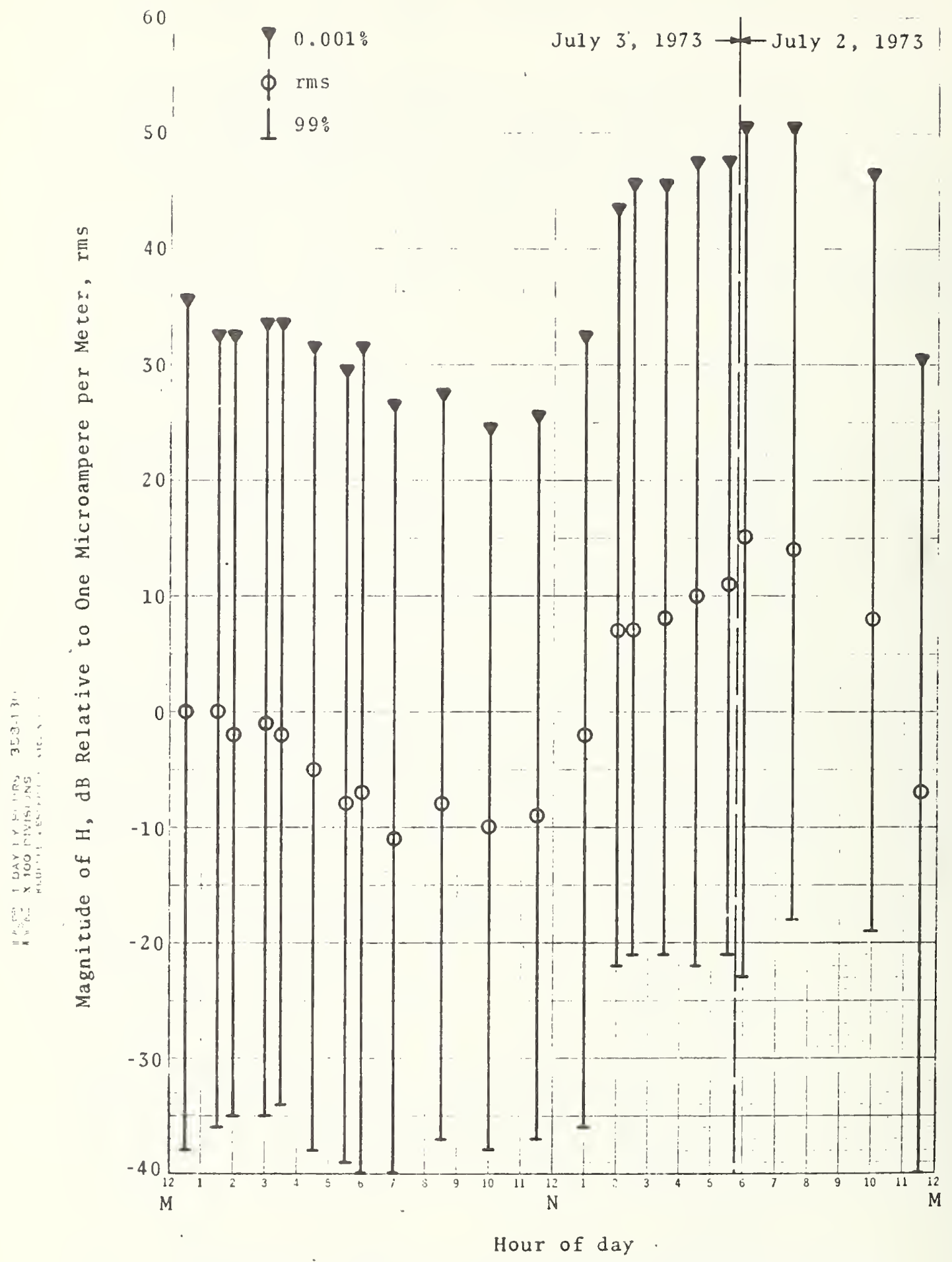

Figure 20. Summary of $25 \mathrm{kHz}$, H-field variations from each APD, Hayes, Hall. 


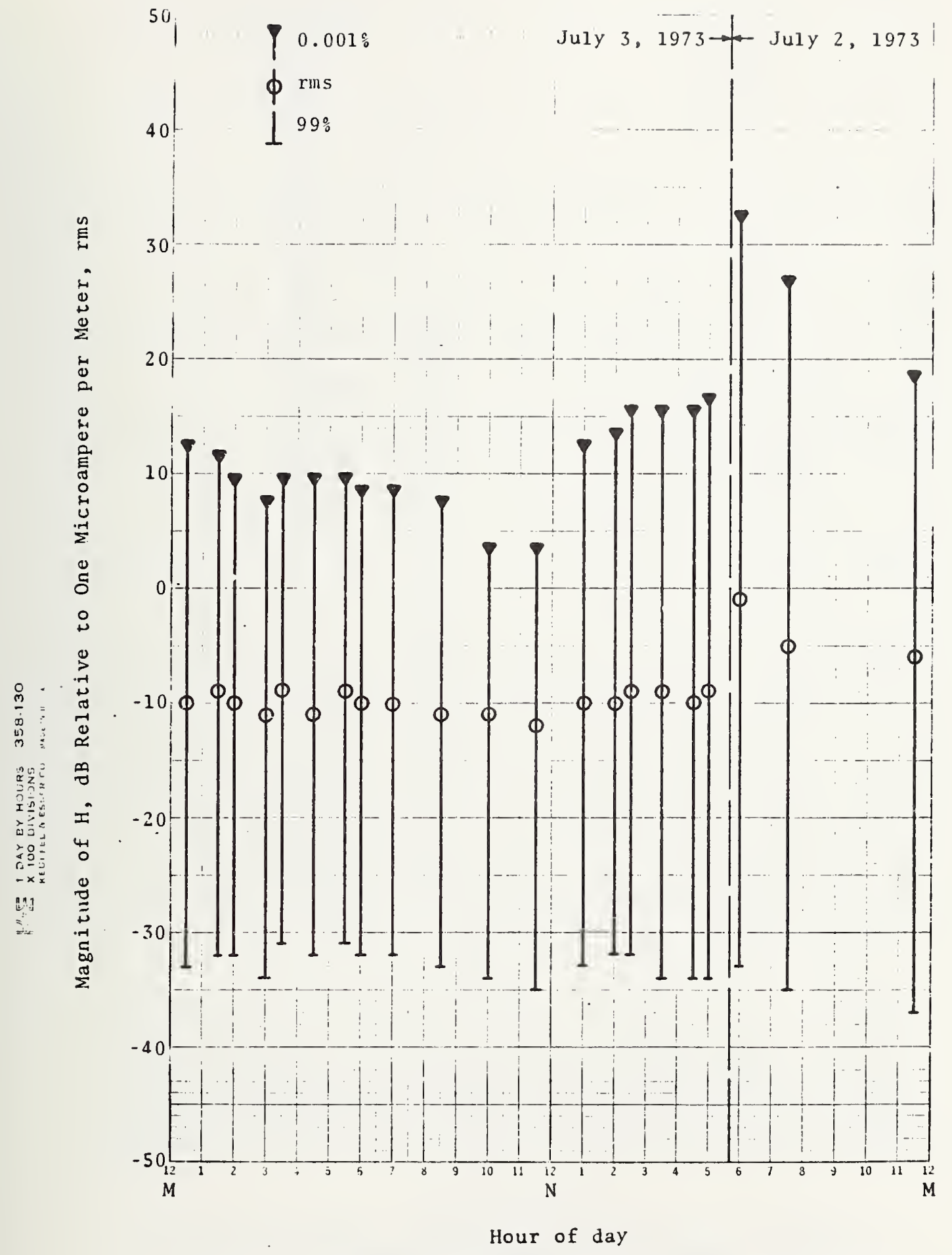

Figure 21. Summary of $250 \mathrm{kHz}, \mathrm{H}$-field variations from each APD, Hayes Hal.l. 


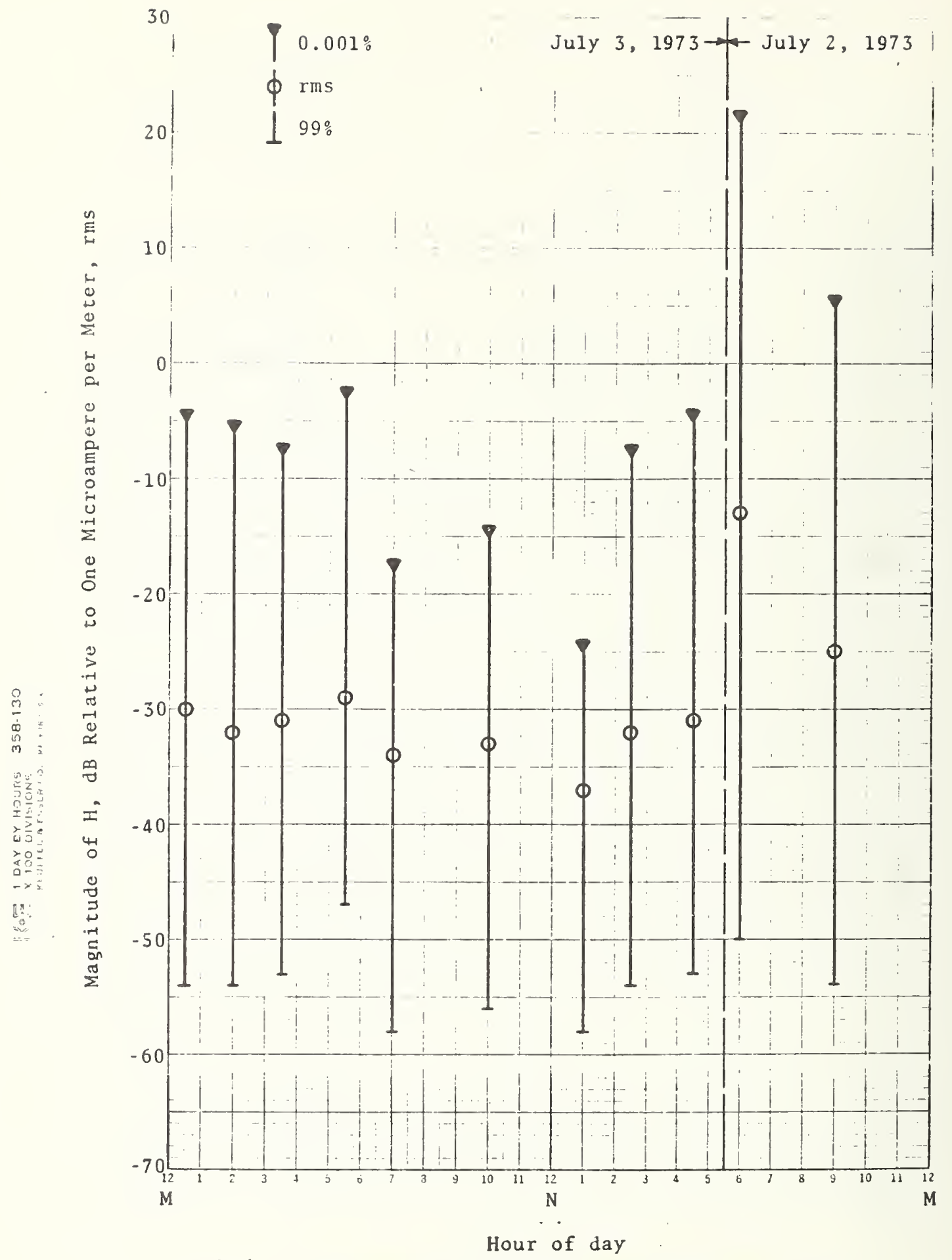

Figure 22. Summary of $1 \mathrm{MHz}$, H-field variations from each APD. Hayes HalI. 


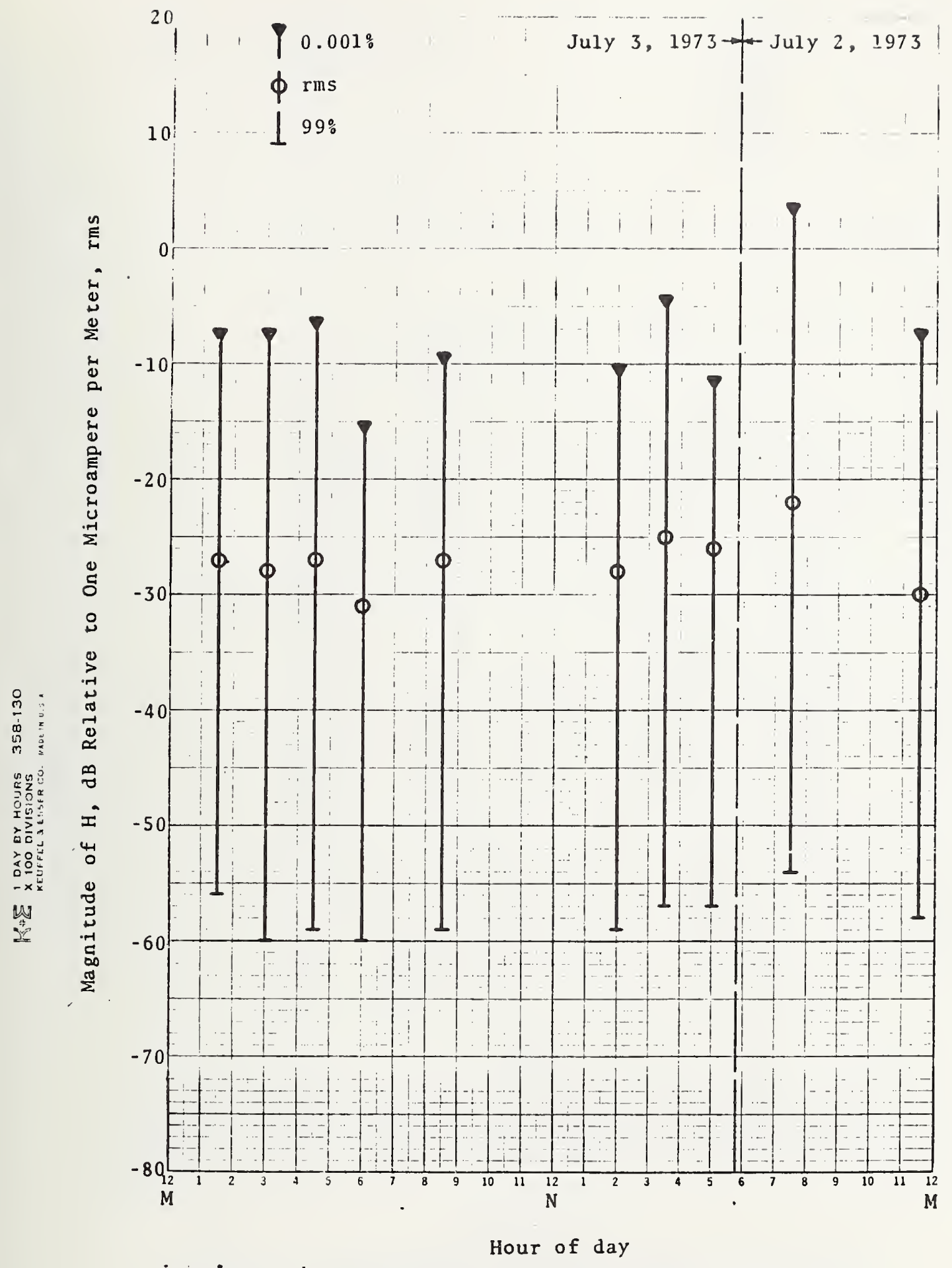

Figure 23. Sumary of $3 \mathrm{MHz}$, H-field variations from each APD, Hayes Hall. 


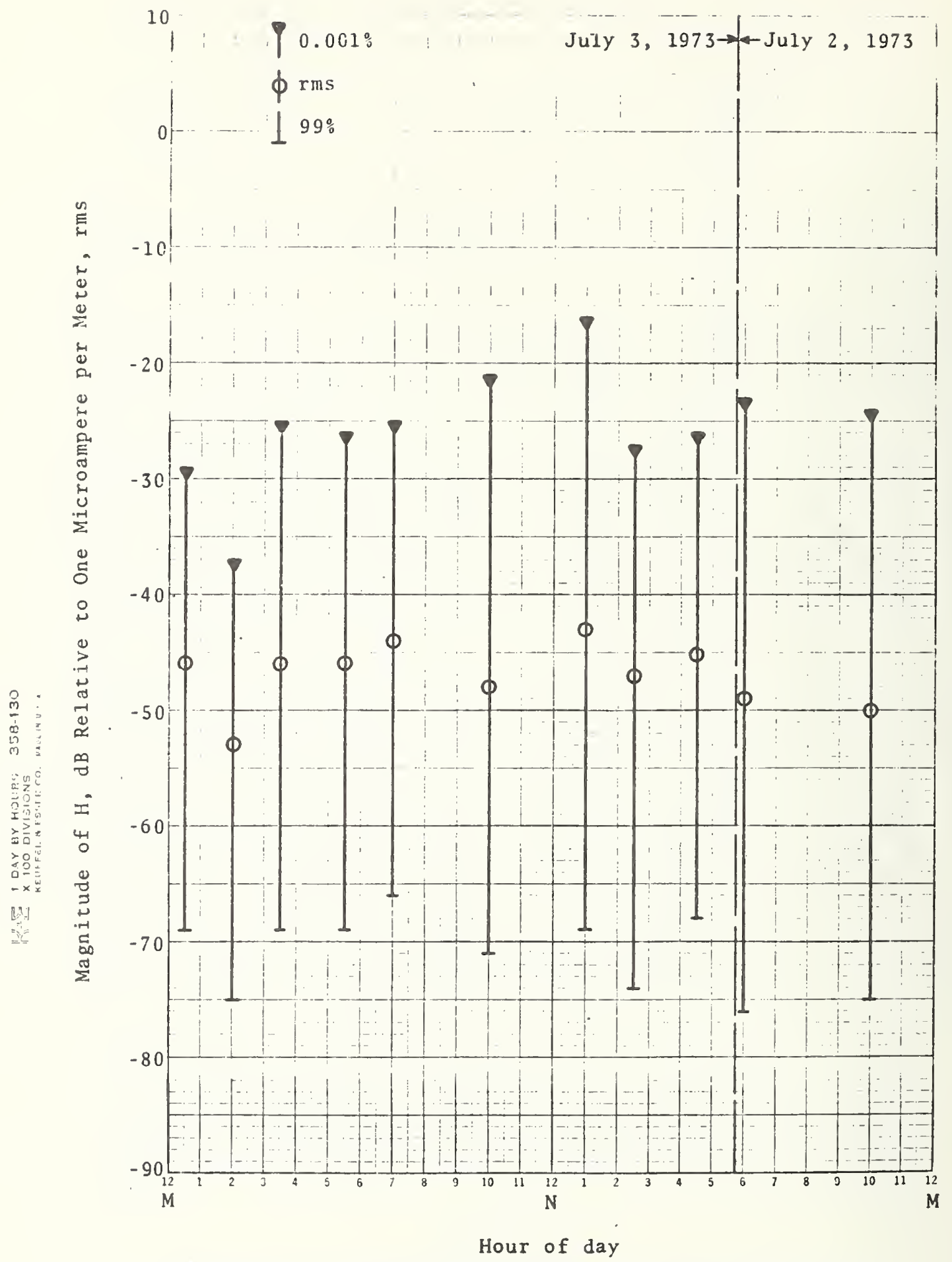

Figure 24. Summary of $10 \mathrm{MHz}, \mathrm{H}$-field variations from each APD, Hayes Hajl. 


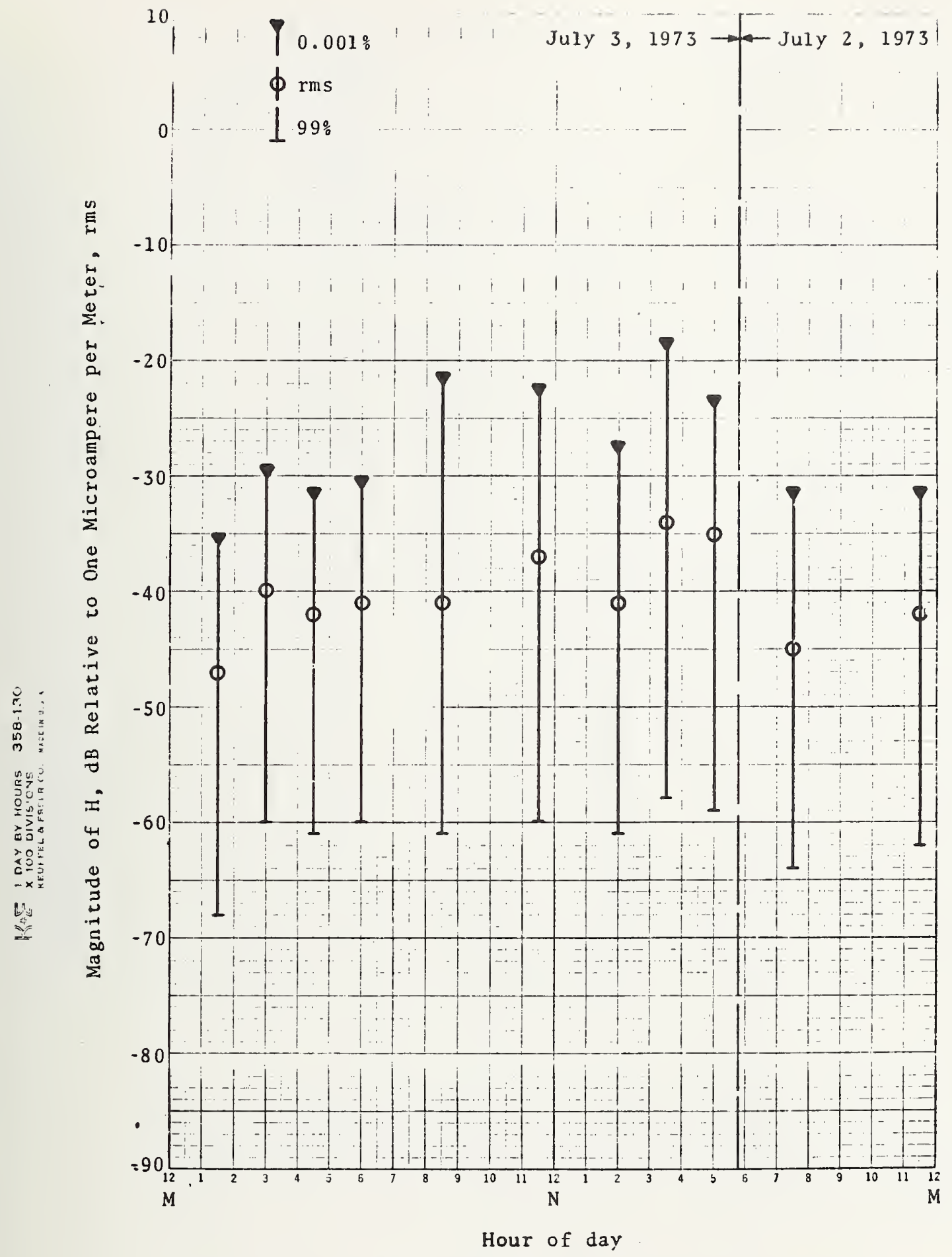

Figure 25. Summary of $30 \mathrm{MHz}, \mathrm{H}-\mathrm{field}$ variations from each APD, Hayes Hall. 


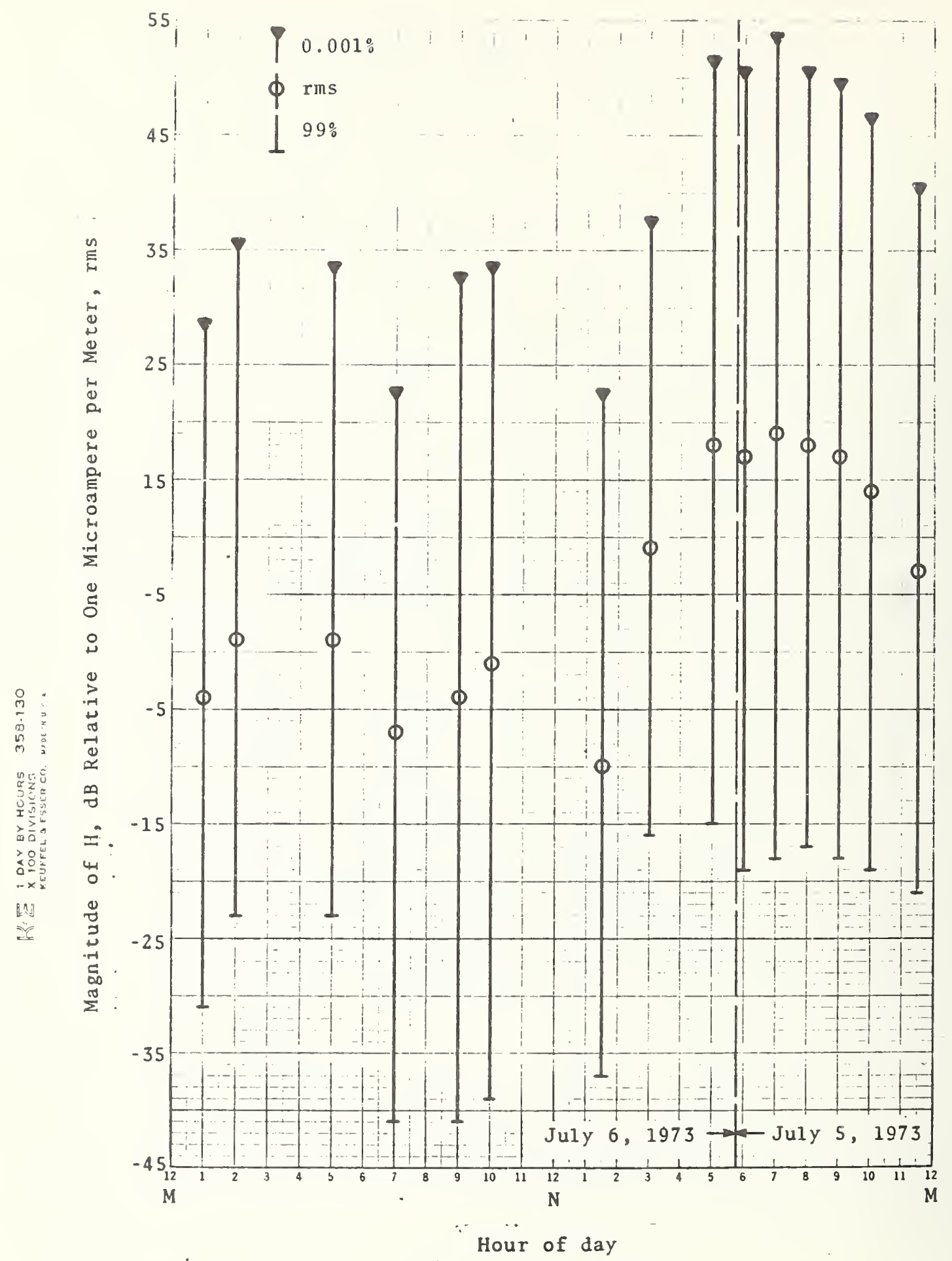

Figure 26. Summary of $25 \mathrm{kHz}, \mathrm{H}$-field variations from each APD, Willcox Dry Lake. 


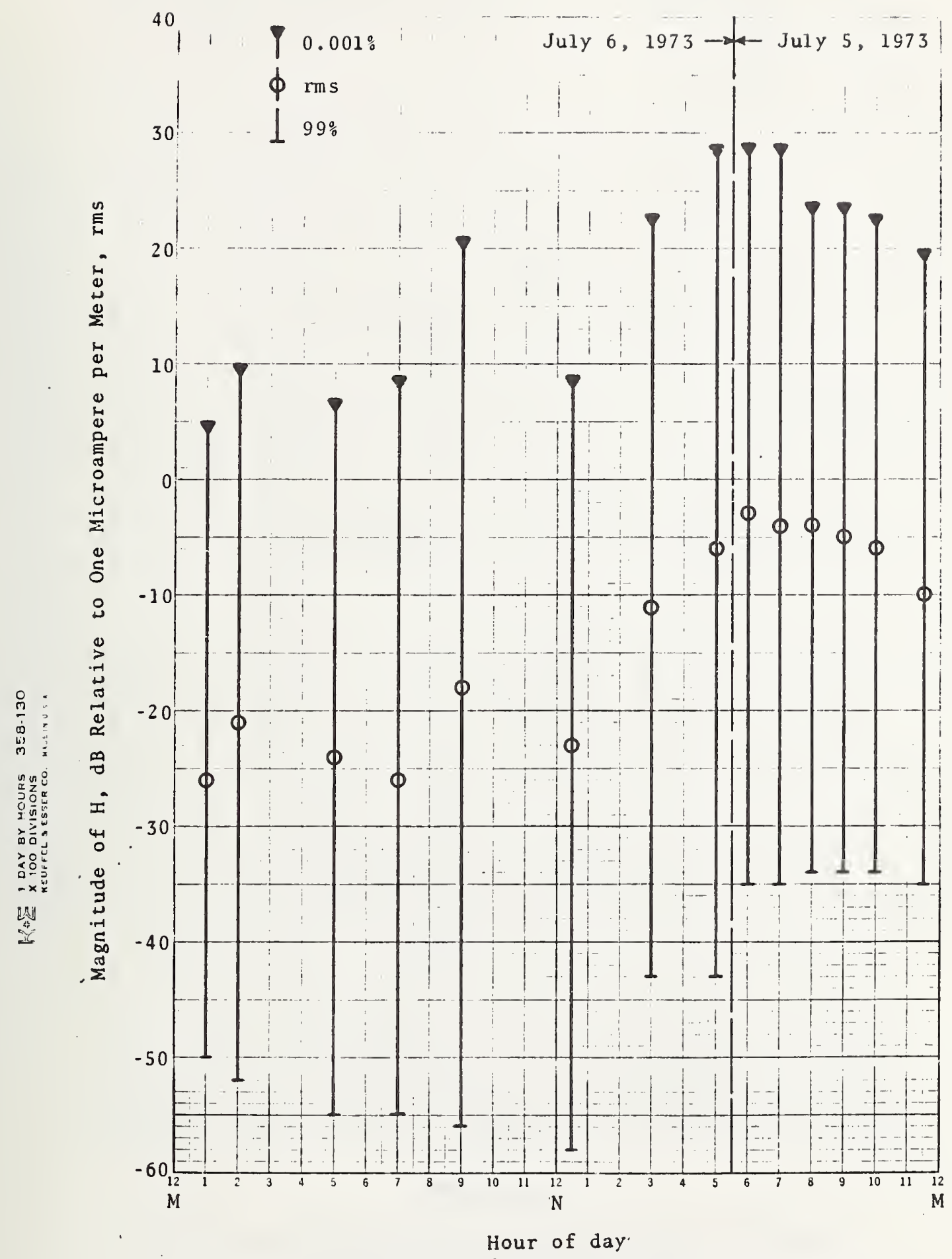

Figure 27. Summary of $250 \mathrm{kHz}, \mathrm{H}$-field variations from each APD, Willcox Dry Lake. 


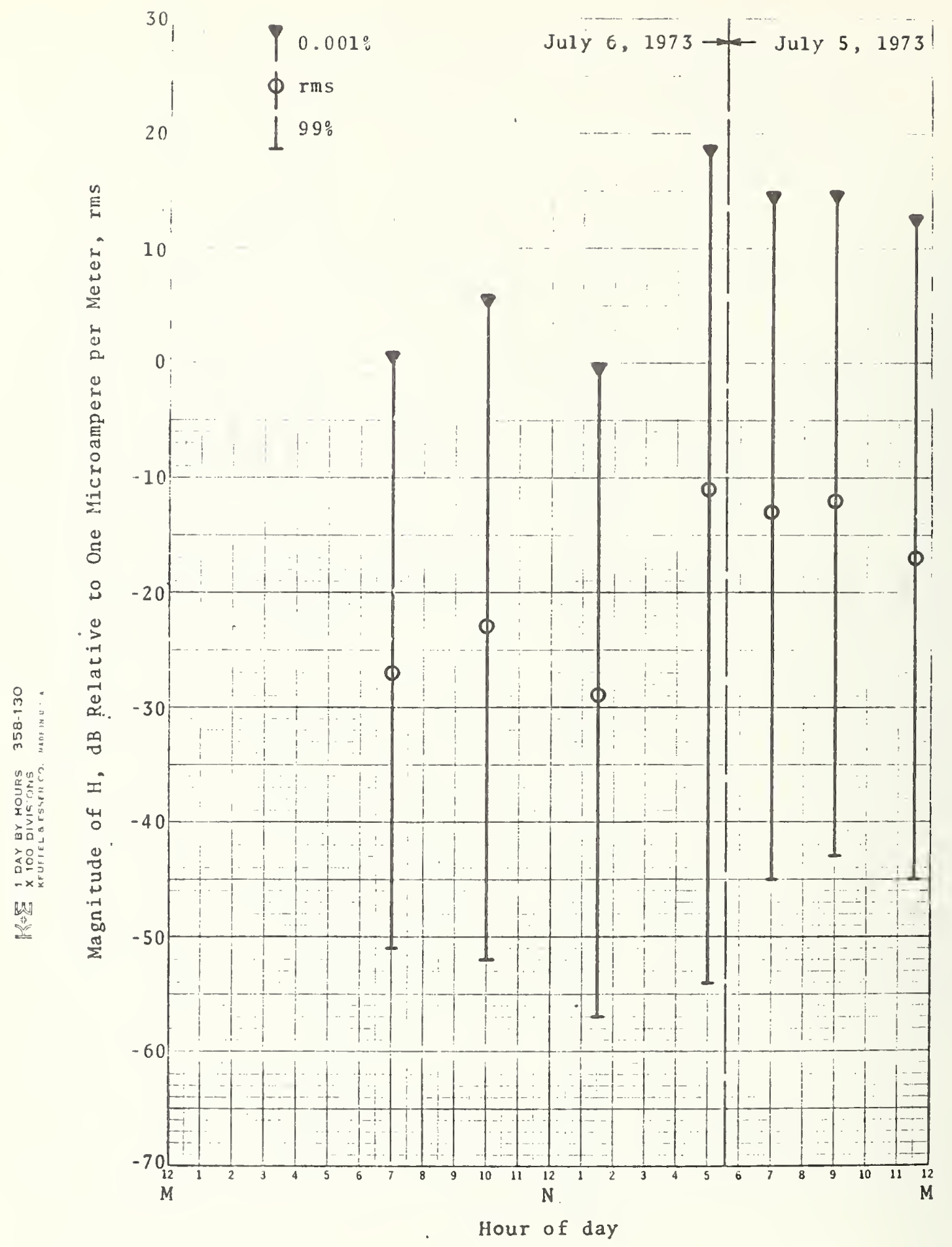

Figure 28. Summary of $1 \mathrm{MHz}, \mathrm{H}$-field variations from each APD, Willcox. Dry Lake. 


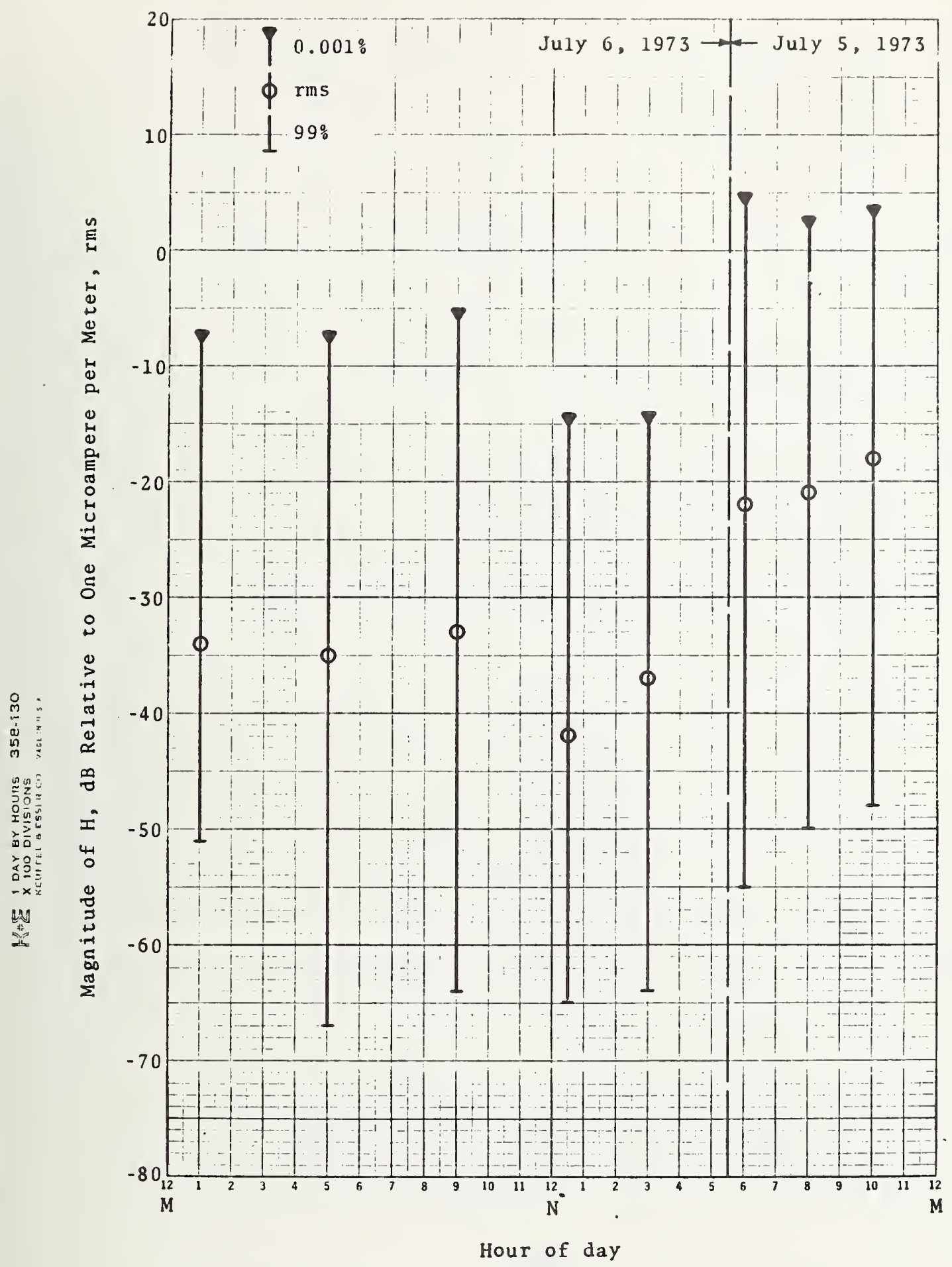

Figure 29. Summary of $3 \mathrm{MHz}, \mathrm{H}$-field variations from each APD, Willcox Dry Lake. 


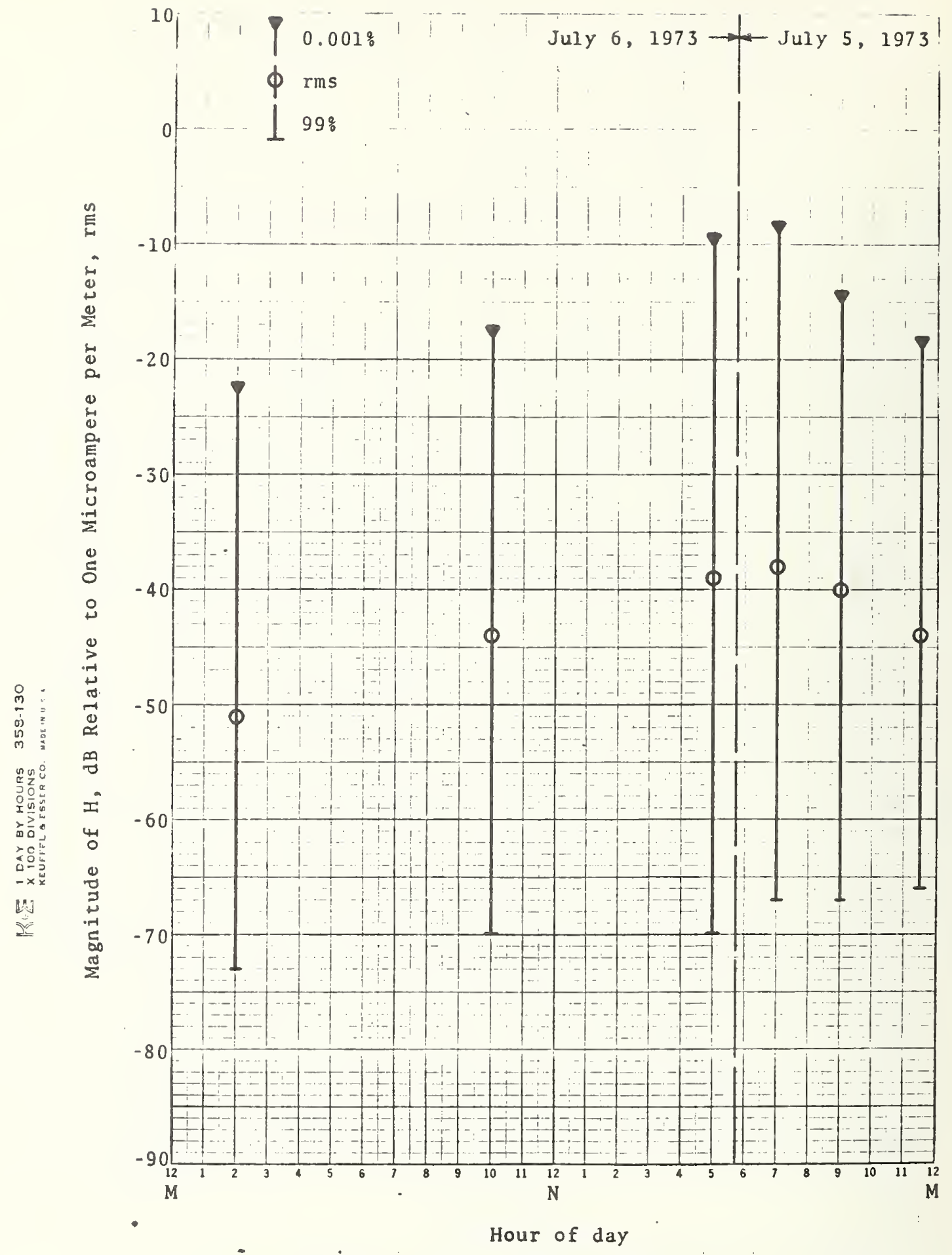

Figure 30. Summary of $10 \mathrm{MHz}$, H-field variations from each APD, Willcox Dry Lake. 


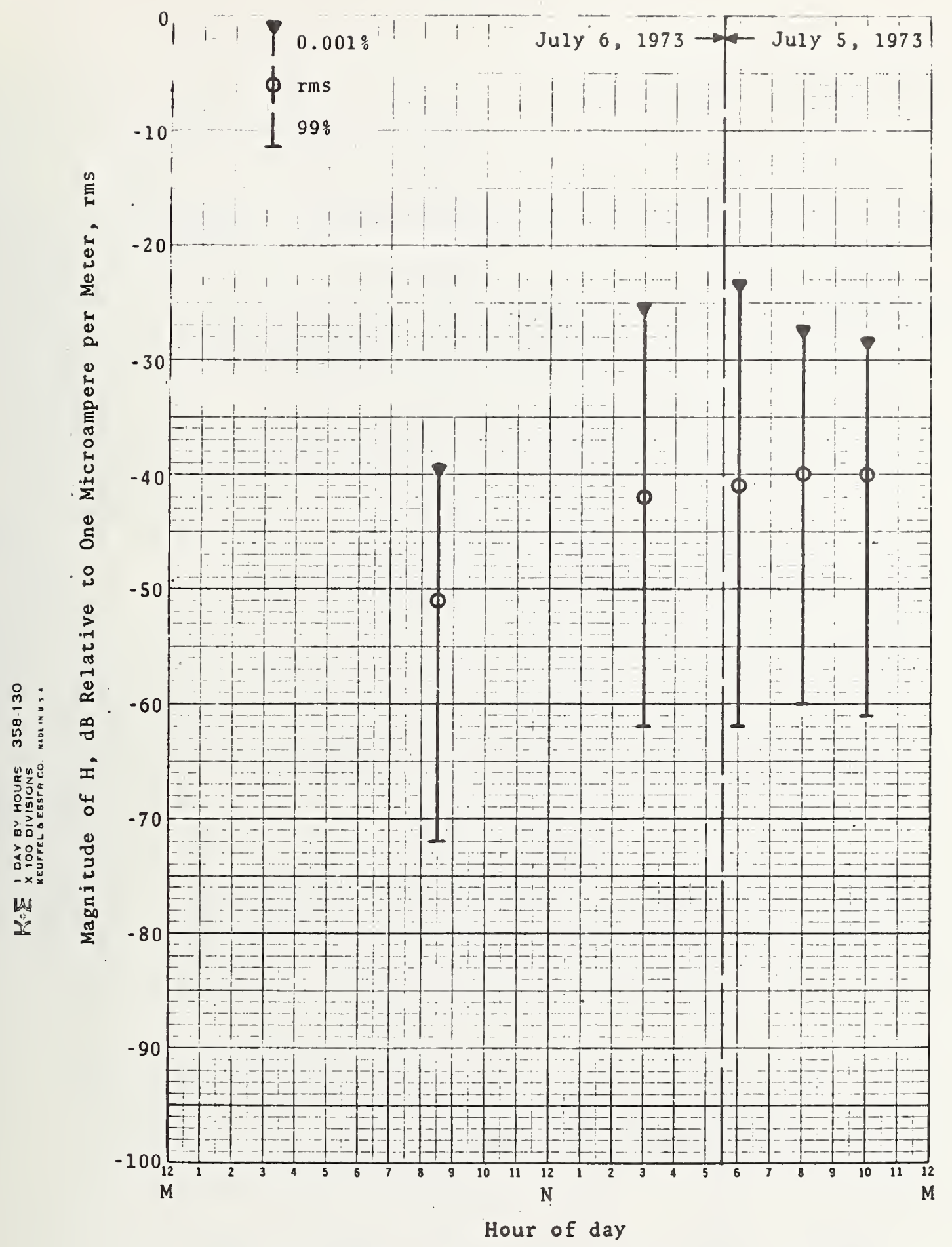

Figure 31. Summary of $30 \mathrm{MHz}$, H-field variations from each APD, Willenx Dry Like. 


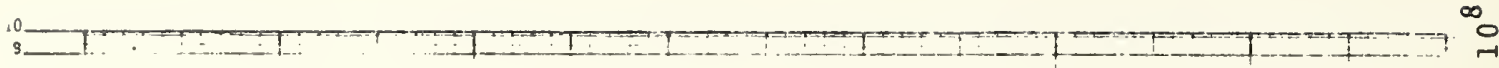
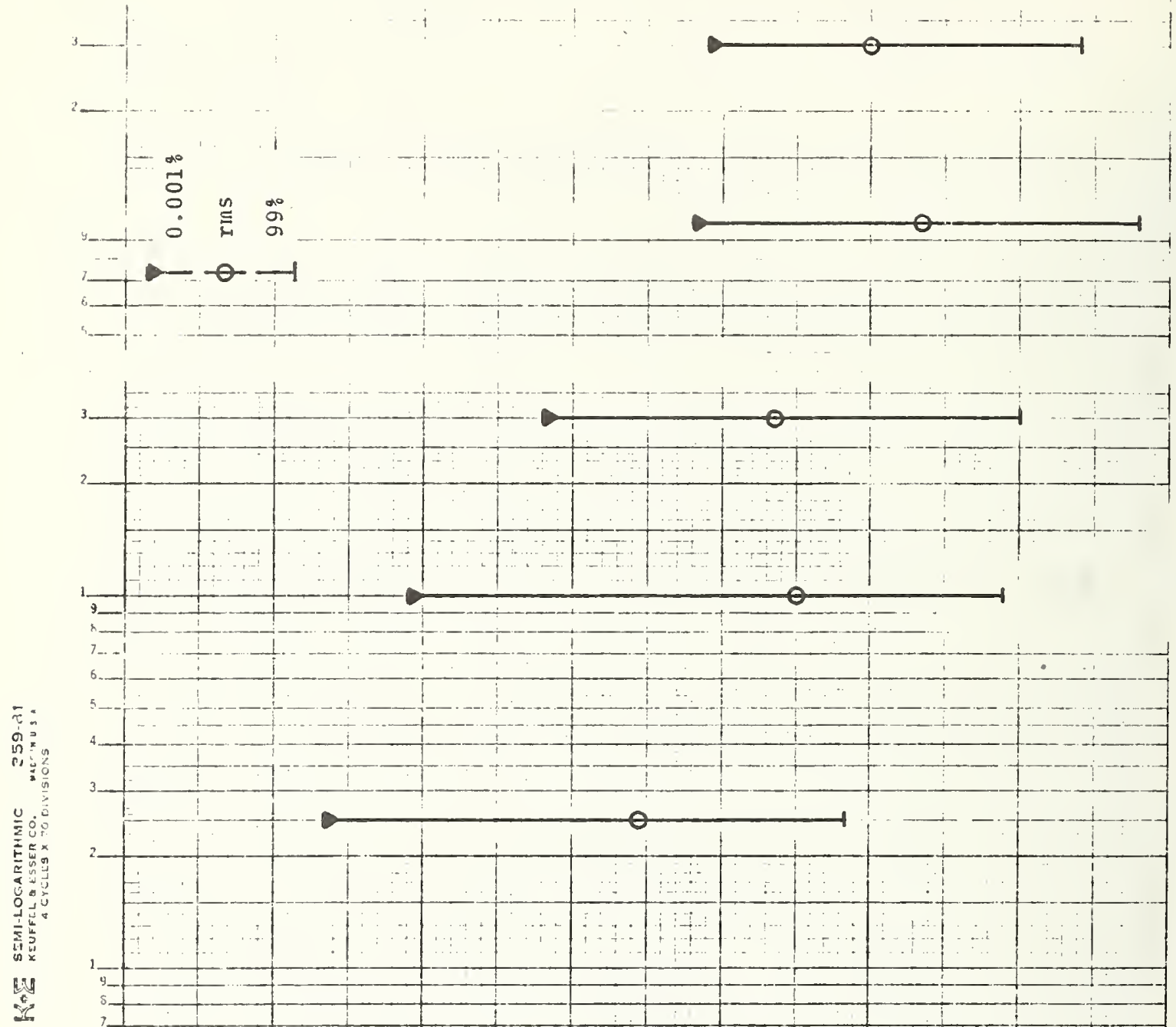

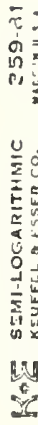
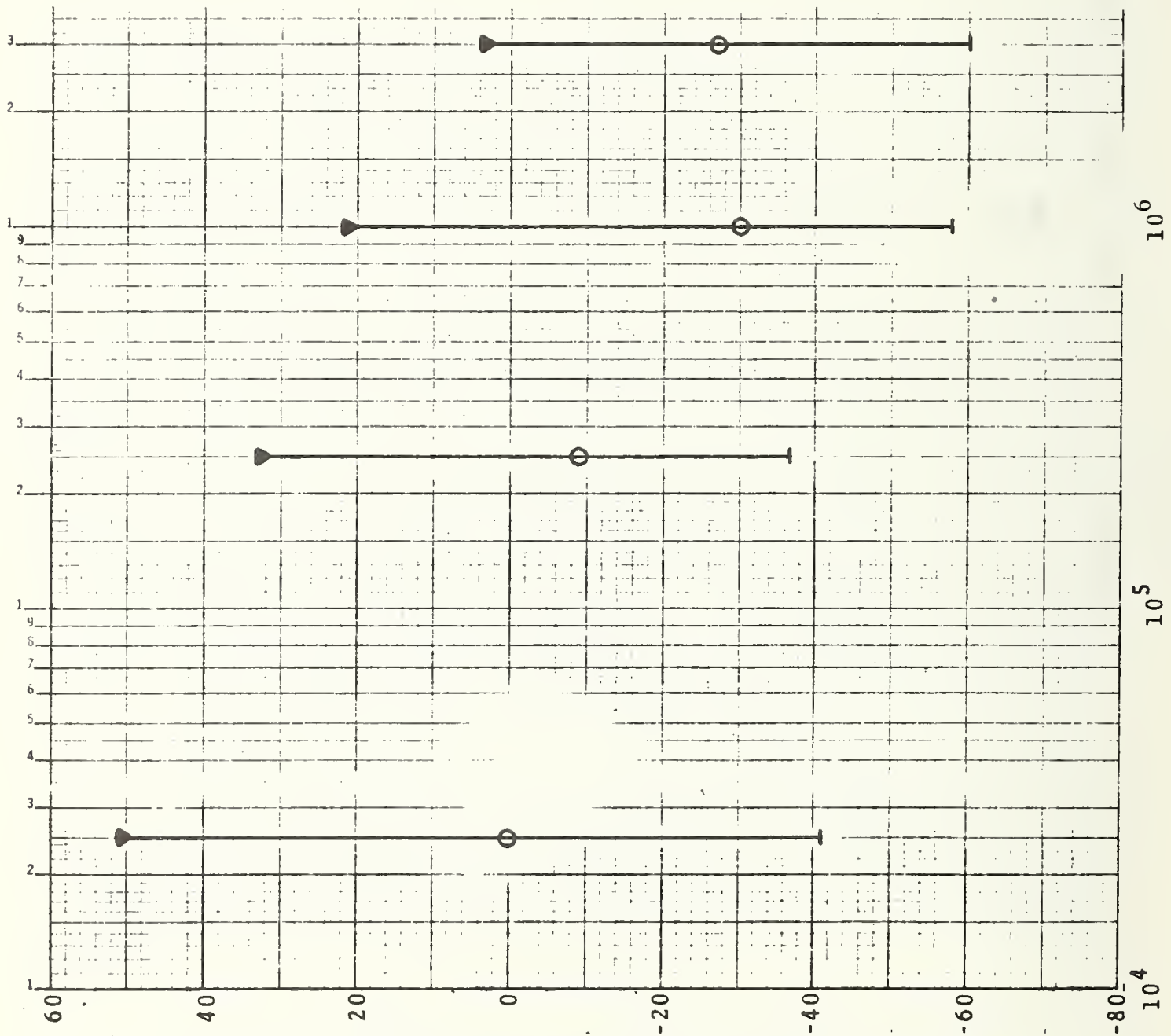

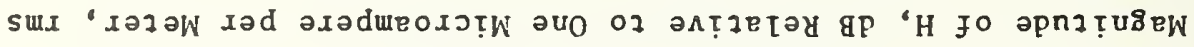




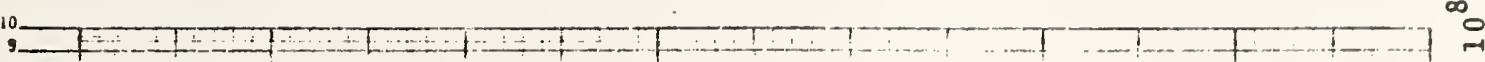

$T_{--}$

$-1$

-
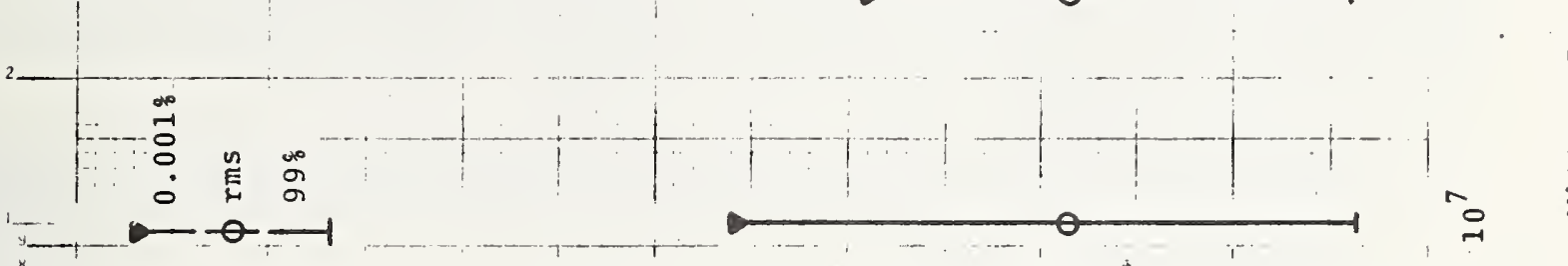

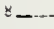

\begin{tabular}{l|l|l|l|l|l|l|l|l|l|l|}
\hline & & & & & & & \\
\end{tabular}

$+\cdots$

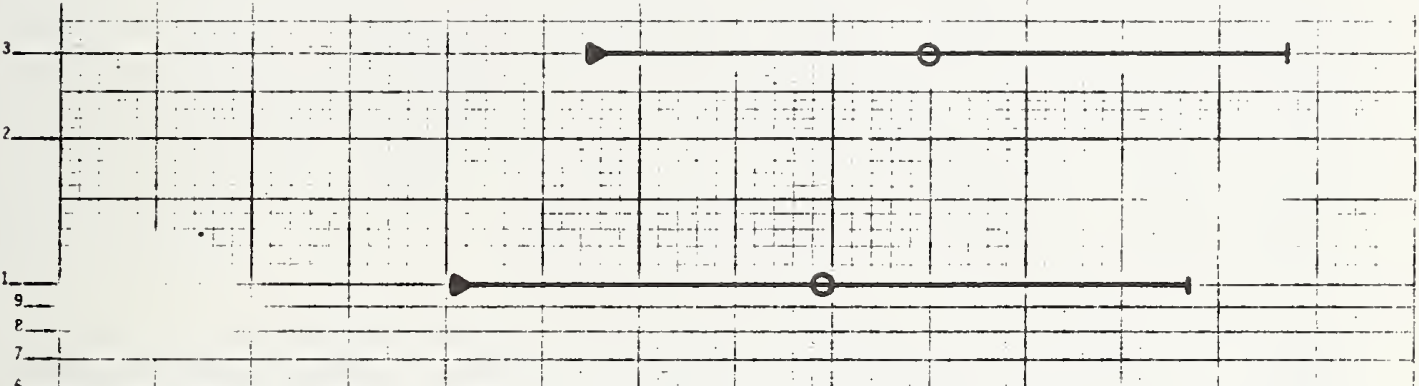

它

6
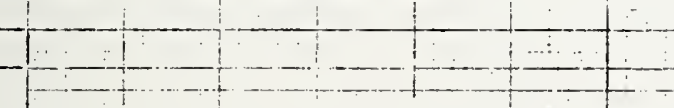

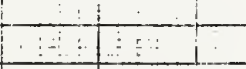

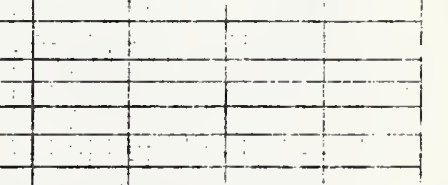

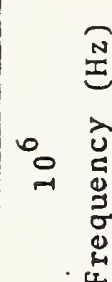
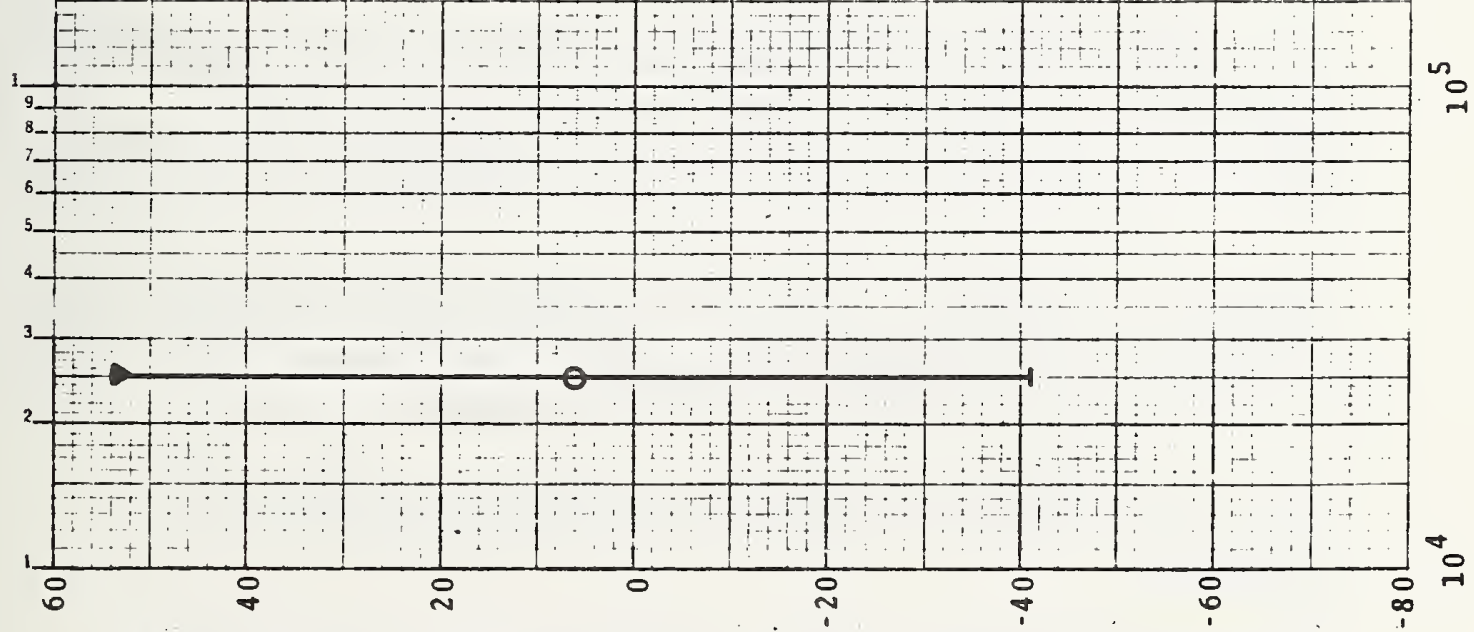
sயI ' 


\subsection{CONCLUSIONS}

An analysis of the measured data shows several factors that should be considered when planning communication links, tests and evaluations; evaluating present plant effectiveness; and planning expanded plant facilities. These are:

(1) The main source of interference is the power 1 ines, with the highest levels of EMI emanating from the Irwin Street power 1 ines.

(2) The power lines serve as transmission 1 ines to bring in electric field interference over the portion of the spectrum from $250 \mathrm{kHz}$ to approximately $500 \mathrm{MHz}$. Above $500 \mathrm{MHz}$, no noise from the power 1 ines was detected. Quantitative differences may be obtained from figures 9(a), $9(\mathrm{~b})$, and 9 (c) (Hayes Hall vs. Willcox Dry Lake).

(3) Below $250 \mathrm{kHz}$ these same power lines provide some shielding of electric field noise.

(4) Magnetic field noise comparisons indicate that power lines have little effect; i.e., magnetic field noise at Hayes Hall Compound is about the same as that at Willcox Dry Lake.

(5) EMI generated by the mercury vapor lights is insignificant when compared to the noise from power 1 ines.

(6) Time variations of magnetic noise have a diurnal range of $95 \mathrm{~dB}$ at $25 \mathrm{kHz}$ and have a short-term range of $35 \mathrm{~dB}$ at $30 \mathrm{MHz}$. Results are summarized in figures 32 and 33. During local thunderstorms, the amplitude and character of the interference change.

(7) The CW carriers from external transmitters can provide a serious source of interference at Hayes Ha11 in those cases where selectivity or directivity cannot be used to discriminate against them.

(8) Willcox Dry Lake area is much quieter with regard to electric field noise than Hayes Hall Compound.

(9) The shielded room provides only a shielding effectiveness of 50 decibels at $1000 \mathrm{MHz}$. A we11designed-and-constructed room will typically provide 100 to 120 decibels at this frequency. 


\subsection{RECOMMENDAT IONS}

Specific recommendations must be based on many factors in addition to electromagnetic noise environment. Consequently, results and data in this report can be used only in conjunction with other factors when making future decisions.

For better use of existing facilities, USASATEC testing should be done near position 2 within Hayes Hall compound, or, for minimal interference at certain frequencies, at Willcox Dry Lake.

Testing during thunderstorms should be avoided, both for EMI reduction and for safety.

Power lines should be avoided, especially high-voltage lines along Irwin Street.

Unless power lines were buried throughout Ft. Huachuca, little would be gained by burying power lines within Hayes Ha11 Compound.

The mercury lights do not make a significant contribution to the EMI environment.

If cw signals are a problem, either (1) tighter control of local sources will have to be achieved; (2) the shielded room will have to be used; or (3) a remote site such as Willcox Dry Lake will have to be used. In case (3), some carriers would still be present.

Shielding effectiveness of the shielded room can probably be improved by:

(1) Uniformly tightening the bolts that hold the room together.

(2) Checking the line filters for proper bonding and tightening if necessary.

(3) Routinely cleaning finger stock on the door. 


\section{ACKNOWLEDGMENTS}

The following people made major contributions to this work: John Workman, Bob Nelson, Leon Saulsbery, Bill Bensema, and Nancy Tomoeda. Winston Scott and John Workman processed the data and assisted with preparation of the final report. Sharon Foote and Janet Becker typed the drafts and final report.

Steve Lung and Phil Wralstad (USASATEC) made necessary arrangements to allow measurements at Ft. Huachuca and Willcox Dry Lake. 


\section{REFERENCES}

[1] W.Q. Crichlow, et al., Amplitude probability distributions for atmospheric radio noise, NBS Monograph 23, 1960.

[2] Taggart, H.E. and J.L. Workman, Calibration principles and procedures for field strength meters $(30 \mathrm{~Hz}$ to $1 \mathrm{GHz})$, NBS Technical Note 370 , March 1969.

[3] R.J. Matheson, Instrumentation problems encountered making man-made electromagnetic noise measurements for predicting communication system performance, IEEE Trans. on EMC, Vol. EMC-12, p. 151, Nov. 1970.

[4] Greene, F.M., NBS field-strength standards and measurements $(30 \mathrm{~Hz}$ to $1000 \mathrm{MHz}$ ), Proc. IEEE, Vol. 55, No. 6, June 1967. 


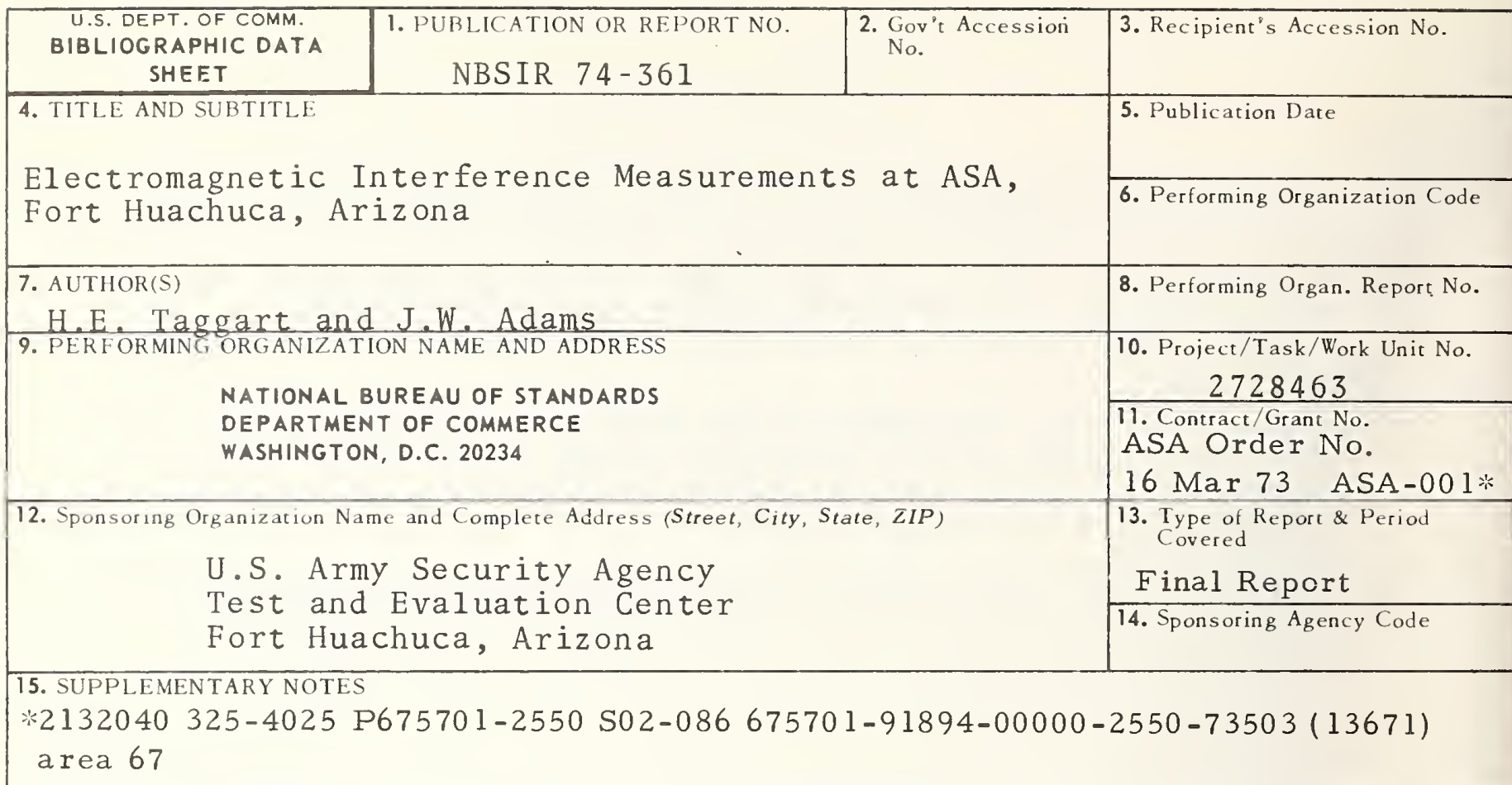

16. ABSTRACT (A 200-word or less factual summary of most significant information. If document includes a significant bibliography or literature survey, mention it here.)

This report describes the work performed for the U.S. Army Security Agency Test and Evaluation Center (USASATEC), Fort Huachuca, Arizona, during the period from April 1973 to November 1973. The purpose of the project was to measure, analyze, and evaluate the electromagnetic environment at selected sites and to recommend methods of reducing the present levels of electromagnetic interference (EMI). The chief sources of EMI were the power lines in the area and sferics from thunderstorms. Both broadband EMI measurements and amplitude probability distribution measurements were made. Both electric and magnetic fields were measured. The frequency range covered was $15 \mathrm{kHz}$ to $10 \mathrm{GHz}$. Measurements were made at three locations: 1) at Fort Huachuca USASATEC; 2) Willcox Dry Lake; and 3) Boulder, Colorado. The report contains the test results, conclusions, and recommendations.

17. KEY WORDS (six to twelve entries; alphabetical order; capitalize only the first letter of the first key word unless a proper name; separated by semicolons)

APD; field strength; interference; power lines.

18. AVAILABILITY

$\Gamma$ For Official Distribution. Do Not Release to NTIS

Order From Sup. of Doc., U.S. Government Printing Office Washington, D.C. 20402, SD Cat. No.C13

Order From National Technical Information Service (NTIS) Springfield, Virginia 22151 \begin{tabular}{|l|l|}
\hline $\begin{array}{l}\text { 19. SECURITY CLASS } \\
\text { (THIS REPURT) }\end{array}$ & 21. NO. OF PAGES \\
UNCL ASSIF IED & 22. Price \\
\hline $\begin{array}{l}\text { 20. SECURITY CLASS } \\
\text { (THIS PAGE) } \\
\text { UNCLASSIF1ED }\end{array}$ & USCOMM-DC 29042-P74 \\
\hline
\end{tabular} 



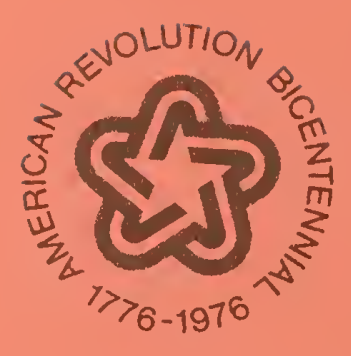

